\title{
Developing Confidence: Visual Art Teaching in a Primary School
}

\author{
lan Bowell \\ A four-paper thesis submitted in partial fulfilment of the requirements for the degree \\ of Master of Education \\ Victoria University of Wellington
}




\begin{abstract}
In New Zealand specialist courses in the arts at undergraduate level, and one year diplomas in teaching have been reduced. Visual art advisory time allocated to primary school teachers has also been reduced. As a result teachers' confidence in teaching visual art is under threat. This study focused on a group of generalist primary school teachers as they worked to develop their confidence in the teaching of visual art. They worked as a non-hierarchical collaborative group, using action research to analyse the voices of the children in their school, and to reflect on their own practice. Following their reflections they used their developed confidence to develop a visual art self-assessment system. Their developed confidence in teaching visual art enabled them to offer support in the teaching of visual art to other teachers within the school.
\end{abstract}

However, the narrow focus of the study did not allow exploration of why the participants were motivated to develop their expertise in the teaching of visual art. The limitations of the data also failed to reveal whether the participants were able to sustain their collaborative working relationship after the study ended.

The study recommends further research into the long-term sustainability of teacher collaborative groups and the motivation that enables teachers to develop their confidence in the teaching of visual art. 


\section{Acknowledgements}

I would like to thank the principal, staff and students of the Wellington primary school where I was able to gain an insight into their working lives. Without their generosity and cooperation this study would not have been possible.

I would also like to thank the Faculty of Education, Victoria University of Wellington for enabling me to complete this study. I would like to acknowledge and thank my supervisors, Barbara Craig and Dr Anne Hynds, whose insightful guidance and advice was invaluable throughout this study.

Finally, without the unquestioning support and understanding I received from Katie, Daniel and Jack, this study could not have been completed. 


\section{Table of Contents}

Abstract

Acknowledgements.

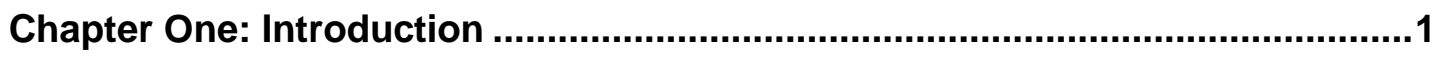

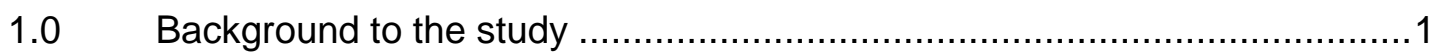

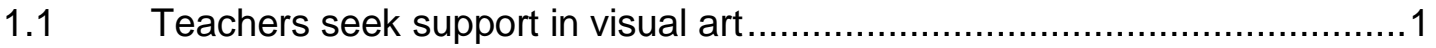

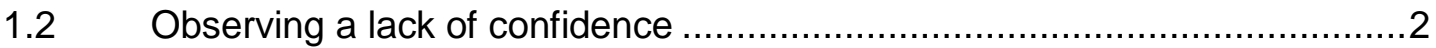

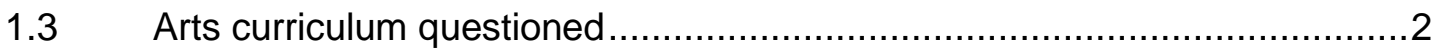

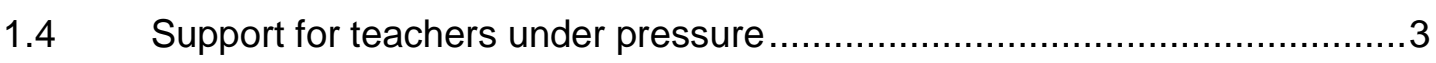

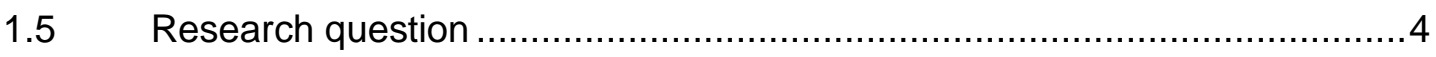

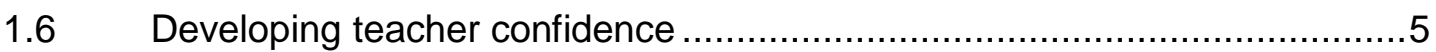

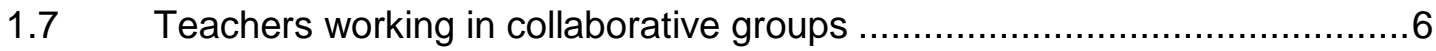

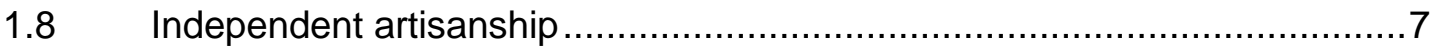

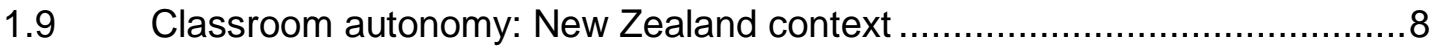

1.10 Supporting a collaborative teaching community ....................................

Chapter Two: Visual Art Education in New Zealand: Historical Context ..........11

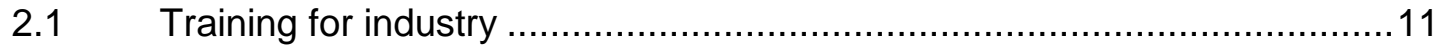

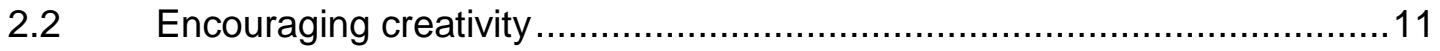

2.3 Cizek's ideas reach New Zealand ...................................................... 12

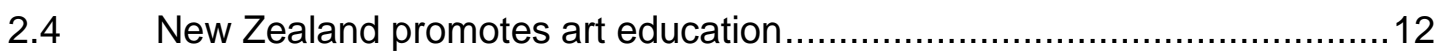

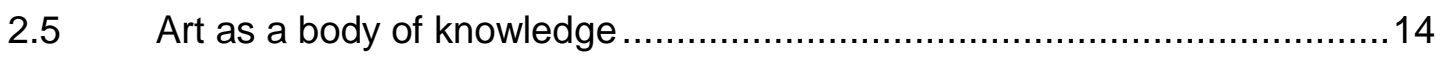

$2.6 \quad$ Art and critical thinking ................................................................... 14

2.7 Developing my own art education philosophy..................................... 16

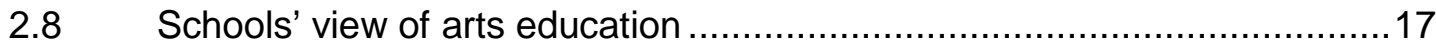

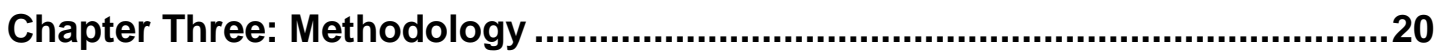

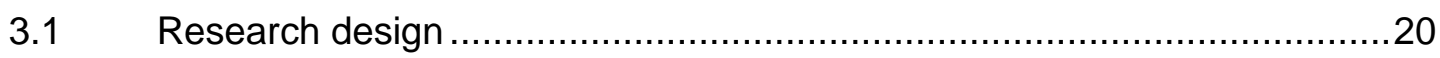

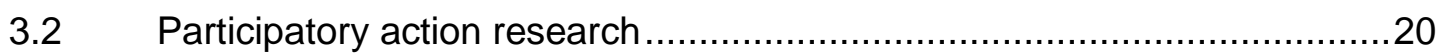

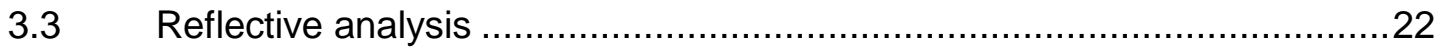

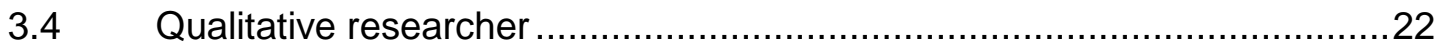

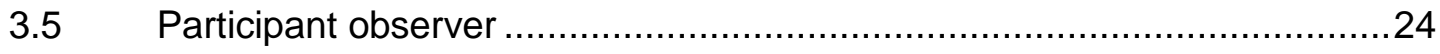

3.6 Developing the role of participant observer ........................................25

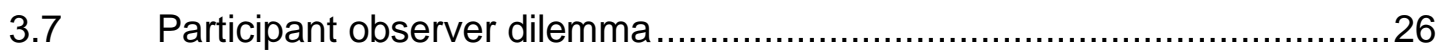

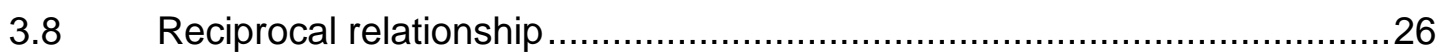




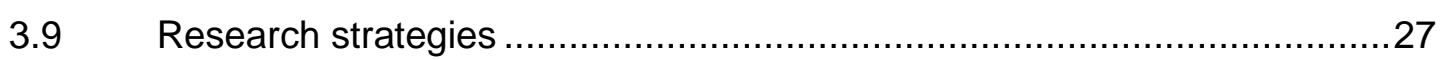

3.9.1 Selecting a site ........................................................... 27

3.9.2 Research journal .......................................................... 28

3.9.3 Semi-structured interviews ….........................................28

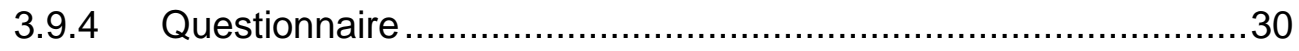

3.9.5 Observation (classroom and meetings) .................................30

3.9.6 Document search ............................................................... 30

3.9.7 Analysing the data ............................................................ 31

3.9.8 Trustworthiness ........................................................... 32

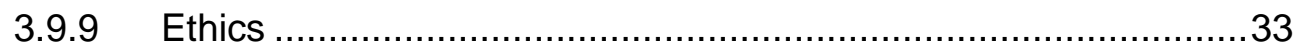

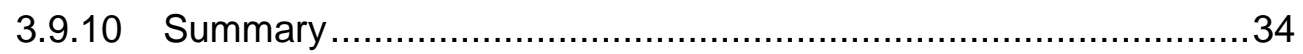

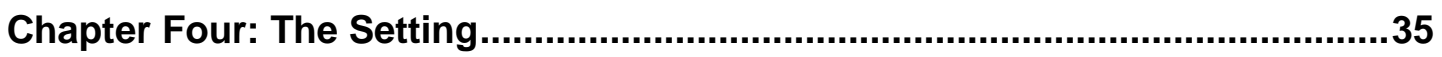

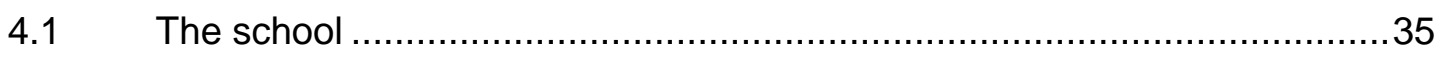

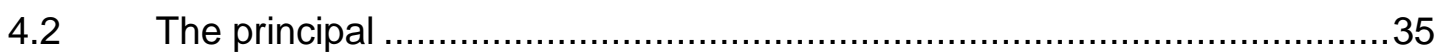

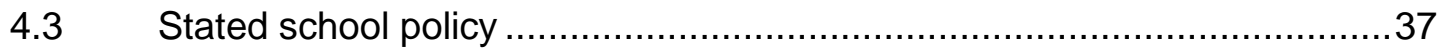

4.4 Initial evidence of a collaborative teaching community ............................40

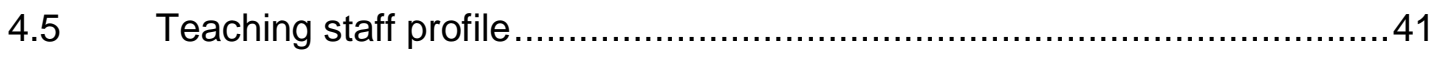

4.6 Meeting the volunteer participant teachers .........................................43

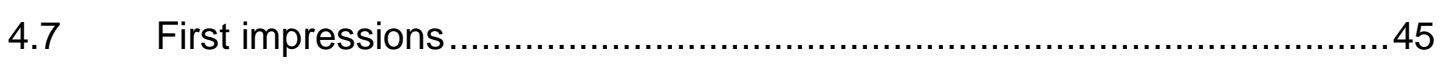

4.8 Principal enables teachers to develop confidence in the teaching of visual

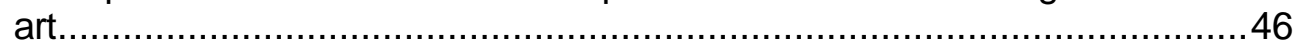

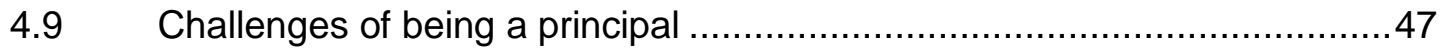

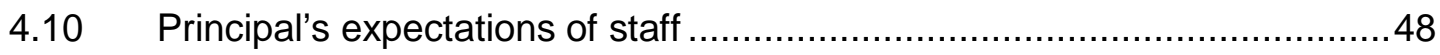

4.11 Principal's expectations create tension..............................................49

4. 12 Frustrations felt during disruptions to routines .......................................51

4. 13 Principal's view of visual art in the school............................................52

Chapter Five: Confidence in Teaching Visual Art ...........................................55

5.1 Confidence in teaching visual art linked to experience in using visual

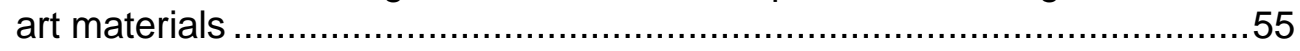

5.2 Gaining experience in visual art in formal settings outside the school

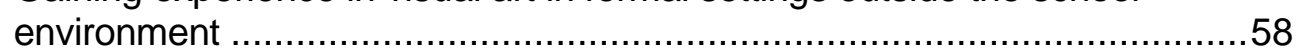

$5.3 \quad$ Informal support network within the school........................................59

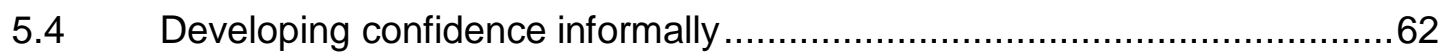

$5.5 \quad$ Sharing ideas with the support of the principal .....................................63

5.6 Developing confidence in visual art formally in settings within the school.......65 
Chapter Six: School-Wide Plan to Develop Teacher Confidence in Teaching

Visual Art (Formal Setting) ............................................................68

6.1 Volunteer participant teachers plan to develop and support teacher confidence in visual art.

6.2 April shares resources to develop and support teacher confidence in visual art

Chapter Seven: Children and Volunteer Participant Teachers Reflect Upon Children's Visual Art-Work.

7.1 Teacher feedback creates a common understanding between child and teacher

7.2 Summary

Chapter Eight: Working Collaboratively to Develop Confidence (Informal Setting)

8.1 Volunteer participant teachers reflect on teacher feedback to children......83

8.2 Volunteer participant teachers reflect on teacher language ......................85

8.3 Volunteer participant teachers reflect on their practice .............................86

8.4 Volunteer participant teachers' reflection leads to ideas on self-assessment

8.5 Volunteer participant teachers develop confidence in assessing children's visual art.....

8.6 Volunteer participant teachers reflect on the use of a common language

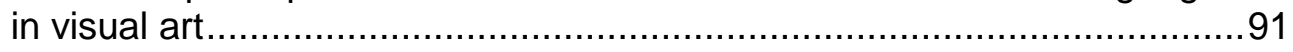

8.7 Participant observer dilemma......................................................93

8.8 Summary of volunteer participant teachers' first discussion .....................94

Chapter Nine: Volunteer Participant Teachers Developing Confidence in Assessing Visual Art (Informal Setting).

9.1 Volunteer participant teachers revisit their analysis and develop their

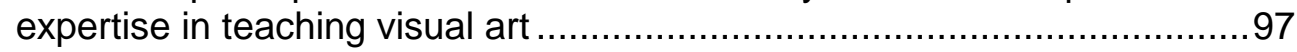

9.2 Volunteer participant teachers use children's work as evidence ................99

9.3 Volunteer participant teachers use analysis of the children's descriptions to develop their confidence

9.4 April's role enables volunteer participant teachers to develop their confidence in visual art teaching 102

Chapter Ten: Developing and Sharing Resources (Informal Setting) ..............104

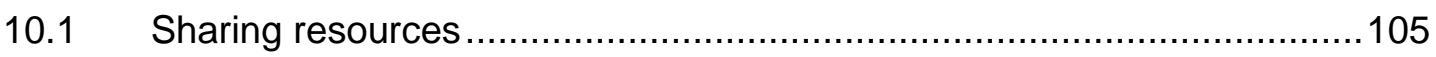

10.2 Teachers develop shared resources .................................................. 108 
11.1 Sharing a common goal in a non-hierarchical group............................114

11.2 Supporting collaborative groups ................................................. 115

11.3 Informal collaborative groups ..................................................... 116

11.4 Children's voices trigger development of teacher confidence ...................118

11.5 Action research process enables development of teacher confidence ....118

11.6 An expectation that ideas could be shared openly ...............................119

$11.7 \quad$ Principal who supported visual art...................................................120

11.8 Support for teachers outside the school .............................................120

11.9 Pivotal role of teacher responsible for visual art ..................................121

11.10 Compensating for diminishing support in visual art.............................121

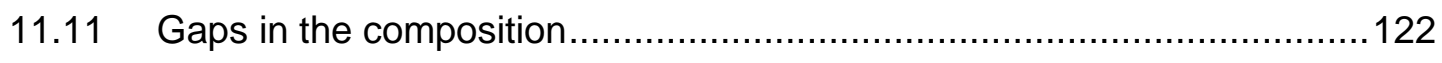

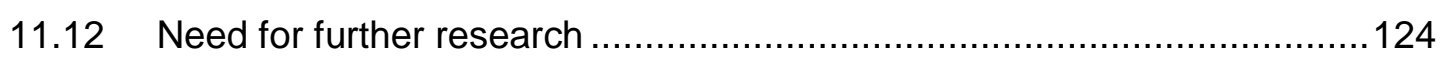

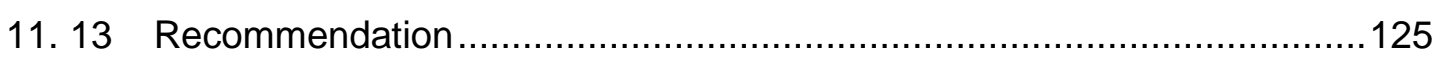

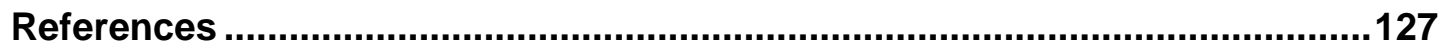

\section{Appendices}

Appendix A Letter to principal ........................................................... 134

Appendix B Consent form - principal ....................................................... 136

Appendix C Information letter to teaching staff ...........................................138

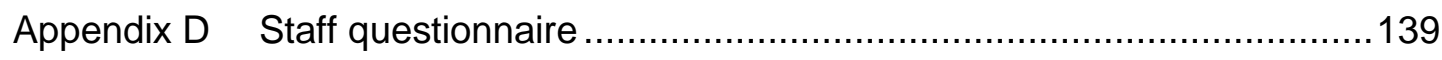

Appendix E Teacher information sheet ...................................................141

Appendix $F \quad$ Volunteer participant teacher - expression of interest ...................142

Appendix G Volunteer participant teacher - consent form ...............................144

Appendix $\mathrm{H} \quad$ Parent/caregiver - information sheet.......................................... 145

Appendix I Parent/caregiver - consent form ........................................... 146 


\section{List of Figures}

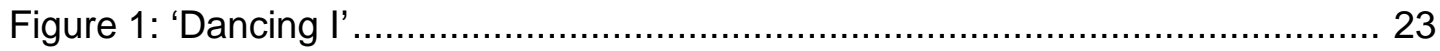

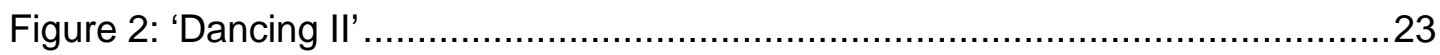

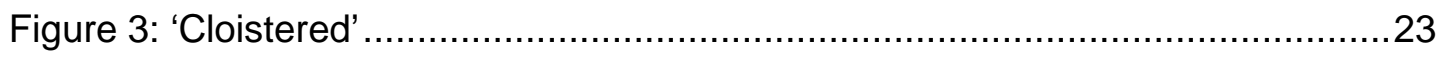

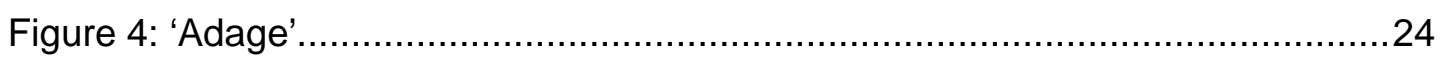

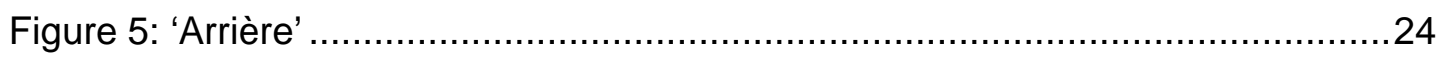

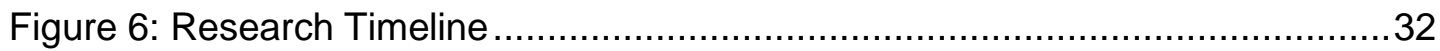

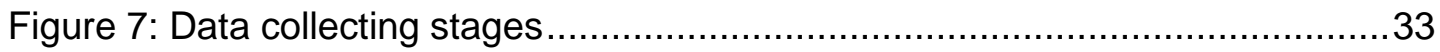

Figure 8: Number of years teaching ........................................................... 42

Figure 9: Support networks for participant teachers in visual art .............................61

Figure 10: Example of work from April's class..................................................75

Figure 11: Example of work from Jo's class ....................................................76

Figure 12: Example of work from Catherine's class ............................................

Figure 13: Example of work from Rebecca's class ...............................................78

Figure 14: Example of work from Carol's class .................................................79

Figure 15: Example from a page Taken from one of Catherine's class workbooks.... 108

Figure 16: Example of Self Assessment from Catherine's classes ........................109

Figure 17: Example of teacher assessment from Catherine's classes....................109

Figure 18: Example of self-assessment from Carol..........................................110 


\section{CHAPTER ONE \\ Introduction}

\subsection{Background to the study}

In New Zealand the contraction of traditional support for primary school teachers has resulted in threatening teacher confidence in teaching visual art. This study focuses on a group of generalist primary school teachers as they work to develop their confidence in the teaching of visual art. Working as a non-hierarchical collaborative group using action research they analysed the voices of the children in their school and reflected on their own practice. The following information provides a background to this study. In particular it sets the scene for the focus of my inquiry. Debates are explored along with an analysis of current literature. In addition, I explore the gaps within the literature alongside my own experiences as a visual art educator.

\subsection{Teachers seek support in visual art}

According to a 2003 Ministry of Education curriculum stock-take (McGee, Harlow, Miller, Cowie, Hill, Jones \& Donaghy, 2003), 20\% of New Zealand primary school teachers expressed a need for professional development in visual art. In March 2003 the Ministry of Education sent questionnaires to $10 \%$ of schools throughout New Zealand. Seven hundred and seventy-four teachers, of whom 608 (78.6\%) were primary school teachers, completed the arts questionnaire and provided information about their experiences in implementing the arts curriculum. Although the focus of the stock-take was to investigate teachers' experiences in implementing the Arts curriculum, some of the data also focussed on teachers' confidence in teaching visual art in primary schools and the way they believed they had been supported in teaching visual art.

In 2006, 26,305 primary school teachers were employed in the state sector in New Zealand. If the percentage of teachers who wanted further visual art professional development in the 2003 survey is extrapolated to the entire primary school teacher population, then it seems likely that a significant number of teachers feel they need support in teaching visual art. 


\subsection{Observing a lack of confidence}

During 2002 I worked with primary school teachers as part of an Arts advisory team in the Greater Wellington region, helping them implement the visual art component of the Arts curriculum of 2000. The teachers I worked with wanted to develop their understanding of the teaching of visual art but I observed that some teachers lacked confidence when it came to the actual teaching of visual art.

While visiting primary schools as a visual art advisor I realised many of the teachers who lacked confidence in teaching visual art linked this to their own perceived capability as visual artists. I heard comments such as 'I've never been good at art' or 'l've never been able to draw'. Although these may have been a genuinely held belief about their inability to work in the area, they could also have been a response to their perception of me as an 'expert'. Whichever reason, I do not believe a teacher has to be a practising artist to be a confident teacher of visual art in a primary school. The skill lies in being able to create an environment in the classroom that enables children to develop their creativity through visual art.

As a visual art advisor I observed that visual art was taught and coordinated across schools in different ways. All the primary schools I worked in had a teacher who was responsible for the teaching of visual art in the school. In some schools this appeared purely an administrative role, ordering art equipment and supplies, and in others it involved planning a visual art course for the entire school. I saw a broad range of confidence in the teaching of visual art. Some schools were a visual art oasis with teachers involving the children in producing a wide range of exciting and creative visual art-work. In other schools visual art consisted only of coloured-in, photocopied line drawings where one child's art-work was indistinguishable from another's.

\subsection{Arts curriculum questioned}

In a review of the existing literature I learned that there are questions over the quality of visual art teaching in New Zealand. In relation to The Arts in the New Zealand Curriculum (Ministry of Education, 2000), Mansfield (2003) sees the combination of all the arts disciplines in one document as marginalising the arts. She feels this is further compounded by all the arts subjects being reduced to one essential learning area in The New Zealand Curriculum Framework Te Anga Marautanga o Aotearoa (Ministry of Education, 1993). In her view part of art education and pre-service teacher training courses should include areas of theory 
that go beyond developmental descriptions of children's drawing. I agree with this sentiment but the problem remains that pre-service courses are themselves under pressure as their time allocation is cut. If this trend continues, visual art education for pre-service teacher training could become minimal, with teachers continuing to be ill-prepared and lacking in confidence when teaching visual art. I have seen the evidence of this in primary schools as teachers use easy formulas to teach visual art, expressing a lack of confidence in exploring a wide range of visual art activities or discussing visual art with the children in their class.

Cherryholmes (1988) urged educators to develop a critical and evaluative attitude towards education. This call has led to the present criticisms of art education in New Zealand where teachers are seen as ill-prepared to develop students' critical and reflective nature in visual art. Grierson (2003) believes that the arts are potentially an area where children can develop their critical abilities but that the Arts curriculum does not support this potential. I believe it is not only the Arts curriculum that does not support this potential but also that primary school teachers are ill-prepared to develop this potential.

Bracey (2003) states that generally over the last 20 years in New Zealand teachers have been encouraged to provide children with a knowledge about art as well as making art-works. However, he maintains that this requirement is seldom reached in current visual art teaching, and one reason for this lies in teacher training practices. I would suggest this would apply to all areas of visual art teaching in primary schools - a lack of confidence in any aspect of visual art is reflected in the quality of the visual art-work produced in a teacher's classroom.

\subsection{Support for teachers under pressure}

A lack of confidence in teaching visual art may be partly attributable to the length and quality of teachers' pre-service teacher training. I have been involved in teacher education for six years and have seen time allocated to visual art cut in pre-service teacher training courses. Naughton (2007) makes the point that within New Zealand specialist courses in the arts at undergraduate level and one year graduate diplomas in teaching have been reduced, leading to the demise of arts education in schools. In Australia visual art education is also under threat, according to Flood (2004). She believes there has been growing evidence that visual art education is struggling to maintain a strong foothold in schools and tertiary institutions. In her view an expanding curriculum and a push towards conformity and standardised 
performance by central government are the main reasons that visual art education is under pressure.

The School Support Service is another traditional support for primary school teachers following their training. In recent years the number of primary visual art advisors across the country has decreased along with the time allocation for primary visual art advisory work. It seems that the generalist primary school teacher who needs more support in teaching visual art may find the traditional areas of support are themselves under pressure.

The literature points to both shortcomings in the ability and confidence of primary school teachers in teaching visual art and a shortfall in the systems available in supporting teachers in developing that confidence. Although highlighting those shortcomings there appears to be a gap in the literature in providing solutions to rectify them and the shortfalls.

If the School Support Service is unable to support all primary school teachers, and pre-service teacher training is less than adequate in preparing newly qualified teachers to teach visual art, teachers may need to turn to new sources for support. One new source of support could be found within the schools themselves. The Ministry of Education's curriculum stock-take (McGee et al., 2003, August) found that almost three quarters $(72.2 \%)$ of teachers identified other teachers at their school as the most important source of curriculum support. It would seem that teachers already view curriculum support from their own colleagues as an important component in developing their confidence.

I wanted to find out how primary school teachers developed their confidence in visual art teaching. If I could find out how confidence in teaching visual art was developed, perhaps a solution could be found to answer the concerns expressed by the literature. To do this I focused on a group of primary school teachers in one school.

\subsection{Research question}

How do a group of primary school teachers work to develop their confidence in the teaching of visual art and what influences this development? 


\subsection{Developing teacher confidence}

When discussing a range of issues faced by beginning teachers in New Zealand, Ball, Russell and Smales (2005) make the point that many say they are anxious about having insufficient depth in content and curriculum knowledge. According to Loewenberg Ball and Cohen (1999) teachers need to understand the subject matter they teach in ways that enable them to develop meanings and make connections within the context of that curriculum area. In order to develop this level of understanding in the teaching of visual art, teachers need more than a superficial knowledge of both the content and the way it is taught. Using Loewenberg Ball and Cohen's view and the observations of Ball et al. the teachers I encountered who expressed a lack of confidence in the teaching of visual art would need to understand the subject matter they were teaching in order to develop their confidence.

When reviewing primary teachers' confidence in the teaching of science in the United Kingdom, Murphy, Neil and Beggs (2007) link an increase in teacher confidence to continuing professional development in both subject knowledge and pedagogical knowledge. Lundberg, Bergland, Klyczek and Hoffman (2003) make the point that action research projects involving teachers and university-based education departments are able to develop teacher pedagogical knowledge and develop teacher confidence. According to Hudson (2005) university-based art education courses can increase the confidence of pre-service teachers to teach visual art. Hudson based her conclusion on evidence collected during a seven week art unit taught at to pre-service teacher trainees in Australia. The seven week course encouraged the pre-service teachers to create to their own art works and therefore enable them to manipulate visual art materials.

The link between knowledge of visual art content and pedagogical knowledge may be one of the keys to developing teacher confidence in teaching visual art in a primary school setting. According to Andrews (2006), beginning teachers increased their confidence in teaching visual art after they had been engaged in arts-based activities with expert practitioners. After assessing the effectiveness of a range of support for teaching the arts in Canada, Andrews came to the conclusion that visual art teaching was strengthened when teachers were able to observe colleagues teaching the visual art, engage in visual art activities and obtain peer feedback about their own teaching of visual art. 
Therefore, a strategy in developing teacher confidence in the teaching of visual art could be for groups of teachers to work collaboratively to develop their understanding of the teaching of visual art by sharing their own knowledge, and inquiring into their own practice.

\subsection{Teachers working in collaborative groups}

Literature concerning inquiry into practice reveals opposing views. Loewenberg Ball and Cohen (1999) believe that if teachers are given the opportunity to inquire into their own practice, this would lead to a better understanding of that practice. This in turn would help to expand opportunities to learn from their own classroom experience. To enable teachers to develop in this way they suggest that changes in the culture of professional learning need to be made. They see teachers developing their understanding in groups as they inquire collectively into the problems of teaching.

This view of developing collaborative teacher groups within schools is not without its critics. Crebbin (2004) cautions there are risks associated with working collaboratively on school-based development. She makes the point that administratively imposed strategies for development are not an appropriate way to achieve personal change. Teacher frustration can easily develop when language such as 'empowerment' and 'ownership' is used, and they feel neither of them. Crebbin says in order for alliances to be effective groups need to be non-hierarchical and voluntary, with peers sharing common goals. It seems Crebbin believes teachers should initiate developing their expertise as they investigate a commonly perceived problem. If primary school teachers are therefore to develop their confidence in the teaching of visual art at their own school then, according to Loewenberg Ball and Cohen and Crebbin, this could be done within a collaborative group of teachers who share a common goal.

In their review of literature on the development of collaborative school cultures, Leonard and Leonard (2001) make the point that additional research is needed to address the role of the principal in creating those cultures. They point out that if collaborative cultures are to be developed in schools then the focus of schools should be teacher empowerment. This empowerment would also require the teachers to possess a number of sophisticated skills in consensus building, decision making and the process of conflict resolution. According to Lally and Scaife (1995) collaborative groups in schools are able to unlock the collective expertise of the group. 
In discussing their findings in a project investigating five New Zealand schools working towards school and schooling improvement through partnership, Timperley and Robinson (2002) found the most successful schools achieving improvement were those where the partners had a shared understanding of the task as well as sharing power. They found a correlation between satisfaction with the mutual relationship and a mutual understanding of the task. It would seem from evidence of this study that a shared understanding of the task or common goal is essential if working collaboratively is to be successful.

\subsection{Independent artisanship}

Huberman (1993) argues that this view of collaborative groups undermines what he identifies as the essential independent artisanship associated with good teaching. He believes teacher professionalism is grounded within this independent artisanship. It is this very independence and a teacher's ability to develop their own professionalism that enables a teacher to become effective. Huberman's use of the term 'artisan', when describing a teacher, paints a picture of teaching as a craft. $\mathrm{He}$ uses the analogy of a jazz musician using improvisational skills that he says are fundamentally individualistic. His fear is that development of school-wide teacher collaboration would undermine, rather than support, artisanship and professional effectiveness. However, I believe Huberman's jazz improvisation analogy is a rather simplistic view. It ignores the other musicians involved in the music, only focusing on the soloist. According to Talbert and McLaughlin (2002), Huberman's (1993) artisanship model thrives in collaborative teacher communities. Their view is that within these communities improved teaching practice is a result of teachers sharing knowledge, evaluating new practices and sharing a repertoire of practice in the same way a jazz improvisation relies on other musicians in order to develop. They call these collaborative teacher communities 'artisan communities'. Their research points to a model of teachers working together on common goals as they support one another's professionalism; in these environments Huberman's independent artisan teacher thrives.

It seems that the key to both Crebbin's and Talbert and McGlaughlin's (2003) view is that collaborative groups of teachers who have a common goal can develop their confidence within a group that is non-hierarchical. If this is the case then the shortfall of both the advisory service and pre-service support for primary teachers in the area of visual art could be compensated for by what Talbert and McLaughlin identify as collaborative teacher communities. According to Robinson, Halliday and Timperley 
(1995), schools that worked towards solving problems were more successful in solving those problems in an environment that was rich in solutions to those problems. If that is the case then a collaborative group of teachers would need access to a range of possible solutions if they were to develop their confidence in the teaching of visual art. This would then raise the question of who would provide that range of solutions or where would the group find those solutions. In the past this would have been one of the roles of School Support Services.

\subsection{Classroom autonomy: New Zealand context}

Within New Zealand, O'Neill (2005) also suggests that teachers' skills and autonomy are under threat. It is his view that the introduction of a set curriculum developed by the Ministry of Education has had the effect of reducing teachers' skills. This view pre-supposes that at one time teachers had a greater autonomy over the curriculum that was taught, and that an imposed curriculum stifles that autonomy.

A similar view was expressed in the United States of America nearly 20 years earlier by Apple (1986) who felt that teachers no longer determined what they did in the classroom but merely implemented policies that had been made elsewhere. If teachers are merely in the classroom to deliver a series of policies and are powerless to develop their own material, and Huberman's (1993) fear of teachers losing their improvisational skills is true, then the future for teaching appears to be rather bleak.

From my own experience as an advisor I would suggest that teachers in New Zealand do have a degree of autonomy and that they are still able to develop their improvisational skills. Although the trend of increased accountability and use of performance measures seems to have added pressure to a teacher's workload, the teachers I have contact with in primary schools still want to develop their own understanding of teaching.

\subsection{Supporting a collaborative teaching community}

If change is to take place in a school, and the collaborative teaching communities described by Talbert and McLaughlin (2002) are to function effectively, then what kind of school environment would support these communities? Lieberman (1996) suggests that for lasting and significant change to take place in teacher learning, professional development should be viewed as an integral part of the life of a school. She goes on to describe examples of schools that have instigated 
organisational and pedagogical change to encourage teacher development. These examples include:

- $\quad$ putting new and experienced teachers together to learn from each other

- creating common planning sessions so that connections can be made across subject areas

- using staff expertise to provide leadership for in-house workshops.

Lieberman describes a changing view of professional learning in schools that moves away from the traditional one-off, in-service development day, towards a broader concept of teacher development. She talks about connecting teachers' personal need for growth and development with a professional need to restructure schools. It seems from Lieberman's observations that an important part of instigating and supporting teacher development within a school is dependent upon the way the school is organised. This implies that a school's management structure has an important role within the school in creating an environment where common planning sessions can take place and where staff expertise is utilised. When discussing the essential elements required to create a positive climate within a school setting to support a collaborative teaching community, Retalick and Butt (2004) found that teachers identified collegial support, recognition and trust, mutual caring and social cohesiveness as more essential elements.

The literature (Crebbin, 2004; Huberman, 1993; Lieberman, 1996; Loewenberg Ball \& Cohen, 1999; Talbert \& McLaughlin, 2002; Timperley \& Robinson, 2002) points to a change in the way teachers could develop their confidence. Their model is one of collaborative groups working towards common goals, although Huberman fears this may inhibit the independent teacher.

Talbert and McLaughlin's research shows that collaborative teacher communities actually support the artisan teacher. It also seems teachers must be involved in looking at their own practice if they are to develop.

Barth (1990) makes the point that teachers cannot teach others without being fully engaged in learning themselves. She talks about teachers observing, examining, questioning and reflecting upon their own practice to develop new practices. To develop teacher confidence in the area of teaching visual art in a primary school it seems a culture of co-operation and collaboration within the school must exist. 
My research question focuses on a group of primary school teachers and the way they work to develop their confidence in the teaching of visual art. The literature points to a model of developing teacher confidence through non-hierarchical collaborative groups working on common goals. The study therefore will examine the dynamics of a group of teachers and the school in which they work. Will the evidence of the study support the literature or not? To find answers to the research question, and make recommendations for the future, it was deemed necessary to consider historical developments in primary art education in New Zealand. 


\section{CHAPTER TWO}

\section{Visual Art Education in New Zealand: Historical Context}

\subsection{Training for industry}

The development of visual art education in New Zealand primary schools has been shaped by social and political influences. According to Chalmers (1999) New Zealand art education in the $19^{\text {th }}$ century was Eurocentric and imperialistic. New Zealand, along with other British colonies, allied themselves to the 'South Kensington' method of teaching art and design. This system was designed around a series of pre-determined tasks. As a consequence, visual art education was characterised by teachers leading children through a series of rather rigid drawing sequences. Children were required to copy prints, drawings and examples drawn by the teacher. Visual art education was a method of training the population in artrelated skills so society could have a workforce capable of contributing to developing industries. Supporting teacher confidence and expertise in teaching visual art was provided in the form of drawing manuals that enabled them to demonstrate to children how to copy drawings.

In the $19^{\text {th }}$ century, the Europeans also viewed art education as a vehicle for 'civilising' indigenous populations throughout the colonies. According to Chalmers (1990) a special drawing curriculum was designed for Maori schools that contained objects deemed suitably civilised and British for study: These objects included ninepins, carrots, plums, apples, pansies, daffodils, croquet mallets, cricket bats, tennis racquets, school bells and flower pots. Formal drawing dominated visual art education in New Zealand classrooms until the 1930s.

\subsection{Encouraging creativity}

In 1904 Austrian Franz Cizek was appointed head of the Department of Experimentation and Research at the Vienna School of Applied Arts. Cizek advocated the free development of spontaneous artistic activity and encouraged children to present, in visual form, their personal reactions to events in their lives. His goal was to develop the creative power found in all children and his ideas exerted a strong influence in both England and America at that time. 
The present-day belief that children are capable of expressing themselves in a creative manner in visual art can be traced back to the work of Cizek. According to Collinge (1978), Cizek was unable to develop an adequate and suitable pedagogy to support the development of his ideas in the classroom. As a result, visual art programmes lacked direction and became chaotic. Teachers needed to be confident, developing an environment where the teacher balanced the child's expression and creativity with a degree of guidance, meaningful structure and creativity. This was a major change from the confidence needed in enabling children to copy prints.

\subsection{Cizek's ideas reach New Zealand}

The 1937 New Education Fellowship Conference held in Australia sponsored new ideas in education, and gave new impetus to art education in New Zealand. A delegation of conference educationalists visited New Zealand and spoke at a series of meetings. One of the delegates was Dr Paul Dengler, who had worked with Cizek, and another was Arthur Lismer who was engaged in exciting work with children's art at the Toronto Art Gallery.

According to Collinge (1978), the message given by Lismer was a revolutionary one for New Zealand. Lismer maintained that visual art should have a central place in the education of all children. He believed visual art could provide people with selfknowledge and self-respect. The fundamental principle of Lismer's ideas, according to Collinge, was that all children are endowed with a capacity for artistic creation, and that visual art leads to the discovery of personality.

\subsection{New Zealand promotes art education}

The ideas expressed by Lismer were embraced by New Zealand's liberal/socialist Labour Government elected in 1935. Peter Fraser, Minister for Education, invited the delegation from the New Education Fellowship Conference, held in Australia, to New Zealand. Visual art education started to change in New Zealand. In 1938 Clarence Beeby, Director of Education, established the Arts and Crafts Branch. In 1946 Gordon Tovey was appointed as the first National Supervisor of Art and Craft by the Department of Education, and for the next twenty years Tovey was a dominant force in New Zealand art education. In 1944 the Department of Education set up a committee of four Training College Art Lecturers. The committee prepared a new scheme which became An Art Scheme for Primary School ( $D$ o $E$ 1945), 
designed for the teaching of visual art in primary schools. It was promoted to teachers throughout the country via a series of refresher courses and films. This support and development of primary visual art education was made possible because of the political climate in the country at the time.

At this time an increasing number of teachers with specialist qualifications in arts and crafts were being trained. The Department of Education actively promoted visual art education in primary schools through professional development. Centres of excellence were set up in schools to develop visual art specialists. It was hoped that these schools would spread new ideas and methods by example. Promoting visual art education the Department of Education encouraged the development of primary school teachers' confidence in the teaching of visual art.

It was Tovey's firm conviction that imagination was an integral part of the educational development of every child. This belief can be traced back to the work of Cizek and to the psychological theories of Herbert Read, as set out in his book Education Through Art, published in 1943. Read's theories, based on those of Jung, have since fallen out of favour. However, one can still trace the ideas of encouraging primary teachers to recognise and allow for individual differences in their pupils. In fact, The Arts in the New Zealand Curriculum (2000, Ministry of Education) states that:

The arts enable individuals and groups to create ideas and images that reflect, communicate, and change their views of the world. The arts stimulate imagination, thinking, and understanding. They challenge our perceptions, uplift and entertain us, and enrich our emotional and spiritual lives. As expressions of culture, the arts pass on and renew our heritage and traditions and help shape our sense of identity. (Ministry of Education, 2000, p. 9)

This view of arts education has its roots in the work of Cizek, Read and the leadership of Tovey who was able to set in place a strong tradition of visual art education in New Zealand. This conviction that visual art played an important part in primary school education was reflected in the support and training in visual art available in both teacher training programmes and teacher professional development. The development of primary teachers' confidence in the teaching of visual art was at this time linked to their practical involvement in visual art making activities. 


\subsection{Art as a body of knowledge}

Between the 1920s and 1950s, after Cizek first developed his ideas about art education, art educationalists such as Lowenfeld and Read focused on the structure of visual art and sought ways in which it could be taught, and looked at the process by which children learned to draw. As a consequence, the Department of Education expected primary school teachers to have a wide range of skills in teaching a variety of art and craft processes. This expectation continued to be supported by the structure of both pre-service courses and the network of the art advisory service across the country until the 1960s when visual art and the development of personality formed the core of the creativity rationale for art education. With the election of the National Government in the 1960's the role and direction of the Arts and Craft Branch changed. It became the Art Advisory Service, and with this change the role of advisors moved from practical hands-on support in schools to in-service courses and consultancy.

Since the 1960's attention has focused on visual art as a body of knowledge that could be learned by children, as well as a series of developmental activities. Eisner (1972) emphasises the types of contributions to human experience and understanding that only the arts can provide. In fact, Eisner (2002) maintained that the arts are able to promote our capacity to imagine. If this is the case and the arts enable students to develop their own creativity and creativity is a transferable skill, then the importance of visual art programmes within an education system are essential. Eisner's views of the unique qualities of the arts in the development of children continue to reinforce the importance of visual art within New Zealand classrooms.

\subsection{Art and critical thinking}

Since the days of copying prints, art educationalists have looked to research and practice from behavioural and cognitive psychology and learning theory to develop practices in the classroom. For example, the child-centred or creative selfexpressive movement has its roots in theories of child development (Dewey, 1934; Lowenfeld, 1947; Piaget, 1970). Eisner's (1972) Educating Artistic Vision is a virtual encyclopaedia of theories. Art educationalists have used visual art experiences to enhance visual perception skills, creativity, critical thinking and problem solving. Deleuze (1983), the French philosopher, views visual art as an act that is a stimulant to mobilise change, and as such has the ability to challenge what is seen by society as the norm of everyday life. The view that visual art can enhance these areas has meant that the Ministry of Education has an expectation that primary 
school teachers use their expertise to enable children to develop problem solving skills as well as their visual awareness.

After Gardner (1983) published his theory on multiple intelligences, the view of art education changed. Art educationalists started to turn their attention to the role visual art has to play in enabling children to critically analyse art-works and in turn transfer these analytical skills to other areas of their life. Taylor (1992) talks about children actively analysing their art, thus becoming more engaged with their artwork. According to Atkinson and Dash (2005), the link between practical art making and critical analysis is inseparable. The development of this view has led to the expectation that teachers should be able to help their children analyse art-works. This view has influenced the present arts curriculum and is reflected in the 'Understanding in Context' and the 'Communicating and Interpreting' strands within the curriculum. Others (Eisner, 1988; Hickman, 2000; Thistlewood, 1990) support the view that visual art education should not consist solely of practice but should also develop critical and contextual understanding of the work of artists.

The first national art syllabus for New Zealand schools Art education: Junior classes to form 7, syllabus for schools (Ministry of Education, 1989) makes the point that the concept of personal expression remains the same, but the scope of art education has been expanded to include studies about visual art and ways of responding to it. The 1989 syllabus states that art is a significant part of the daily life of all New Zealanders and that art education has an essential place in the curriculum for the students' first years at school. The Arts in the New Zealand Curriculum (Ministry of Education, 2000) makes the distinction between the way children learn through the practical hands-on experience of art making and the way they communicate and interpret meaning through the study of visual art. Clearly this document recognises both the art-making experiences and the importance of fostering understanding and responses to visual art.

There is a large body of literature (Atkinson \& Dash, 2005; Dewey, 1934; Eisner, 1972; Gardner, 1983; Hickman, 2000; Lowenfeld, 1947; Piaget, 1970; Taylor, 1992; Thistlewood, 1990) that supports the role of visual art in education as an important vehicle for the cognitive development of children, and as a means of developing children's ability to critically analyse the world around them. Through my own observations as a primary visual art advisor visual art also plays a vital role in developing children's literacy skills in their early years at school. It is common practice for teachers to use children's art-work when developing their literacy skills. 
According to Shifrin (2007), the University of New Hampshire has developed programmes that use visual art to train teachers in the use of images to improve reading and writing skills. With the evidence pointing towards the importance of visual art within the primary school classroom, it is of concern that support for developing primary school teachers' confidence in teaching visual art is diminishing.

In the past the importance placed on visual art in primary schools was reflected in the time devoted to visual art education when training primary school teachers and the support given to primary school teachers by the Schools Advisory Service. As mentioned earlier, these traditional forms of teacher support are under increasing pressure. Primary school teachers are expected to create an environment in their classrooms where children not only develop skills to express themselves through visual art but also analyse art-works. I have been unable to find any New Zealand research studies that focus on alternative models of supporting primary school teachers as they develop their confidence in the teaching of visual art. It seems there is a need to look at alternative ways to provide support for primary school teachers to enable them to teach visual art effectively.

\subsection{Developing my own art education philosophy}

A person's view of visual art education is often a reflection of their own experience of visual art, both in an educational setting and in their own life. Debate around visual art education, according to Hickman (2005), has broadly followed the debates within education in general. Opposing education philosophies have developed around the subject-centred approach and the student-centred approach.

The reality in schools is that the view of visual art education is partly a reflection of those teaching in the school. My own view of visual art education is a reflection of my own background and experience. Having been a student in school during the late 1950s and 1960s I was part of the Herbert Read tradition of free expression, where teachers stood back in case they inhibited children's creative flow. While training in visual art and education I encountered the philosophy where students were allowed to act upon their own instincts. In a recent interview with Michael Craig-Martin ${ }^{1}$ he said, 'It seems to me the most important thing about art school is the creation of a sympathetic ambience, in which people feel comfortable and free to act according to their ability' (Madoff, 2007, pp. 74-79).

\footnotetext{
${ }^{1}$ Taught at Goldsmiths College, UK from 1974 to 1988 and again in the 1990s
} 
My own view of visual art education has developed during my experience both as an art student and as an art educator. Using my own experience as a practising artist I have found that an understanding of art processes enables my own work to develop. A combination of this understanding and expertise enables me to realise my ideas. I also believe my confidence in teaching visual art is associated with my understanding of visual art processes and experience in the use of visual art materials.

In the same way, I believe that in order to teach visual art effectively a balance between creativity and an exploration of materials must exist. Creativity in visual art is about breaking the 'rules' and working outside the constraints of convention. If you do not know the rules or the conventions in the first place how can they be manipulated? Part of understanding the processes and conventions associated with visual art is looking at art-works in context, and being able to analyse those works. My own view of art education is therefore an amalgam of various views.

If primary school teachers' views of visual art education and confidence in the teaching of visual art are a reflection of their own experiences of visual art and those experiences are diminishing in their pre-service courses and in teacher professional development courses, then primary school visual art education in New Zealand could be under threat.

\subsection{Schools' view of arts education}

Within a primary school setting the approach to visual art is also an amalgam of views. According to Bresler (1996), arts education in a school is shaped by the traditions of a school and its community, by the beliefs and knowledge of its teachers, by the goals of the school and the demands of the curriculum. Bresler presents the idea that the orientation of arts education in schools can be divided into four distinct groups:

1. Social orientation

2. Subservient to academic disciplines orientation

3. Affective orientation

4. Discipline-based orientation.

The social orientation school is one where the school views the arts as a vehicle for social functions and a vehicle to present an image to the wider community. Arts activities revolve around holidays and social events. 
The subservient to academic disciplines orientation is a school where the arts are used to illustrate academic concepts. The arts are not seen as a distinct curriculum area but rather a way of servicing other curriculum areas.

Schools that have an affective orientation often use open-ended student-centred projects where art-works are created according to a student's imagination.

The discipline-based orientation usually requires teachers to have a degree of expertise in the arts. The arts are studied in depth with students developing their knowledge of both practical experience and wider critical understanding of the arts in a historical context.

I have observed all of these orientations in my role as visual art advisor. In some schools more than one orientation is evident in the same school. It seems that visual art education within a primary school is a reflection of the ethos of the school which is in turn a reflection of the local community, the principal and the staff.

The evidence (Atkinson \& Dash, 2005; Collinge, 1978; Eisner, 1972; Grierson, 2003; Hickman, 2000; Mansfield, 2003; Taylor, 1992; Thistlewood, 1990) suggests that visual art is an important element in the primary school classroom. Historically, the importance placed on visual art in primary schools has been reflected in the time allocated to the training of primary school teachers in the area of visual art, and in the support available to primary teachers from the Schools Advisory Service. The era of the 'New Right' user-pays policies of the 1980s saw support for primary school teachers' change as the Ministry of Education started to contract out advisory services. As a result advisory time in visual art decreased. Today visual art time allocation for pre-service courses has been cut and visual art advisory time is less than adequate, combining to provide inadequate support for primary teachers in the teaching of visual art.

In Chapter One I highlighted a body of literature (Barth, 1990; Crebbin, 2004; Loewenberg Ball \& Cohen, 1999; Lieberman, 1996; McLaughlin \& Talbert, 2002) all pointing towards a model of developing professional knowledge by creating a culture of collaborative groups within schools.

If generalist teachers in a primary school setting do not have the confidence to teach visual art effectively, and limited resources are available to provide them with 
support, then perhaps this model of developing professional knowledge can be applied to developing primary teachers' confidence in the teaching of visual art.

The focus of this study is to investigate how a group of five primary school teachers, April (teacher-in-charge of visual art), Carol, Jo, Rebecca and Catherine (all pseudonyms) work to develop their confidence in the teaching of visual art. The data for this study were collected from one primary school over a period of five consecutive terms covering two academic years. The details of this data collection process are outlined in Chapter Three. 


\section{CHAPTER THREE \\ Methodology}

\subsection{Research design}

The principal focus of the study is to evaluate how both the individuals and the group involved in the study develop their confidence in the teaching of visual art. The methodology used was participatory action research and my role within this qualitative study was that of a participant observer.

To address the research question I looked at a single primary school and worked with a group of generalist primary teachers. As well as interacting with the participants I also collected and analysed data that focused on the way they developed their confidence in the teaching of visual art. The volunteer participant teachers reflected on their practice and as a result were able challenge their own assumptions about the ability of children to reflect on their art-work. The data I collected during this process gave me a unique view of the volunteer participant teachers developing their confidence in the teaching of visual art.

\subsection{Participatory action research}

Action research has been an established research methodology in educational settings since the 1960s. According to Kemmis and McTaggart (1988) and ZuberSkerrit (1992), action research originated with the work of American psychologist Kurt Lewin in the late 1940s. McKernan (1991) explains Lewin's premise that social scientists would need to include practitioners from the real world at every stage of the inquiry in order to understand and change certain social practices. The view of Herr and Anderson (2005) is that action research is inquiry conducted by, and with insiders of an organisation or community. This view of action research as a methodology has evolved over the last 40 years and is now an established part of the educational research landscape. Practitioners improve their understanding of events, situations and problems within the setting of their classroom or school through reflection on their practices and often in dialogue with researchers.

As a methodology within an educational setting, action research has developed mainly to initiate change. By using participatory action research in this study primary school volunteer participant teachers analyse and reflect upon their own experiences of teaching visual art. Action research, according to McKernan (1991), 
attempts to solve immediate and pressing day-to-day problems of practitioners. The volunteer participant teachers (practitioners) in this study expressed a desire to develop their confidence in the teaching of visual art. Participatory action research enabled them to reflect as a group on visual art teaching, and then act upon this reflection. As a participant observer I was able to be part of this group of teachers, thereby giving me an insight into the way they developed their confidence in teaching visual art. According to Bresler (1994) action research gives practitioners and researchers the opportunity to explore ways to become active critics of both the shape and the direction of their own learning. Thurber (2004) makes the point that action research is often naturalistic, with a range of data analysed and interpreted for emerging themes and issues. Action research has the potential, therefore, to initiate change or improvement within the research context.

According to Kemmis and McTaggart (2005), there has recently been an increase in the popularity of participatory action research reflected in the scale and attendance at world congresses on participatory action research. However, participatory action research has not been without its critics. Kemmis and McTaggart (2000), make the point that these criticisms usually centre on its lack of scientific rigor, and confusion of community activism and development, with research.

Criticisms leveled against such projects included the belief they were manipulated by politically motivated outsiders. Bearing this criticism in mind, my own role in this study could be seen in this light. I was an outsider to the school, I had decided that a problem existed and I then approached the school. However, as part of the wider visual art education community and being a member of that community, I had identified a problem (see 1.1 and 1.2). From the outset of the study I was acutely aware that I could be perceived as the visual art 'expert' and, as such, the participant teachers could look to me for constant guidance. To counter this potential dilemma I allowed myself to be used as a 'sounding board' only during discussions.

Despite different viewpoints about participatory action research, there does seem to be agreement that the action research process involves a spiral or cycle of selfreflective stages (Elliott, 1991; Kemmis \& McTaggart, 2000; Winter, 1989). These are: planning, acting and observing, reflecting, then back to planning. However, Kemmis and McTaggart (2005) make the point this process does not conform to a neat spiral of self-contained cycles. The stages may overlap, with initial plans quickly becoming obsolete in the light of data analysis and the process can become 
more fluid, open and responsive. In this study the carefully planned initial stages changed, combining or becoming obsolete as the study evolved.

Herr and Anderson (2005) point out that action research can produce knowledge that is grounded in local realities and is useful to the local participants. The local reality of this study is that the school and the volunteer participant teachers were able to develop knowledge about the teaching of visual art which could then inform their own classroom practice.

\subsection{Reflective analysis}

According to Kottler, Zehm and Kottler (2005), since the 1980s a great deal of emphasis has been placed on the importance of the teacher being a reflective practitioner. This importance is demonstrated in a range of professional literature (Eby, Herrell, \& Hicks, 2001; Ghaye \& Ghaye, 1998; Goethals, Howard, \& Sanders, 2003, Guskey, 2000; Kauchak \& Eggen, 2005).

A teacher's ability to develop their own practice through reflective analysis of classroom experiences is, according to Hart (2000), an integral part of school development. It is also her view that the potential for teachers to learn from each other's experiences could be lost if there are no formal structured opportunities for teachers to share their experiences. In this study the teachers shared their ideas and reflective analyses within the structure of the participatory action research process. Hart goes on to make the point that the greatest impact on children's learning occurs when teachers reflect upon their practice in groups rather than in isolation. For most of this study the volunteer participant teachers worked together to reflect upon their own practice, as well as develop their confidence in the teaching of visual art.

\subsection{Qualitative researcher}

According to Durrheim (2006) the qualitative researcher is able to identify issues as they attempt to understand categories that emerge from the data. Denzin and Lincoln (2005) use the term bricoleur when describing the role of qualitative researcher, referring to someone who assembles a montage from a series of separate parts. The assembled whole is then used to interpret or make sense of where these parts have come from. These descriptions of the qualitative researcher could also describe my own practice as an artist. The metaphor of combining separate parts has a familiar ring and was one of the reasons I was drawn to using 
qualitative research. In my own art-work I use a range of materials and techniques to interpret an idea and clarify the work. Figures 1 and 2 are taken from a series of drawings I completed to explore a dancing figure.

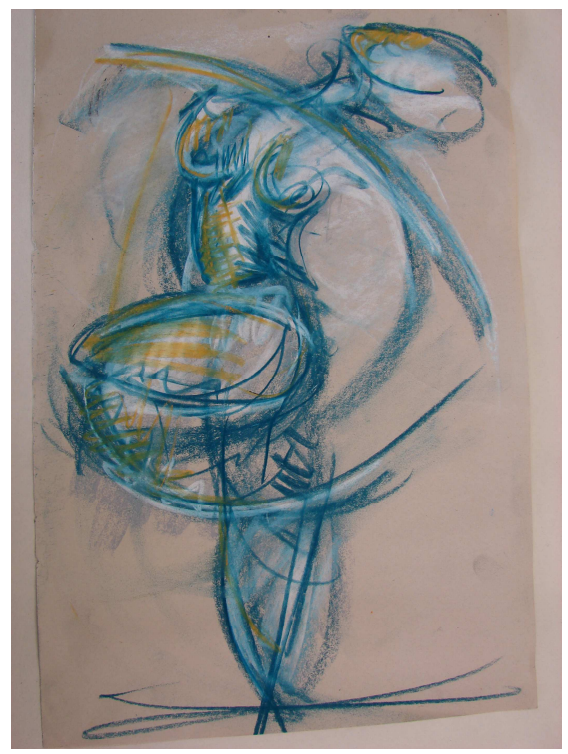

Figure 1: 'Dancing l'

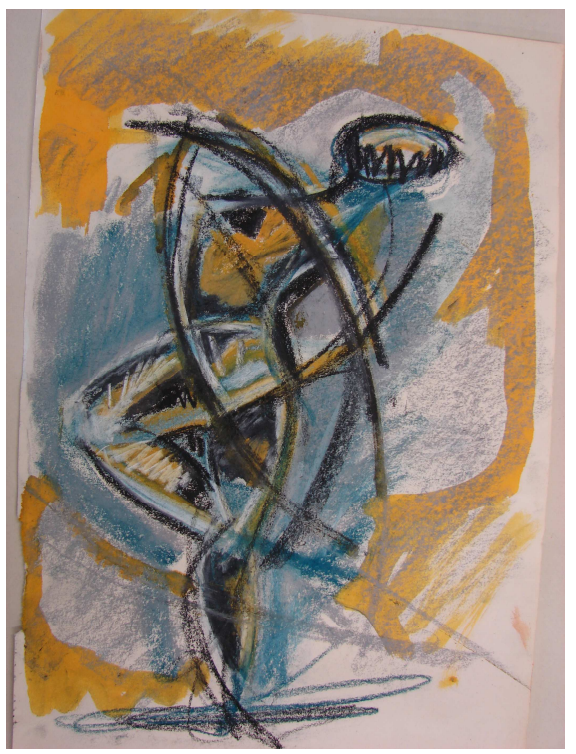

Figure 2: 'Dancing II’

At the same time I was working on these drawings I was also working on a painting (Figure 3) that explored the relationship between figures within an architectural setting. These seemingly unrelated pieces of work then informed two sculptures I worked on (Figures 4 \& 5).

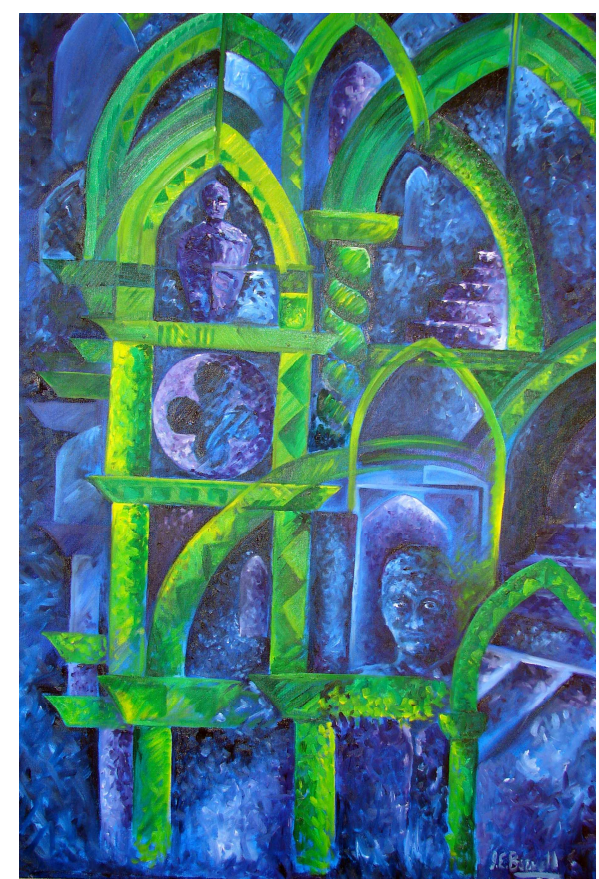

Figure 3: 'Cloistered' 


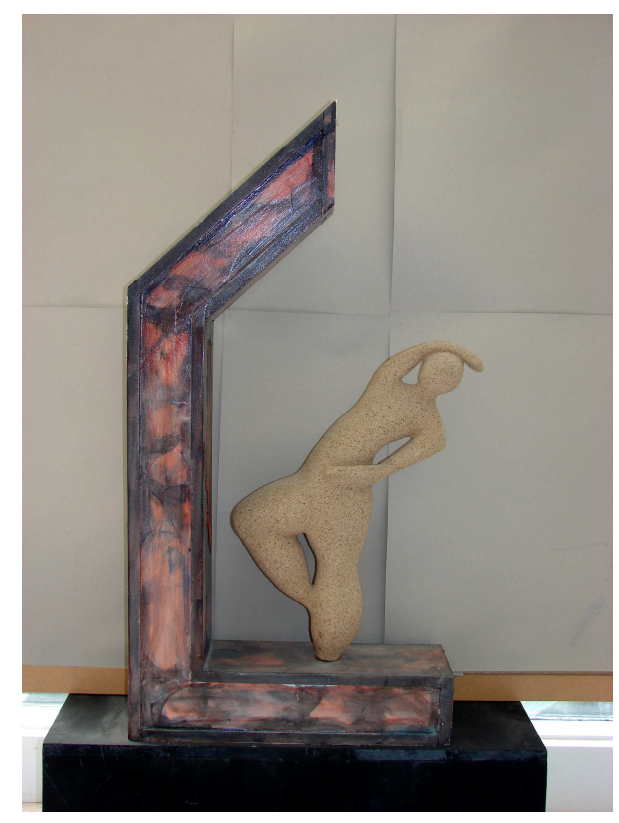

Figure 4: 'Adage’

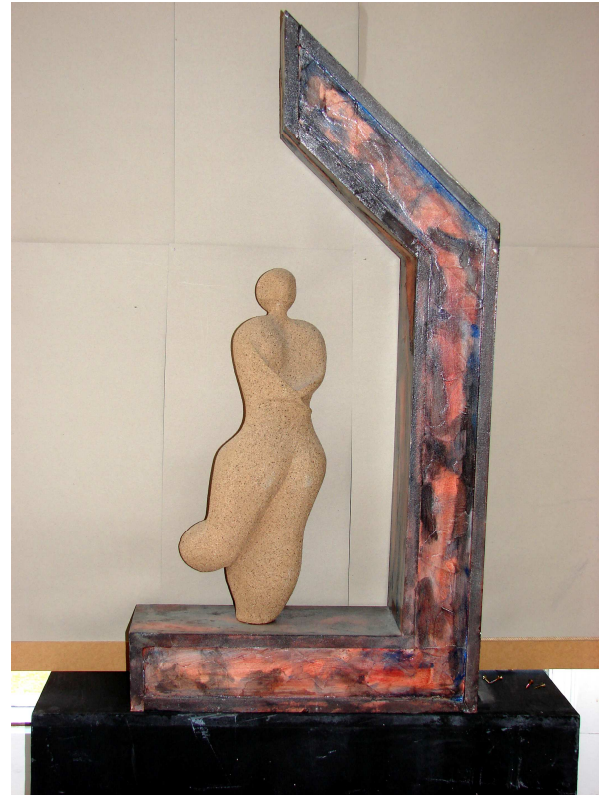

Figure 5: 'Arrière’

I used the information from the drawings and painting to inform the sculptures. When viewed together, rather than in isolation, each piece takes on a new meaning. I used a range of materials and techniques to interpret a theme. In the same way I used a range of research tools in this study to interpret a theme.

Analysis of the data in this study was similar to creating a montage with each new piece of evidence adding to the composition. Often gaps remained in the composition as it developed and occasionally those gaps were filled when elements in the composition were re-analysed. Using the metaphor of developing a montage composition to analyse the data enabled me to realise that each piece of analysed data relied on its relationship with other pieces of data to give it meaning, much in the same way a montage composition relies on all its parts to give it meaning.

\subsection{Participant observer}

Being an active participant gave me the opportunity to use the method of participant observer $^{2}$ to gain an insight into the participants in their own environment. SanchezJankowski (2002) makes the point that participation-observation has the advantage of allowing the researcher to directly view the actions and behaviours of those being researched. A range of methods was used to collect data and this collected data helped me develop a broader picture of both the participants and their environment.

\footnotetext{
${ }^{2}$ See page 30 for information detailing the process of observation.
} 
As mentioned earlier, participatory action research involves a spiral of planning, acting and reflecting and then back to planning.

At varying stages of this process collected data enabled the participants to reflect upon their own practice and enabled me to reflect upon the way the participants developed their confidence in the teaching of visual art. Cohen, Manion and Morrison (2001) suggest that methodology not only helps us understand the findings of the inquiry but can also help us understand the process itself. With this in mind I was aware of the effect of my presence in the process while analysing the data.

\subsection{Developing the role of participant observer}

Birch and Miller (2002) talk about the research 'participants' and how important it is for them to feel part of the research process. They also emphasise the importance of the researcher negotiating participation in the research at the outset. For me, this meant giving all of the participants a clear outline of the study. Throughout the early stages I made sure that all the participants were fully informed of both its aim and their role in it.

As a participant observer, my identity as a researcher was clearly recognised by everyone in the school. It was important for me was to spend as much time as possible at the research site and to use this time to develop trust and rapport with those taking part in the research. Denscombe (2005) makes the point that the trade mark of participant observation is the insight that emerges from the trust developed between the researcher and the participants. In order to develop trust between myself and the participants I made sure they were fully informed of the research process and their role in it. I hoped that by developing a degree of trust with the participants I would gain insights into the way they developed their confidence in the teaching of visual art.

I needed to develop a structure in order to collect the data from the research site (see Figure 6). In part, the structure was a reflection of the participatory action research process which involves a continuous spiral of planning, acting, observing and then replanning. I hoped that analysis and interpretation of the collected data would reveal the way the participants developed their confidence in the teaching of visual art.

The data collection stages in this study and the techniques used to collect the data had to be carefully designed and planned. Not only did they need to fit into the 
structure of the school, they also had to provide a variety of views of all the participants including five volunteer participant teachers, the principal, 50 children, a provisionally registered teacher and the teaching staff.

The analogy of triangulation is often used to describe the use of a variety of data collection methods. Triangulation involves locating a fixed point by referring to two or more coordinates. Denscombe (2005) makes the point that separate and distinct views are added to the same topic by using a variety of methods to collect data. By using a variety of methods the researcher allows their findings to be corroborated or questioned by comparing the data produced by these different methods. For me, the use of a variety of methods to develop a range of perspectives was very much aligned with the way I work in visual art. I could easily see the relationship between the process of qualitative research and developing an idea in visual art.

\subsection{Participant observer dilemma}

For the majority of the meetings held by volunteer participants I only participated by asking the whole group how they would use the information they had gained through analysing data. There were occasions during some of these meetings when I was asked by the volunteer participants to provide either my opinion or information. This created a dilemma for me as I had to decide whether to provide either an opinion or information. If I provided an opinion my role would change to that of 'expert', thus potentially influencing the way the volunteer participants developed their confidence in the teaching of visual art. My response to these requests was to generate a series of questions which would enable them to refocus on their analysis.

\subsection{Reciprocal relationship}

After my first meeting with the principal and the teacher in charge of visual art (April) I felt they both saw the project as an opportunity to provide professional development for staff in the area of visual art. I saw the project as a way of investigating the way primary teachers develop their confidence in the teaching of visual art. These differing viewpoints are an example of reciprocity, where the relationship between the researcher and those involved in the research must be one of mutual respect.

According to Bishop and Glynn (1999), reciprocal participation will enable the participants to have control over the project. Therefore, it is important the views of all those involved in the research are listened to and acknowledged. The direction of 
the research is in some way dictated by all the participants. The project takes on a life of its own and is dependent on co-operation. For me, the reciprocal involvement of the volunteer participant teachers was an important dimension and would help to ensure the project was relevant to them.

\subsection{Research strategies}

\subsubsection{Selecting a site}

Having decided to investigate how a group of primary teachers developed their confidence in the teaching of visual art within the setting of a primary school I needed to find a school that had demonstrated a degree of commitment to the teaching of visual art. If there was a degree of confidence in teaching visual art within the school I could find out how this had developed and if it was passed on to other members of staff. I consulted five colleagues in order to select a school for this project; they included regional arts advisors and teacher education lecturers with professional connections to primary schools in Wellington, New Zealand.

All those I consulted recommended the same primary school, emphasising it was one that valued the arts and, in their view, would be the most suitable for my proposed project. The recommended school was a full primary school (years $1-8$ ) in the greater Wellington region with a roll of 413 . The school was divided into four syndicates with 18 full-time and two part-time teachers. I spent five terms over a period of two academic years collecting data from the selected school.

Denzin and Lincoln (2005) suggest when qualitative researchers study phenomena in their natural settings they are able to reflect upon them in terms of the meaning people bring to them. I collected the research data from the natural setting of a primary school combining several data collection methods, which were:

- Research journal

- Questionnaire

- Semi-structured interviews

- Observations

- Document search.

The use of a combination of methods, according to Silverman (2005), enables the researcher to corroborate the data collected. Using a combination of methods also enabled me to compare and examine emerging themes, establishing trends or 
patterns in the way the participants developed their confidence in the teaching of visual art.

\subsubsection{Research journal}

Throughout the study I kept a research journal which enabled me to reflect on my observations at the research setting and my interactions with all the participants. Initially I used the journal to note down the various interactions between the participants and my reflections on these interactions. I also noted my thoughts on my own role within the research process and how that role could have an impact upon the participants. The journal therefore became a reference point as I analysed other data. I used the journal in the same way I use a sketch book when developing a piece of work - by referring to original drawings and sketches to understand or develop a piece of art-work.

\subsubsection{Semi-structured interviews}

As well as collecting data I wanted to use the interview process to enable me to develop my relationship with the volunteer participant teachers. According to Kelly (2006) the process of interviewing is a far more natural process of collecting data than asking people to complete a questionnaire. He makes the point that it gives the researcher the opportunity to get to know those involved in the interviews. Using semi-structured interviews allowed me to be flexible in terms of the topics discussed. According to Denscombe (2005) semi-structured interviews let the interviewees develop ideas on issues raised by the discussion. I wanted the volunteer participant teachers to develop their understanding of the teaching of visual art as they reflected upon their own practice. The use of semi-structured interviews helped in this process. During the study I conducted semi-structured interviews with the following participants:

- School principal

- Five volunteer participant teachers

- Teacher in charge of visual art

- 50 students

- A provisionally registered teacher.

Each of the semi-structured interviews lasted between 20 to 50 minutes and all were taped and transcribed. 
I interviewed the five volunteer participant teachers at the start of the study and after I had observed them teaching. The aim of the first interview was to gain an insight into their views and concerns about the teaching of visual art. The semi-structured interviews involved asking the participants about the following areas:

- Their level of confidence in teaching the arts curriculum

- The role visual art played in their classroom

- Assessing children's visual art-work

- How they shared ideas about the teaching of visual art

- How visual art planning is undertaken

- Their beliefs about the teaching of visual art.

The second semi-structured interview with the volunteer participants centred on them describing a selection of art-works produced by children in their class.

I interviewed 50 randomly selected students (10 from each of the volunteer participants' classes). The interview was based around an art-work they had completed in their classroom. This art-work was the same one that had been described by the volunteer participants. During the project, the volunteer participants analysed the transcripts of their own description of the art-work and compared this description to the children's description of the same art-work. Having analysed the two descriptions, the volunteer participants then discussed their findings with each other and started to develop their understanding of teaching visual art. In this way the data from each class were analysed by three people - two of the participants and myself. According to Gall, Borg and Gall (1996) the three perspectives gained from the analysis is a form of member checking and helps ensure the accuracy of the findings.

One of the volunteer participant teachers was also responsible for the visual art curriculum within the school. She had been newly appointed to the role of teacher in charge of visual art and at the time of the project, the teaching of visual art within the school was being reviewed. I conducted a 40 minute semi-structured interview with her focusing on her role within the school and the challenges that role presented to her.

A provisionally registered teacher within the school had attended a visual art professional development course and then shared the information from that course with other members of staff. I conducted a 30 minute semi-structured interview with this teacher. The interview looked at her confidence in teaching visual art, the professional development course she had attended and the way she shared her newly developed expertise and confidence with other members of staff. 
Throughout the study, one of the developing themes was the influence of the principal on the way the teachers developed their confidence in the teaching of visual art. Having identified this as a theme I conducted a 50 minute semi-structured interview with the school principal. The data from this interview enabled me to gain a further insight into my earlier analysis of other data.

\subsubsection{Questionnaire}

One method used to gain a view of the overall setting (see Chapter 4) was for all the teaching staff to complete a short questionnaire. This questionnaire was designed to give me a broad picture of the profile of the staff and discover how confident they felt in teaching visual art (see appendix D).

\subsubsection{Observation (classroom and meetings)}

Throughout the study I collected data from observations of the following:

1. The teaching of visual art by the five volunteer participant teachers. Each was observed on three separate occasions.

2. Meetings of the volunteer participant teachers when they discussed a range of issues related to the teaching of visual art. I was present at six of these hour long meetings and taped and transcribed them.

3. One whole staff meeting at the start of the study when I made notes in my research journal on the way the meeting was conducted.

Analysis of the data from these observations, which was in the form of both transcripts and journal reflections, enabled me to gain a view of both the working dynamics of the school and the group of five volunteer participant teachers. Not only did this analysis give me an insight into the environment that enabled the teachers to develop their confidence in the teaching of visual art, but also into how they were able to do this.

\subsubsection{Document search}

Apart from the questionnaire and observations, I also completed a document search of all the schools' official documents. The search enabled me to identify school policy and any visual art initiatives the school had undertaken. This helped me reflect upon the environment the volunteers worked in. Analysis of the document search revealed school policy related to the teaching and role of visual art in the school. I felt that this policy may have an effect upon the way the participant teachers developed their confidence in the teaching of visual art. 


\subsubsection{Analysing the data}

As I collected a variety of data, I used a variety of analyses when viewing the data. Most of the data were in the form of transcripts of meetings or of semi-structured interviews. I used a system of open coding to analyse the transcripts. According to Ryan and Bernard (2003) open coding describes a process of text analysis where the researcher identifies potential themes from the text by pulling together real examples. Open coding is associated with the Grounded Theory Method of Glasner and Strauss. According to Densccombe (2005) the key to 'grounded theory' is the way the researcher organises the research material and codes it to make sense of it. Grounded Theory Method is a contested concept but according to Bryant and Charmaz (2007) this does not detract from its value and contribution to qualitative research. Holton (2007) makes the point that within grounded theory it is essential that researchers develop their own coding as the coding stimulates the researcher's conceptual ideas.

As I collected and analysed the data, at times the analysis informed the type of data collected. For example, during my initial analysis of the semi-structured interviews with the volunteer participants and of my early field notes, it became apparent the principal had an influence over the way the participants worked in the school. Therefore, this initial analysis suggested further investigation of the principal's role and I arranged a semi-structured interview with him as part of the data collection.

Initially I coded the transcripts to look for common themes. Morse and Richards (2002) emphasise that open coding is about opening up the data by identifying themes within the data. Once these initial themes had been identified I constructed a table with column headings being the title of an identified theme or group. The data were then re-analysed, focusing on the developing themes. For example, in my initial analysis, one of the recurring themes in the semi-structured interviews was the way the participants talked about working with other members of staff within the school. I called this theme 'working together' and then re-analysed the data looking for any components that made up this theme. I also looked for further evidence from observation field notes and the school document search that could relate to this theme. Analysing the emerging theme 'working together' revealed two settings in which working together occurred; these were formal and informal. I was then able to compare formal and informal settings to find out if the participants worked differently within them and what enabled those settings to function. Using the montage metaphor enabled me to identify correlation between one emerging composition and another. For example the montage created by the emerging theme of a formal 
setting revealed these settings were both inside and outside the school. The formal setting had created a group of visual art experts and in turn these visual art experts were able to support others within the school through an informal support network. All the data was collected over a period of six consecutive terms (see Fig. 6).

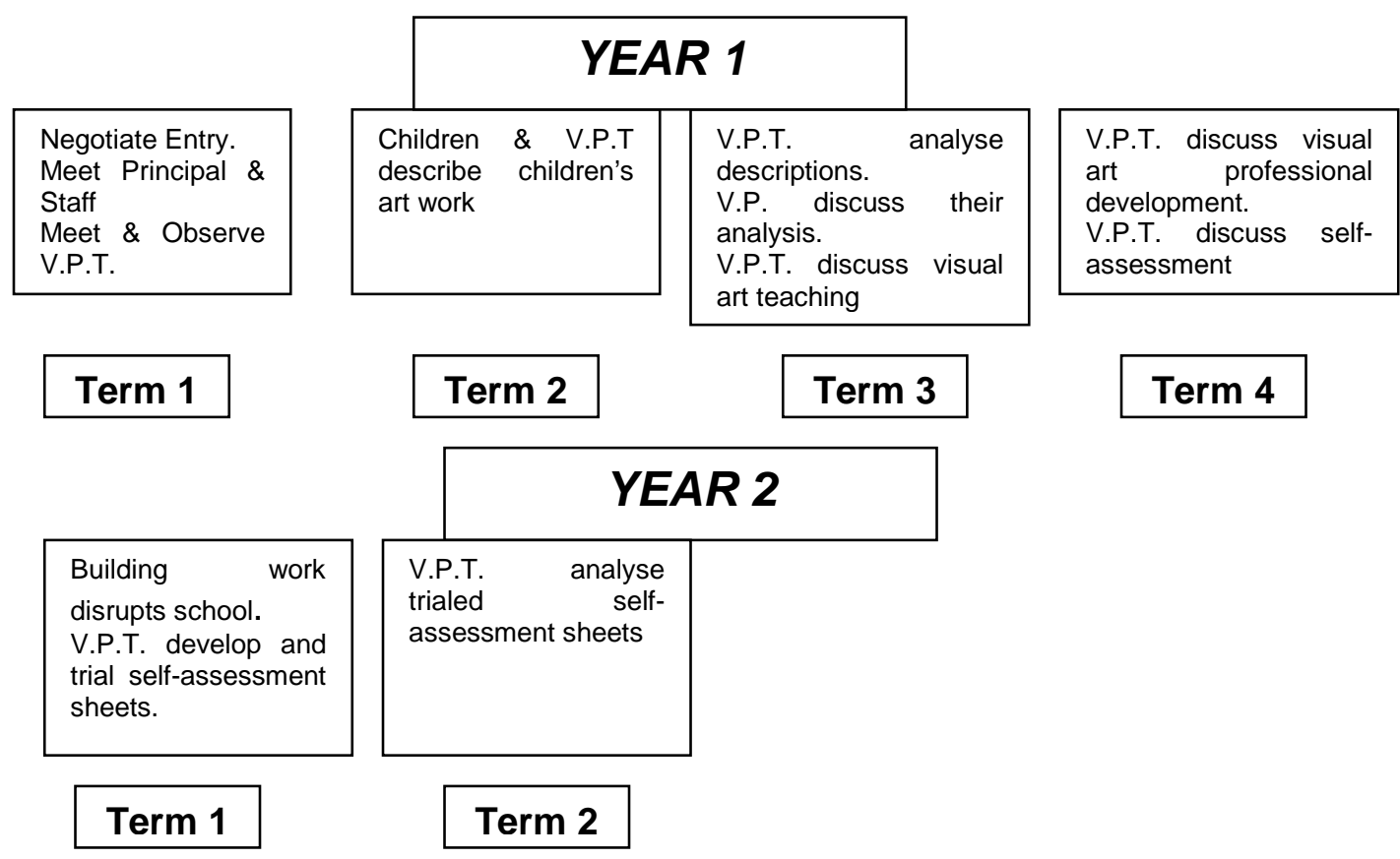

Figure 6: Research Timeline

\subsubsection{Trustworthiness}

A definition of 'trustworthy' in Collins English Dictionary (2004, p. 1750) includes the words 'dependable', 'reliable' and 'honest'. Denzin and Lincoln (2005), when discussing trustworthiness in relation to qualitative research, uses words such as 'dependability' and 'credibility'. These are all words that not only describe the research itself but could also describe the researcher. In my role as a researcher I needed to be honest, dependable and reliable. Throughout the project I demonstrated my honesty by making sure the participants were always informed of the intent of the project. I was able to ensure dependability and reliability by thorough planning and constantly taking the needs of those involved in the study into account during the planning. My representation of the data through my analysis has been done openly, with the participants invited to comment on that analysis. 


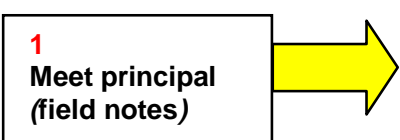

6

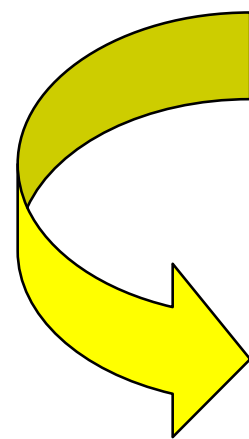

Observation of participants' teaching (field notes)

\section{7}

Children describe artworks (taped \& transcribed)
Staff Meeting

Ask for

volunteers

(questionnaire

/ field notes)

Meet with

individual

participants

(semi-structured

interviews taped

\& transcribed)

\section{8}

Teachers

describe

art-works

(taped \&

transcribed)

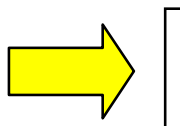

Meet participants

(field notes)

Document search

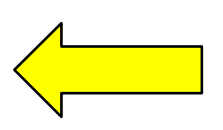

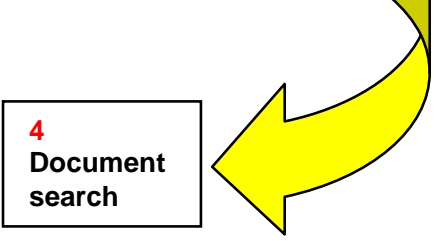

9

Analyse

teacher's and

children's

descriptions

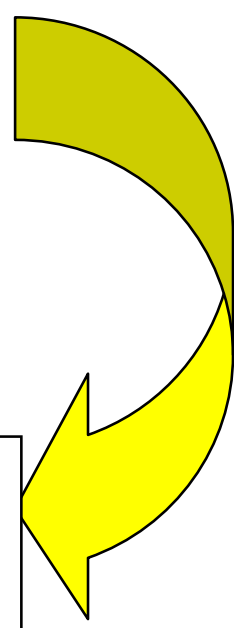

Participants

discuss their

findings (taped \&

transcribed)

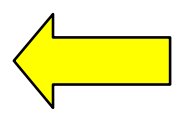

10

Participants

analyse

descriptions

discuss visual
art (transcribed)

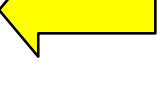

14

13 Participant $i / c$ of

V.A. talks (taped \&

transcribed)

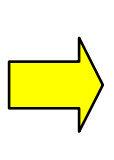

Teacher talks

about V.A. P.D,

experience

(taped \&

transcribed)

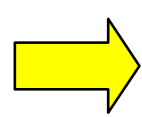

15

Participants

discuss self-

assessment

(taped \&

transcribed)

\section{7}

Participants report

back on trialed self-

assessment sheets

(taped \&

transcribed)

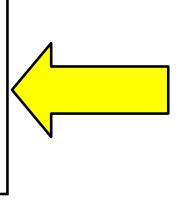

16

Principal talks

about his role.

(taped and

transcribed

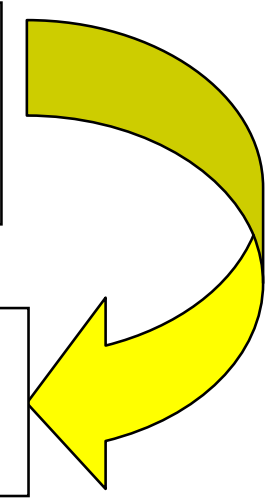

Figure 7: Data collecting stages

\subsubsection{Ethics}

As a participatory action research project it was essential that all the standards of research ethics were observed. Prior to starting this study I applied for, and gained, ethics approval from the Human Ethics Committee at the School of Education, Victoria University of Wellington. Entry to the research site was negotiated through the principal. Informed consent was obtained from all the participants (see appendices $\mathrm{A}-\mathrm{I}$ ) and their identities have been protected by the use of pseudonyms. 
Informed consent was gained from the parents/guardians of all the children interviewed as part of this project (see appendices $\mathrm{H} \& \mathrm{I}$ ). The development of the study was open to the volunteer participants and all data collected were made available to them. Throughout the project I was often aware of the differing views of the volunteer participant teachers, and analysis of these views gave insight into the various ways teachers develop their confidence in teaching visual art. Cardno (2003) emphasises the importance of the researcher acknowledging and recognising contradictory views held by the participants in participatory action research. Analysis of the data enabled me to use the volunteer participants' views to examine the dynamic of the group as they worked together.

I was aware at the start of the project that school principals are often viewed as 'gatekeepers' as they are in a unique position to grant permission to would-be researchers to work in their schools. According to Hammersley and Atkinson (1995), the 'gatekeeper' can provide entry to the site and help researchers locate people and places to study. Bogdan and Biklen (2007) make the point that gaining permission to enter the site is only part of the process of gaining access to it. The process also involves the development of a good rapport with those with whom the researcher will be spending time. I also paid particular attention to Denscombe (2005) and Cohen, Manion and Morrison (2001) as they pointed to the essential nature of negotiated entry to the research site in order to achieve goodwill and cooperation. I was able to develop a good working rapport with the volunteer participants, particularly because I acted as a sounding board for their ideas and concerns in the teaching of visual art.

\subsubsection{Summary}

In this chapter I have described the methods I used to carry out this study and in doing so have drawn a parallel between my own practice as an artist and the process of data collection and its analysis. In the following chapters I will present the analysed data as it starts to describe how a group of teachers at a primary school developed their confidence in the teaching of visual art. 


\section{CHAPTER FOUR \\ The Setting}

Within this chapter I set the scene of this research study by describing the site (school) and introducing the principal, staff and volunteer participant teachers.

\subsection{The school}

Having consulted five colleagues in order to select the school (see 3.9.1) I had already started to develop a view of the school. I had made the assumption that the school was committed to the arts because of the recommendation by regional arts advisors and teacher education lecturers who had professional connections with the school. My first observational impressions of the school, as recorded in my field notes $(5 / 7 / 05)$, were that it was large and well presented, with a variety of children's visual art-work displayed both inside the school and on the outside walls. The work appeared to be current, colourful and vibrant and gave me the impression that visual art was valued in the school. At the time of this first visit my initial impression supported the opinions of those I had consulted.

\subsection{The principal}

My initial contact with the principal was by telephone and I arranged to meet him at the school. Before the meeting I sent him an outline of the proposed study (see appendix A). He invited April, the teacher in charge of visual art, to this initial meeting. At the time I felt that this invitation might be evidence he was trying to create an atmosphere of collegiality within the school by involving staff members in new projects. I also felt this invitation to another member of staff could be an indication that he wished to use this staff member's expertise in visual art. According to Speck and Knipe (2005), the principal has an important part to play in developing a culture of collegiality within a school. If the principal's invitation to April was evidence of his developing an atmosphere of collegiality within the school, then I felt at the time he could be an element in enabling the teachers to develop their confidence in the teaching of visual art.

At the time of the meeting I did not know whether April was genuinely interested in the proposed study, or if she felt obliged to attend this after-school meeting the principal had invited her to. She had recently been given the role of teacher in charge of visual art. However, during the meeting she said she saw the study as an 
opportunity to develop the role of visual art in the school. The principal and April both expressed positive views about the proposed project.

I can only see it (the project) as useful. (April)

This is at a time of a Visual Art review within the school. (Principal)

The principal suggested using four teachers to participate in the project, one from each syndicate. Using one teacher from each of the four syndicates would mean the entire age range of the school would be represented. He offered to talk to the syndicates and request volunteers for the project, but I suggested making a presentation to the whole staff outlining the proposal and then asking for volunteers myself. My concern was that I did not want staff to perceive any pressure from the principal to volunteer. In the initial meeting I was aware the principal might inadvertently exert pressure on the staff to volunteer, in his enthusiasm to get the study underway. Griffin (1991) says teachers must have common goals if they are to have an effective collaborative working relationship. Common goals help to develop a school culture which is rewarding for both teachers and children. I felt that a common goal could not develop with the pressure of the principal asking for volunteers as it would be perceived as being the principal's goal. I wanted the teacher volunteer participants to make their own decision after being presented with all the relevant information.

I had made the decision to negotiate entry to the school through the principal knowing that he would be the 'gatekeeper' to the site. Although I wanted to develop a good working relationship with the principal I was equally aware, during this first meeting, that he could potentially exert influence over the staff members who took part in the study. I wanted to observe a group of volunteer participant teachers who agreed to take part without feeling they were obliged to by the principal. This dilemma associated with top-down negotiations highlighted the importance of being conscious of any influence the principal may exert over the participants.

During the first meeting with the principal he made the point that he saw the arts as a way of learning not as a 'decorative add on'. In 2.6 I looked at the work of Eisner (1972) and Gardner (1983) that focused on the role of visual art in enabling children to transfer their ability to critically analyse art-works to other areas of their life. It seems from the principal's comments that he also saw a greater role for visual art. He may have been familiar with Gardner's and Eisner's work, and as a result this influenced his view of visual art and its' role within the school. 
Apart from recently appointing April to be responsible for the visual art programme, he had also just employed a part-time specialist dance and music teacher. For me, these appointments were evidence that the principal was committed to the arts within the school. He may have seen my presence in the school and staff participation in the study as an opportunity for staff professional development, especially as April had been newly appointed to be responsible for the visual arts within the school. I had made it clear that my role was that of observer during our meeting and in the outline of the proposed study (see appendix A). Despite this, he may have seen me in my role as visual art advisor rather than researcher.

\subsection{Stated school policy}

This early evidence that the principal was committed to the development of the arts in his school was supported by the analysis of official school documents. Analysis of the documents revealed a whole school strategy to develop a range of essential skills. In describing how its students would demonstrate these skills the document states that students would, 'exercise imagination, initiative and flexibility' and 'try out innovation and original ideas'. The Arts in the New Zealand Curriculum (Ministry of Education, 2000) states the following '...the arts disciplines offer unique opportunities for imagination and innovation.' The arts, according to the curriculum, provide unique opportunities, which imply they are not provided by any other curriculum area. In fact, according to Davis (2005), the arts are able to provide for teaching and learning and for making and finding meaning in any discipline. In order for the school to achieve its stated goals it would need to promote the arts.

The school had also developed a strategic goal for the arts, and as part of this goal the following statement appeared, 'Assessment data will indicate $80 \%$ of year 4, 6, 8 students will be achieving their chronological age in the Arts strand using assessment tool indicators in 2005.' The strategic goal also states that 'Professional development is provided for staff to maintain their effectiveness in using the arts curriculum'. It seems from the school's strategic goals for the arts that staff should be able to use a range of assessment tools within the arts, and the school should provide staff with professional development to enable them to maintain their effectiveness in teaching the arts. Evidence from the school documents indicated a principal who wanted an environment where teachers are supported in developing their confidence in teaching visual art. 
Analysis of the school documents also revealed that the school encouraged staff to swap classrooms as another way of implementing the school's arts strategic plan. According to the strategic goal, the staff were encouraged to 'swap' classrooms to allow 'strength teaching' enabling the most able teachers of visual art to teach the children progressions of skills. This view of teachers being able to teach a progression of skills in visual art is reminiscent of the view of visual art as a body of knowledge (see 2.5). It was after Cizek had developed his theories about art education that visual art education focused on the structure of visual art and sought ways in which it could be taught. In 1.6 I discussed the link between content and pedagogical knowledge and the research of Andrews (2006). He found teacher confidence in teaching visual art improved when teachers had observed colleagues teaching visual art and engaged in visual art based activities. The school's strategic goal to allow 'strength teaching' could potentially be used to develop teacher confidence in the teaching of visual art if teachers were able to observe 'strength teaching' in visual art.

It was unclear from the school documents what 'strength teaching' in visual art was and how it was identified. I wondered if the most able in teaching visual art meant the most experienced teachers in terms of years in teaching or those teachers with a strong pedagogical and content knowledge of visual art teaching. The document was also unclear as to who within the school would decide a teacher had demonstrated 'strength teaching' within visual art. April was teacher-in-charge of visual art - would she decide on the strength teachers in visual art or was it the principal? Earlier I looked at the view of Griffin (1999) who felt that teachers must have common goals if they are to have an effective collaborative working relationship. Was the policy of 'strength teaching' a common goal? Was the principal's view that visual art was more than a 'decorative add on' a common goal? Analysis of the school document provided a view of the school but the view was unclear.

The school also identified the need to use children to evaluate their own learning and the need to provide appropriate staff training. In describing the school's assessment guidelines the school documentation states, 'Pupils will, as far as is practical, be involved in the evaluation of their own learning'. It also states that, 'Appropriate staff training will be made available where necessary'.

In 2004 the principal developed a goal for the school that he called 'Deeper Learning'. The goal focused on the children learning skills that enabled them, '..to 
start thinking and learning for themselves.' The principal said in an open letter dated February 2004, 'Teachers must 'scaffold' learning by demonstrating, modeling and 'thinking aloud'. By spending time on a task we allow for a positive interactive and diagnostic role for the teacher and in the process empower students to become independent learners'.

In this study the teacher participants would be given the opportunity to develop their understanding of the child's art-work as they analysed the child's view of that work. This would complement the principal's goal of allowing for a positive interactive and diagnostic role for the teacher, and empowering children to become independent learners and may partly explain why the principal was enthusiastic about allowing me to conduct this study in his school. If some of his staff were involved in the project they may develop their understanding in the way children viewed their artwork and therefore help in supporting his 'Deeper Learning' strategy.

Analysis of school documents revealed that the school expected children to develop imagination, initiative and flexibility and try out innovative and original ideas. These skills are woven into the arts curriculum and the promotion of visual art within the school would certainly help the school realise these expectations. The school's strategic goals for the arts within the school also stated that professional development should be provided for staff in order to maintain their effectiveness in using the arts curriculum. The school policy of using 'strength teachers' to teach visual art could in part relate to the school's policy of providing professional development in maintaining teacher effectiveness in using the arts curriculum. I felt that this policy could in fact perpetuate a situation where those who were not confident in teaching visual art would relinquish their responsibility to perceived visual art experts. Confidence could only be developed within this strategy of 'strength teaching' if those identified as 'strength teachers' within visual art were able to work with those who lacked confidence in teaching visual art.

Analysis of the school documents revealed a number questions - who and how was a strength teacher in visual art identified and were the goals expressed by the document search common goals or the principal's goals? I did feel, however, that the analysis of the school documents helped to explain the principal's view that the arts are a way of learning, his support for both the teaching of the arts and his support for this project. In 2.6 I discussed the changing view of art educationalists in the late 1970's and 1980's as they move from the view that visual art was a body of knowledge to one where visual art can be used to develop children's ability to 
critically analyse.The unique nature of learning through the arts is emphasised by the work done by Eisner in the 1980s. He viewed formal education as quite limiting as it was constrained by verbal and numerical forms of representation. Eisner (1982) argued for a balanced curriculum that allowed children to develop through visual, auditory and tactile sources as well as numerical and verbal forms of representation. Echoes of Eisner's call for a balanced curriculum using the unique qualities of the arts were evident in the official school documents. The important role arts education plays in children's creative development has been explored by many academics and they all make the point that the arts play a key role in enabling children to understand and make meaning of the world around them (Bloomfield, 2000; Callaway \& Kear, 2000; Efland, 2002; Eisner, 1998; Feldman, 1996; Fiske, 1999; Goldberg, 2006). Research in New Zealand suggests that visual art teaching provides students with stimulating learning experiences that in turn create high levels of success and engagement (Holland \& O'Connor, 2004). It seems from the evidence of the school documents that the principal also recognises the important role visual art has to play in the development of children.

\subsection{Initial evidence of a collaborative teaching community}

In Chapter 1 I suggested that developing a collaborative teaching community within a school could be a vehicle for supporting the development of teacher confidence in the teaching of visual art. In $1.10 \mathrm{I}$ referred to the findings of Retalick and Butt (2004) who identified collegial support, recognition and trust, mutual caring and social cohesiveness as the essential elements in a school setting if a collaborative teaching community was to exist. I also discussed the view of Lieberman (1996) who felt that for lasting and significant change in teacher learning to take place schools should view learning and professional development as an integral part of school life. Lieberman went on to describe schools that had successfully encouraged teacher development as ones that:

- $\quad$ put new and experienced teachers together to learn from each other

- created common planning sessions so that connections could be made across subject areas

- used staff expertise to provide leadership for in-house workshops.

The evidence from the first meeting with the principal and the analysis of the official school documents seemed to be indicating someone who was committed to providing quality teaching within the arts and wanting the arts as an integrated 
strand throughout the whole school. The principal had invited April to the first meeting and analysis of the school documents had revealed a system where the principal wanted to use staff expertise in the classroom and in the development of the arts. This first glimpse of the site through the lenses of my journal notes and analysis of the document search pointed towards an environment where the teachers could develop a collaborative teaching community to support the development of their confidence in the teaching of visual art. Analysis of the official school documents did not make it clear if staff worked towards common goals or if the school goals in the teaching of visual art were solely the goals of the principal. If the data collected from one meeting with the principal and April and the document search provided a glimpse of the site, meeting the teaching staff would allow me to gain a more rounded view of the school.

\subsection{Teaching staff profile}

My first meeting with all the teaching staff was at a whole staff meeting where I planned to outline the proposed study. Data collected from both my observations and the results of a questionnaire (see appendix $\mathrm{D}$ ) enabled me to develop an initial profile of the teaching staff at the school.

The staff meeting was informal and friendly and I was made to feel welcome by the principal and other members of staff. The meeting was structured around a series of agenda items with various members of staff contributing to the meeting. The principal did not dominate the meeting, and he and other senior management members sat within the body of the staff, which appeared to me to create an informal atmosphere. I felt this informality and sense of collegiality could be evidence that the staff worked collaboratively.

Of the 18 teachers present at the meeting, 16 returned completed questionnaires. Analysis of the questionnaires revealed that the staff were spread across the syndicates as follows:

- Junior syndicate (Year 0-2) four teachers

- Middle syndicate (Year 3-4) five teachers

- Middle syndicate (Year 5-6) four teachers

- Senior syndicate (Year 7-8) three teachers.

Of the teachers who completed the questionnaire, $18.75 \%$ (three) had been teaching between one and six years; more than $56.25 \%$ (nine) had been teaching 
between six to 11 years, and $25 \%$ (four) had been teaching for more than 11 years (see Figure 7).

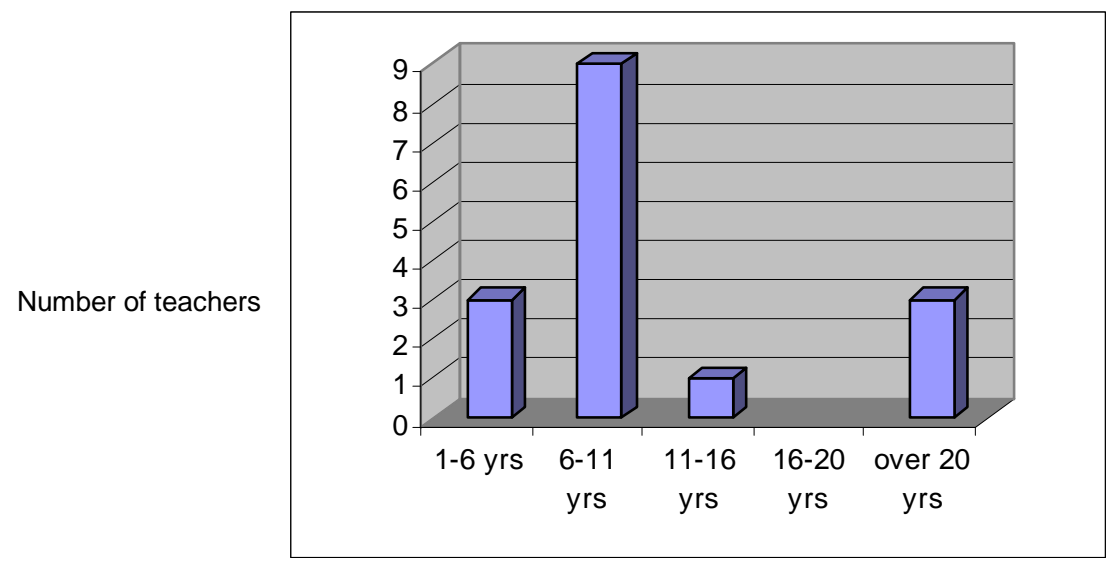

Figure 8: Number of years teaching

These figures indicated that staff at the school were experienced teachers and would have a combined pool of expertise and knowledge.

Only eight teachers had attended any professional development related to the new arts curriculum. Of these, seven had received an average of five hours of professional development; one staff member had received 24 hours. Two members of staff had received professional development in assessment related to visual arts. When asked how confident they were in assessing visual art-work, 75\% (12) of the staff had no, or only some, confidence in this area. Only one member of staff said they were very confident in assessing children's visual art-work.

When the analysis of the questionnaire is compared to the analysis of the document search it highlights a contradiction between the school's expectation of the way staff use assessment in visual art and teachers' self-reported level of confidence in the use of assessment in visual art. The school's expectation was for $80 \%$ of year 4,6 and 8 students to be achieving their chronological age. The school documents also revealed that assessment was to be used to measure student achievement. The schools strategic goals were that staff should be able to range of assessment tools within the arts. Allied with this expectation within the school's strategic goals was the expectation that students be involved in the evaluation of their own learning. The school documentation states, 'Pupils will, as far as is practical, be involved in the evaluation of their own learning', and, 'Appropriate staff training will be made available where necessary'. Therefore the school has identified the need for children to evaluate their own learning, and the need to provide appropriate training to staff. The questionnaire revealed the majority of staff (62.5\%) assessed children's visual art-work themselves against set criteria. Therefore, there seems to be a discrepancy 
between the school's expectation of assessment in visual art and the assessment practices of the staff.

Analysis of the school documents revealed that the school should provide staff professional development to maintain their effectiveness in using the arts curriculum. Although the school documents indicate the intention of the school was to provide teachers with professional development in using the arts curriculum, analysis of the questionnaire indicated that only $50 \%$ of the teaching staff had attended any professional development in that area. Seven of the eight teachers who had attended any professional development had spent an average of five hours in this area. Again, there appeared to be a gap between the expectations of the strategic goal of the school and the experience of the staff.

Although the results show that the school has a range of experienced staff, the amount of professional development in the area of visual art and confidence in the assessment of visual art is low. These results, taken in conjunction with the results of the stock-take report (McGee et al., 2003) where $20 \%$ of respondents in a national sampling study felt that they needed more professional development in the arts, point to a need for greater professional development in the teaching and assessment of visual art.

The contradiction in the data led me to believe that this project could provide the participants with the opportunity to involve children in the evaluation of their own learning. The school's strategic goals for the arts within the school stated that professional development should be provided to staff to maintain their effectiveness in using the arts curriculum. Even though the school's strategic goal identified use of assessment in the arts to monitor children's achievement, the staff questionnaire revealed a lack of confidence in this area. Encouraging staff to share their strengths in the teaching of visual art was identified as a way of implementing the school's arts strategic plan. This study could give the volunteer participant teachers an opportunity to share strengths in the teaching of visual art and perhaps develop their confidence in the teaching of visual art having analysed the children's views.

\subsection{Meeting the volunteer participant teachers}

Having been presented with the information about the study (see appendix E), staff were given a week to decide if they wanted to volunteer to take part in it. They were given the opportunity to phone or email me if they wanted any further information 
about the study. I wanted any potential volunteers to make their decision without the pressure of a staff meeting especially as the principal was present at that meeting.

Two teachers contacted me and asked about the level of time commitment to the project. I explained I would be responsible for collecting the data and that the teacher volunteer participant teachers would be asked to analyse the transcripts of interviews with 10 children from their own class and to attend meetings to discuss their findings from the analysed transcripts. I explained I had set aside a block of time when I would be available in the school to support them, and that most of the project work would be done as part of their normal teaching day.

Listening to the concerns expressed by potential participants I felt those pertaining to extra workload were a possible barrier to the study. If this was a common concern then one of my roles would be to be aware of it. I felt that one way of alleviating these concerns would be to ensure I did not get in the way of their everyday routines and carry as much of the workload as possible myself.

The teachers' concerns about time commitment raised the question of time allowed for teachers to reflect on their work and develop their own classroom practice. As mentioned earlier, Loewenberg Ball and Cohen (1999) believe that if teachers are given the opportunity to inquire into their own practice, this can lead to a better understanding of that practice. However, to achieve this better understanding, it seems that time needs to be set aside. This was also a concern to me as I was expecting the volunteer participant teachers to spend time analysing both children's art-work and the children's view of the same work. If time was a real concern for the volunteer participant teachers then it would become a barrier to the study.

Four of the 18 teachers completed the return slips expressing an interest in volunteering for the project. Their names were Jo, Carol, Rebecca and Catherine (pseudonyms) and they taught classes from years 2, 3, 5 and 7, thus spanning a broad range of ages in the school.

April, who was responsible for visual art, also contacted me. She explained she would like to be involved in the project but was uncertain if her involvement could put off the other volunteers. Her reasoning was that she was responsible for visual art within the school and that the other teachers may feel threatened. 
I told April I felt she would be an ideal person to take part, because she could share her expertise with the other volunteers. April decided to take part; therefore the study comprised five volunteer participant teachers. I believed the study would give April the opportunity to develop the role of teacher responsible for visual art, which she had recently been appointed to. As she was new to the school I thought the study would give her the opportunity to develop her relationship with the other volunteer participant teachers.

\section{7 $\quad$ First impressions}

Discussions with colleagues, meeting the principal and April, conducting a document search, attending a staff meeting and meeting the volunteer participant teachers gave me a range of distinct views of the school. My initial observations of the site had shown a large primary school in a middle class suburb of Wellington that openly celebrated children's visual art-work. Through conversations with the principal I had learnt that he saw visual art as playing a key role in teaching and learning in the school. Observations at the staff meeting had revealed a friendly staff able to discuss and share ideas in an open forum. However, analysis of the questionnaire, allied with the document search, revealed a gap between the expectations of the school and the confidence of the staff in assessing visual art.

My first meeting with the participants had informed me that although they were enthusiastic about being a part of this study, they were also concerned about an increase in their workload. The concern the participants had expressed about their increased workload not only made me realise that I needed to support the participants throughout the study, but also that there may be other factors influencing the teachers that I had not originally considered. Oja and Smulyan (1989) talk about the climate of the school affecting the teachers' willingness to be involved in action research projects. They suggest teachers are more receptive to action research projects if there is frequent communication among staff and management and if teachers are involved in decision-making and policy-making. Perhaps the climate I had observed during my initial entry into the site, where communication between staff and management was encouraged, was incorrect. If the volunteer participant teachers were actively involved in the study and were working towards a common goal, this may in part alleviate their concerns about workload. Their commitment to the study would be a product of their own concerns and therefore the benefits of the work they were doing would be clear. Perhaps time and workload is an issue with teachers when they are expected to implement the 
ideas and plans of others and the benefits are not apparent. At the conclusion of this meeting the five volunteer participant teachers signed informed consent forms (see appendix F).

\subsection{Principal enables teachers to develop confidence in the teaching of visual art}

Within this study's findings analysis of all the data collected revealed a complex system in which teachers were able to develop their confidence in the teaching of visual art. The system involved the use of teacher expertise within the school and the expertise of others outside the school environment to develop teacher confidence in the teaching of visual art. The physical nature of the school and the relationship between staff members was shown to be a catalyst in enabling this system to function (see Chapter Five).

I broadly categorised the environments in which the teachers developed their confidence in the teaching of visual art, as informal and formal. At times it appeared that these two environments were able to exist due to the influence of the principal. Teachers within the school talked about the principal wanting to change the use of the staff meeting to one where ideas were shared (see 5.4). They also talked about being supported by the principal in their endeavours to develop their confidence in the teaching of visual art (5.5). I felt one reason the principal had invited me into the school was to enable teachers in his school to develop their confidence in the teaching of visual art. If the principal was a factor in the way the teachers in the school developed their confidence in the teaching of visual art, then what was his motivation in developing that influence?

I had taped a conversation with the principal to discover how he perceived his role within the school. Analysing the transcript revealed the following themes:

- Challenges of being a principal

- Setting up an appraisal system

- His expectations of his teaching staff

- Appointing new teaching staff

- His view of visual art within the school. 


\title{
4.9 Challenges of being a principal
}

The principal talked about the constant changes in education, and the expectations from the Ministry of Education, the Board of Trustees and the local community.

\begin{abstract}
Education's always in a state of flux and in a school there just seems to be this constant changing of the way that you do things ... the parents are very selective of who they want their child to be taught by ... I found that quite dispiriting, you know, but you could also get one person saying, I don't want my kid in this class and you'd have another person saying, I want my kid in this class. The expectations of the school are incredibly high. They want the best for their kids... but they're very supportive of the school within that. They will talk to us if there's anything that they think is wrong. ... a lot of this literature that's coming to principals is about - you know, from the ministry is student check this, student - it's just student achievement... (Principal)
\end{abstract}

He sees the expectations of the Ministry of Education, the Board of Trustees and parents of children in the school as placing pressure on him. I asked him if he thought pressure from the community also affected staff.

I don't believe so if my kids are being the best that they can be, or we want our children to be achieving their full potential, it's not for the community to tell me that. (Principal)

The principal sees part of his role as absorbing pressure placed on him and keeping this pressure away from teaching staff. Interestingly, when talking to the volunteer participant teachers they said the following about pressure from the community.

And we are reminded of expectations of the community a lot. (Volunteer teacher participant)

It filters down. (Volunteer teacher participant)

It seems pressure from the community does reach staff. I would assume parent expectations would be known to teaching staff as it is common for parents to talk to teachers, often at the end of a school day. The volunteer participant teachers also made the point that community expectations are fed through to staff by senior management. This difference between the perception of the principal and that of the staff may create tension between the two. If tension exists between management and the teaching staff, then my original view of the school as one where the principal encouraged staff to share ideas and take on responsibility may be wrong. A comparison of the principal's comments and the teachers' comments seems to point to a tension between the principal and his staff that I had not observed initially. If the principal felt he was acting as a buffer between outside expectations and teaching staff, how did he translate the expectations placed on him into his own expectations of his teaching staff? 


\subsection{Principal's expectations of staff}

The principal translated his expectations of the teaching staff into the setting up of a staff appraisal system. The appraisal system was linked to a series of goals, developed through consultation with staff and the Board of Trustees. Analysis of earlier conversations with volunteer teacher participants did not make it clear if the staff and principal worked towards common goals. The evidence of this conversation with the principal would indicate they developed common goals through the school appraisal system. The principal talked about the teaching staff working together to develop the goals that formed the core of the appraisal system.

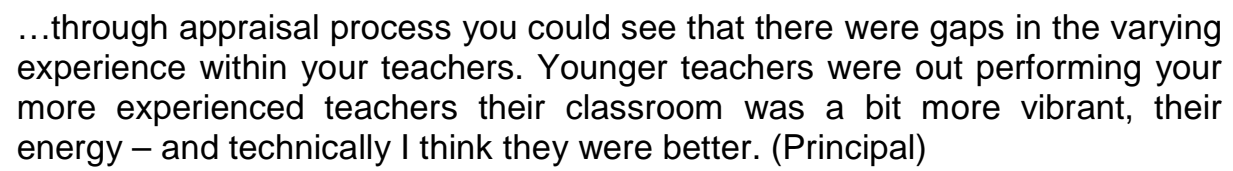

The principal makes the point that he often feels that his younger teachers are better teachers than his more experienced teachers. Analysis of the staff questionnaire showed that of the 16 teachers who completed it, 12 had been teaching from one to 11 years and only four had been teaching for more than 11 years. It would seem the majority of teaching staff at the school are in the early part of their career. When I talked to the principal about appointing new teachers, he said there was only one member of staff at the school who he had not appointed. When April talked about developing enthusiasm for visual art in the school she pointed to the enthusiasm of new members of staff (see 5.6). The principal had been responsible for appointing those staff members, and it seems that April was able to use their enthusiasm to develop visual art within the school.

As the principal had been at the school for five years and in that time had appointed every member of staff except for one, I asked him what he looked for in a new member of staff.

\footnotetext{
A sense of confidence, and also an easiness in disposition. I think l've got an amazing staff and I think they've got...they're quite similar in a way - they're receptive to new ideas. (Principal)
}

During the study I observed the volunteer participant teachers working well together as they developed confidence in the teaching of visual art. The volunteer participant teachers seemed to have the traits the principal looked for in his staff and this could be the reason they worked so well together. As the principal was the one who appointed them, and looked for those qualities, it implies the principal is a factor in the way the staff develop their confidence in the teaching of visual art. He has 
looked for a particular type of teacher and as a consequence they are able to work well together.

The principal likened the appraisal system to a professional development model that uses mentors from outside the school and expert leadership from within the school. It is possible the principal saw me in the role of outside mentor, and seems to explain his intentions when he appointed April to the role of visual art expert within the school. Whilst describing the traits he looks for in teachers the principal said:

...somebody with the leadership or the energy to come through. (Principal)

In my view he describes the personality traits of April. He seems to have identified the qualities of leadership and energy of April and then given her the responsibility of developing the teaching of visual art in the school. This would confirm the way teachers develop their confidence in the teaching of visual art in the school is directly related to the principal in the school. He has actively sought a particular person within the school and then given that person the responsibility to develop visual art.

\subsection{Principal's expectations create tension}

The principal talked about his role:

I see my role as leader as setting the framework for them to achieve their potential ... I focus more on my staff than the children, my staff are the biggest resource ... the results of a poor teacher or a teacher teaching poorly are hideous for a group of kids. So they all need to be performing well and they all need to be feeling that they are performing well. I would say that I do set a framework and I do have high expectations and I do set expectations. I am not in their face, and I'm not authoritive. I think I have a strong understanding of how the school is going, is operating, and that causes a lot of stress because, you know, you can see ways which things might be done better, and to achieve that involves a lot of thinking and a lot of planning and it's not a case of calling a staff member and saying, this is what I think. (Principal)

There is a contradiction between him not wanting to be authoritative and telling someone what he thinks should be done. A tension exists between the principal trying to allow the staff to develop and be themselves, and wanting them to move in the direction he sees the school travelling.

When I talked to the volunteer participant teachers they talked about the pressure they felt was exerted on them: 
...there is subtle pressure ... you're letting the side down, you're letting your team down, and some teams are held up as glowing examples of what should happen and other teams are busting their gut to try and be over-achievers. (Participant)

My conversation with the volunteer participant teachers about the pressure they felt they were under was at a time when the school was undergoing major re-building work. The school was in physical turmoil and it was clear that teaching staff were under some strain as a result of the disruption. Some classrooms and the staffroom were out of action and I felt the lack of the staffroom may have isolated some staff, thereby adding to the existing pressure of the volunteer participant teachers.

The principal was appointed by the Board of Trustees to develop the school in a particular way. Pressure on the principal from the board, the community and the Ministry of Education is being translated into a situation where the principal wants his staff to take on responsibility and develop but at times finds it difficult to step back.

I asked the principal if he found it easy to delegate responsibility:

One of the tensions is that you get from everybody is how busy they are so therefore in theory if everyone's full and busy and can't do anything else, how can I delegate something else on to them? You feel incredibly guilty and then people say to you when you're stressed and overloaded, why didn't you...you know? I don't believe schools are set up, management-wise, a school this size, appropriately for the devolution of power to be done in an adequate way. (Principal)

The principal feels schools are not given enough time to enable him to delegate extra work without adding to their workload. The majority of his staff are full-time classroom teachers, and tell him they are already busy. This situation seems to add to his pressure and may account for the contradiction of wanting to allow teachers space to develop, but also telling them what to do. This may also be related to the types of responsibility he is offering the staff. As mentioned earlier (4.7) staff could express their concerns about workload when they have no direct input into the work they are asked to do or if they can see no direct benefits to themselves. If the principal was asking them to implement his own ideas with no input from staff then their reaction could be that they are too busy to take on the extra work. This again raises the question of developing common goals amongst staff. The principal had talked about creating common goals through the appraisal system and yet is concerned about the reluctance of staff to take on extra responsibility; perhaps this reluctance would be less if the principals and teachers' goals were common. 
In 4.4 I referred to Retalick and Butt (2004) who identified collegial support, recognition and trust, mutual caring and social cohesiveness as essential elements in sustaining a collaborative teaching community. It was Lieberman (1996) who made the point that lasting and significant change takes place in a school if learning and professional development are seen as an integral part of school life. Perhaps these areas identified by Lieberman and Retalick and Butt are dependent upon the amount of freedom teachers are given to develop their own practice rather than working on the ideas of others with no input of their own.

It seems the principal has high expectations of his staff, and these expectations are translating into stress for both the principal and the staff. High expectations can be highly motivating, but it would seem that when there is disruption to the norm, in this case the lack of a staffroom, motivation can be turned into stress and frustration for all parties.

\section{12 Frustrations felt during disruptions to routines}

When the volunteer participant teachers expressed their frustrations and seemed to be under pressure I felt this may be in part a result of disruptions caused by building works. I asked the principal if he felt that the building work had had an impact upon the staff.

I think it has. I think there's a high level of frustration... So it's a high level of frustration for me, frustration for them, I think. (Principal)

The principal recognises the fact that staff are frustrated by disruption to their routine. The principal's expectations of the staff had not changed during the time I was conducting the study, and yet the volunteer participant teachers expressed their frustrations at a time when there was a disruption to their routine. Perhaps when disruption is outside of a person's control, frustration is expressed by focussing on something that is more immediate and perhaps within a person's control, in this case the principal's expectations of the staff.

In the findings analysis of the initial semi-structured interviews with the participants revealed that the staffroom was an important element for staff being able to work together (5.4). Both the principal and April had talked about using the staffroom to help them develop an atmosphere of collegiality. Analysis of the volunteer participant teachers' semi-structured interviews had revealed the staffroom had become an important part of the school in allowing teachers to informally share ideas. Building work at the school meant the staffroom could not be used; perhaps 
its absence had lessened the collegial atmosphere in the school. Physically the school had become fragmented and members of staff were remaining in their rooms during morning tea and lunchtime. The lack of informal contact with one another might also have contributed to the staff's frustration.

\title{
4. 13 Principal's view of visual art in the school
}

The principal talked about the role of visual art within the school:

\begin{abstract}
Visual art is very important to the school. It's important in it's one of those things which presents student achievement to the wider community. Quality art - like you walk into a school and the first thing that hits you is the art-work. Wow, look at that, gosh a six year old painted that! That's magnificent! ... it's one of the true opportunities to be creative, to be individualistic, it's a wonderful skill, there's the planning process, there's the ability to communicate with others, there's just so many good things that coming out that come out of an experience with visual art... (Principal)
\end{abstract}

When talking about the role of visual art within the school the principal focuses on two areas. Firstly, he talks about the role visual art plays in presenting student work to the wider community. This may be associated with pressure he feels from the community. If the school looks good on first impressions, then the assumption is that things are going well at the school. In fact, I based my initial impressions of the school on seeing the art displayed around the building. When talking about my first impressions of the school (see p. 36), I referred to my field notes which recorded that the school had a variety of art displayed inside the school and on the outside walls. I made the assumption that as the art-work was current and varied, visual art was valued in the school.

Secondly, the principal talks about the role visual art plays in developing children's creativity. When analysing the document search I talked about the principal's 'Deeper Learning' strategy. In analysing this strategy I referred back to 2.6 and made reference to Eisner (1982) and his view that children needed to develop through visual, auditory and tactile sources, as well as numerical and verbal forms of representation. I also looked at literature that talked about the important role the arts play in enabling children to understand and make sense of the world around them (Bloomfield, 2000; Callaway \& Kear, 2000; Efland, 2002; Eisner, 1998; Feldman, 1996; Fiske, 1999; Goldberg, 2006). It seems the principal may have been influenced by the art education theories developed in the late 1970s and gradually expanded upon over the years. Clearly he recognises the important role visual art plays in developing creativity in children and that recognition has resulted in his actively supporting the development of visual art teaching in the school. 
The evidence of this conversation with the principal helps to confirm he has influenced the way the volunteer participant teachers have developed their confidence in the teaching of visual art. He has:

- encouraged professional development in visual art (see Chapter Five)

- brought in expertise from outside (see Chapter Five)

- appointed April to develop visual art within the school

- linked creativity and visual art in whole-school goals.

The way the principal has encouraged the development of visual art may also be connected to his attributes as a principal. Blase and Anderson (1995) described factors exhibited by an 'open principal', after collecting data from 770 teachers asking them to describe the attributes of open and effective principals. The teachers identified the following seven attributes:

- honesty

- high expectations

- communicativeness

- encouraging staff participation

- collegiality

- informality

- support to staff.

The principal's invitation to April to join my initial meeting with him (p. 36), the informality of the staff meeting (see 4.5), his encouragement of staff participation (see 5.4), his high expectations (see 4.11) and his willingness to support staff (see 5.5) all point to having the attributes of an 'open principal'. If possessing the attributes of an 'open principal' are combined with recognising the importance of visual art within the school, then the principal would be a factor in the way the volunteer participant teachers develop confidence in the teaching of visual art.

The developing montage composition of the setting for this study reveals a number of related elements. Observation of the staff meeting revealed the staff sharing and discussing ideas within the confines of the staffroom and analysis of semi-structured interviews pointed towards a principal who encouraged staff to use the forum of staff meetings to share ideas. A contradiction emerged between the stated expectations of the school and staff self-reported confidence in their ability to assess children's visual art work. The volunteer participant teachers expressed concern about their workload and the pressure of high expectations. At this stage in the analysis it is 
unclear if staff are able to share and discuss ideas outside of the confines of a staff meeting. It is also unclear if all the goals expressed by the principal and school documents are common. Although the volunteer participant teachers expressed their concern about an increase in their workload by taking part in the study, they did express enthusiasm for it. In terms of a developing montage the emerging elements in the composition provide only a scant view of the setting with a number of gaps in the overall picture. 


\section{CHAPTER FIVE \\ Confidence in teaching visual art}

In section 1.6 I discussed the findings of Loewenberg Ball and Cohen (1999), who felt that teachers need to understand the subject matter they teach in ways that enable them to develop meanings and make connections within the context of that curriculum area. Ball et al.'s (2005) felt that teachers lacked confidence when they have insufficient depth in content knowledge. Both these views are strengthened by the findings of Andrews (2006). He concluded that teachers developed their confidence in the teaching of visual art when they engaged in visual art activities with expert practitioners, and observed colleagues teaching visual art. During this study the volunteer participant teachers and a provisionally registered teacher (PRT: Mary) talked about their level of confidence in teaching visual art, the use of the Arts curriculum and their level of confidence in assessing children's visual art-work. I analysed the transcripts of these conversations looking for evidence of how they viewed their level of confidence in the teaching of visual art and ways in which this confidence had or had not been developed.

\subsection{Confidence in teaching visual art linked to experience in using visual art materials}

The five volunteer participant teachers and Mary all linked their level of confidence in teaching visual art to their experience in using visual art materials. Catherine talked about her past experiences in visual art adult evening classes and linked this to her confidence in teaching visual art:

I've done art lessons as an adult.....I've done watercolour and I've done mixed media and we've used gauche as well, and l've also done acrylics. I haven't done oil painting, but I've worked in acrylics and with charcoal and sketching and that sort of thing. (Catherine)

My observations of Catherine teaching visual art support her view of herself as confident using a range of visual art materials and processes. She would demonstrate various techniques to the children who would then explore those techniques in their work. This is how she described her style of teaching:

I model for them what they have to do or what the skill is, they go away and have a practice of it. We have lots of practices before they might actually produce a piece of art so I'm going through the art process. (Catherine) 
However, Mary links her lack of confidence in teaching visual art to her lack of experience in the use of visual art materials and processes:

Visual art was an area that I wasn't having a lot of success in. I felt that the, you know just, I love art history myself and I could get the kids all inspired discussing Picasso and Matisse and all sorts of things like that but when it came to actually getting something on the page it was always disappointing and probably because it was not an area I feel at all confident in. (Mary)

Jo also linked her lack of confidence in teaching visual art to her lack of experience in using visual art materials. Of the six teachers, Carol, Rebecca, Catherine and April talked about being confident in teaching visual art because of their experience in handling visual art materials, and Jo and Mary talked about their lack of confidence in teaching visual art, linking it to their lack of experience in the use of visual art materials.

If their confidence in teaching visual art is linked to their experience in using visual art materials and processes, the question arises where did they gain this experience?

As mentioned earlier, Catherine talked about adult evening classes that were not part of a teacher professional development programme. Rebecca talked about a range of teacher professional development programmes linked to visual art:

I did a course last year on Pacific Art which was a day, just a whole day. I've done one on clay, we're doing clay this term. Again it was about two years ago. I like doing art myself so I probably do it more than somebody who didn't like to do it. (Rebecca)

As well as these courses Rebecca also talks about being interested in 'doing art' herself. Not only has her experience in the use of visual art materials and processes been developed through teacher professional development but she is also motivated to develop these experiences because of her personal involvement with visual art. This would also apply to Catherine who talked about her interest in visual art and developing that interest through attending adult visual art classes.

My initial observations of the volunteer participant teachers and their own perceptions of their confidence in the teaching of visual art being linked to their experience in the use of art materials and processes would support the conclusions of Andrews (2006). Andrews concluded that confidence in teaching visual art is from a confidence developed in the use of visual art practice. When they talked about courses from which they gained this expertise, only two of the courses mentioned were linked to 
professional development organised by School Support Services ${ }^{3}$. All the courses they mentioned focussed on developing skills and expertise in the use of visual art materials. Mary talked about a PRT visual art course she attended in her first year of teaching:

I went to an art-workshop in my first year of teaching and all they did was talk about the curriculum and we did a little bit of practical art and I don't remember ever using it. I can't even really remember what it was. I remember walking away insanely frustrated because I had nothing I could actually use with my class. So, I know there's lots of theory and all that but actually the bottom line is you want something you can do with your class. (Mary)

It seems that for a teacher in Mary's position, who is just starting her career and has little confidence in using visual art materials, professional development in the use of those materials would enable them to develop their confidence in teaching visual art in the classroom. Mary's comments support the findings of Andrews (2006) who made the point that beginning teachers increased their confidence in teaching visual art after they had been engaged in visual art activities.

All the volunteer participant teachers and Mary make the link between their own confidence in teaching visual art and their experiences in the use of visual art materials and processes. This implies that the experience in the use of visual art materials and processes not only creates a degree of confidence in their uses but also a level of confidence in teaching visual art. This view is supported by the following literature: Loewenberg Ball and Cohen (1999); Ball et al. (2005); Andrews (2006), who all make the link between a level of confidence in the use of visual art processes and confidence in teaching visual art. The volunteer participant teachers and Mary all show a degree of enthusiasm in wanting to develop their confidence in teaching visual art. They have actively sought out ways to develop their confidence; in fact Rebecca said:

I like doing art myself so I probably do it more than somebody who didn't like to do it.

This comment implies Rebecca is more likely to develop her confidence in the use of visual art materials and processes because she gets enjoyment from being involved in visual art herself. Mary made the point that she had always liked art history but was frustrated by her lack of confidence in the use of visual art materials and processes. Perhaps her enjoyment of art history was a motivation for her to develop her confidence in the teaching of visual art. This evidence therefore may also suggest that in order for teachers to develop their confidence in teaching visual

3 School Support Services organized courses linked to the introduction of the Arts Curriculum. 
art they must first have a degree of enthusiasm for visual art. This would then imply that in order to develop a teacher's confidence in teaching visual art the starting point would be to create a degree of enthusiasm for the curriculum area. For teachers such as Catherine and Rebecca who are already enthusiastic about visual art, developing their confidence in the teaching of visual art would be linked to their enthusiasm for the curriculum area. It would be more difficult to develop a teacher's confidence if the teacher had a negative view of the curriculum area.

The reasons teachers have a negative view of the curriculum area could be related to their own experience of visual art. As mentioned earlier (see 2.7), a person's view of visual art education is often a reflection of their own experience of visual art, both in an educational setting and in their own life. If a teacher does have a negative view of visual art and developing confidence in teaching visual art is linked to gaining experience in the use of materials and processes, then one of the keys to overcoming the negative view could be to focus on the benefits of visual art to students. Focussing on the benefits of visual art to students could then be translated into a positive view of visual art.

\subsection{Gaining experience in visual art in formal settings outside the school environment}

Mary, Catherine, Rebecca and April all talked about gaining experience in the use of visual art materials outside the school environment in a formal setting using visual art experts. Catherine had been to a range of workshops run by a local artist who offered workshops to primary school teachers. Her experience in these workshops had helped develop her confidence in the teaching of visual art. Mary talked to Catherine about her lack of confidence in teaching visual art:

I confessed to a couple of my colleagues that I was really feeling that practical art, visual art, was an area that I wasn't having a lot of success in. (Mary)

As a result of this conversation Catherine recommended to Mary the workshops run by the artist that she had attended. Mary said:

So I went too, I think it was a one day course at (name of centre) and it was the first time I had been to anything with (visual art expert) and yeah it was fantastic. (Mary)

The change in Mary's confidence following the course was almost instant:

I taught the kids straight away. I was really inspired and I had samples. The first thing I did the very next day, I told the kids they always know when I'm going on 
courses and I showed them what l'd done and they loved it and they were really excited and I was excited and pleased with what l'd done and produced, and the kids were excited so I kind of got them just motivated from looking at the samples and then the following, that Friday I took one of the lessons that she had taught us. Yeah, and did that with my class. With great success. (Mary)

The workshop taken by a visual art practitioner outside the school in a formal setting had provided Mary with the opportunity to develop her confidence in the teaching of visual art. Mary may never have known about the opportunity to develop her confidence on this particular course had it not been for the informal conversation she had had with Catherine. Mary's comments about her conversation with Catherine could indicate a network of support within the school which is informal and may be a component in enabling teachers to develop their confidence in teaching visual art. All of the volunteer participant teachers talked about the informal networks they had used to develop their confidence in teaching visual art.

\subsection{Informal support network within the school}

Like Mary, Carol and Jo also talked about approaching other members of staff to help them develop their confidence in teaching visual art:

I've gone through it [Arts Curriculum] all myself and sorted it out and went through it with an experienced teacher. (Carol)

And if I get really stuck I know I can just run and ask them for help, and they come straightaway. (Jo)

Although Mary, Jo and Carol describe a support network within the school there is a difference between these networks. When Carol talks about going to an 'experienced teacher' she was talking about someone outside her syndicate, namely Rebecca and Catherine. Catherine and Rebecca were involved in professional development associated with the launch of the Arts curriculum. Carol was now using the expertise Catherine and Rebecca had gained during that professional development. When Jo talked about 'run and ask them for help' she was talking about other members within her syndicate. Mary's conversation with Catherine was within her teaching syndicate. Mary also talked about seeking support from Rebecca who was outside her syndicate:

Rebecca here was wonderful. She actually sat down with me one day and showed me a technique, showed me Scraffito and we actually did it together and that was excellent and I was able to use it so that was really good. (Mary)

Mary, Jo and Carol have developed their own networks within the school to develop their confidence in the teaching of visual art. Thorpe (2007) makes the point that it is important for teachers to not only listen to the ideas of the learner but also to seek 
advice from colleagues who may offer alternative suggestions, or support. The evidence suggests the volunteer participant teachers do look for advice from colleagues.

Mary, Jo and Carol's responses could indicate that a collaborative atmosphere existed in the school, where teachers were able to ask one another for support. Speck and Knipe (2005) describe the culture of a school organisation as collaborative when each teacher within the school has a built-in network of support. Mary was able to talk to Catherine about her lack of confidence in teaching visual art and approach Rebecca for practical help. Jo described how she was able to ask her colleagues for help when teaching visual art and that she found their response to be immediate. Mary, Jo and Carol's comments illustrate Speck and Knipe's (2005) view of a learning community where teachers have developed their own support network within the school organisation.

The syndicate member who Jo referred to when she said, 'run and ask them for help', is April. Jo sees April as an 'expert' in visual art, and as such looks to her for support. April was initially unsure about taking part in the study because she was concerned how the other participants might perceive her. In my initial meeting with the principal and April I felt they may view the study as an opportunity for professional development. It may be that the dynamic of April being perceived as an expert makes it difficult for her to seek support within the school in the area of teaching visual art and sees this opportunity to take part in the study to gain support. It would also seem both Mary and Carol view Catherine and Rebecca as experts, as they use them to support their developing confidence in the teaching of visual art.

The participants talked about a range of support networks both inside and outside school. Carol and Mary seek support from Rebecca and then use this developed understanding in both teaching visual art and planning visual art programmes. As well as visual art courses outside of the school, Catherine and Rebecca were supported by the Ministry of Education professional development programme following the introduction of The Arts in the New Zealand curriculum in 2000. They use this developed understanding to plan visual art units of work for their respective syndicates. Jo seeks support from April who plans visual art units for her syndicate. April talked about looking outside of the school environment for support. If April does seek support from outside of school, she may see me as a way of developing her confidence in the teaching of visual art. 
Figure 9 illustrates the variety of support networks described by Carol, Rebecca, Mary, Catherine, Jo and April. If all the teachers within the school mirrored the support networks described in Figure 9, then the relationships between the teaching staff within the school would be interdependent.

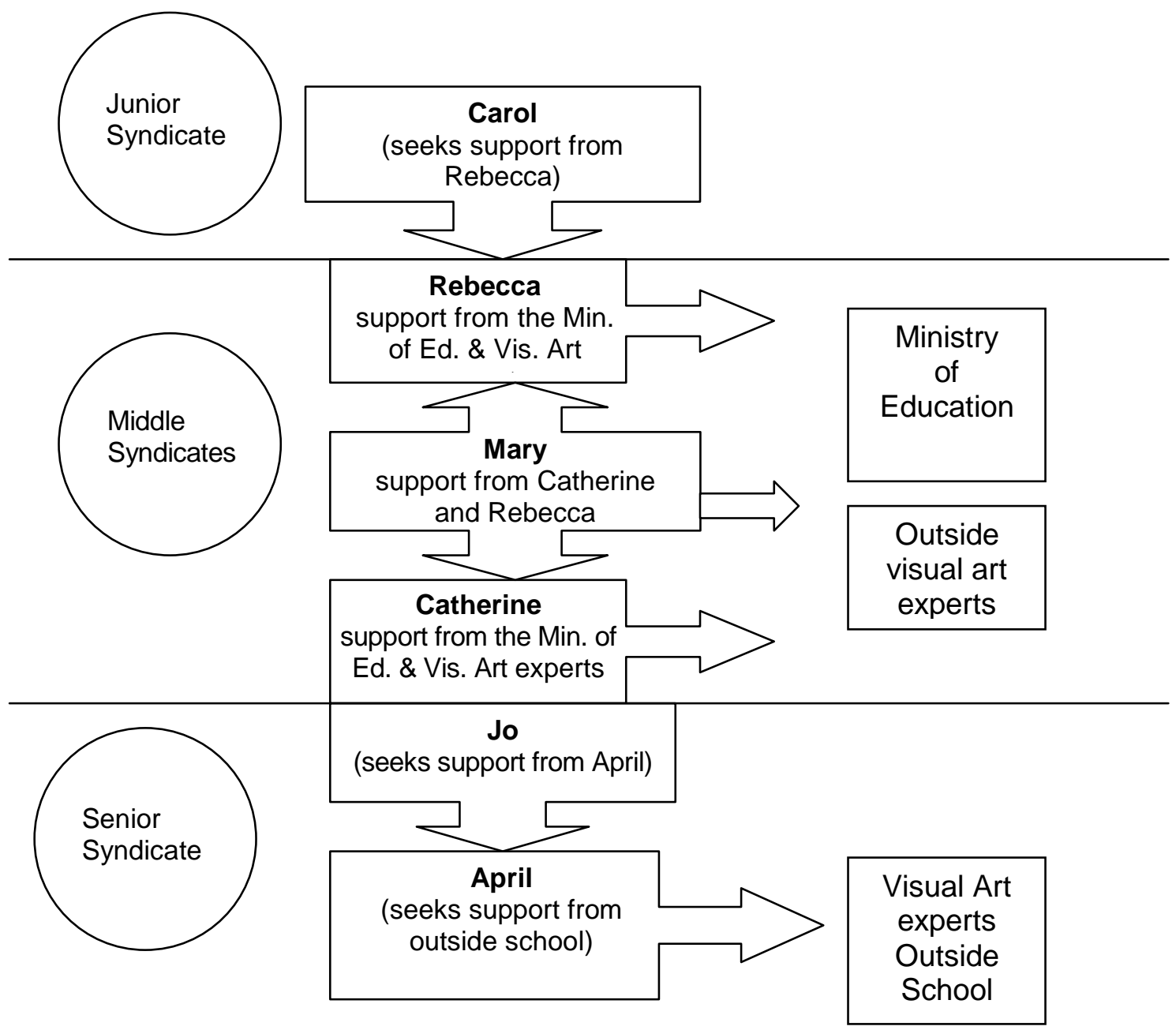

Figure 9: Support networks for participant teachers in visual art

The network of support revealed by the analysis of these transcripts demonstrates its reliance on the expertise of a number of staff members. It would seem that some staff members are perceived as visual art 'experts' within the school and that role of expert is used to support teaching staff in an informal way. A picture is starting to emerge of a system where a group of 'experts' within the school are able to support teachers as they develop their confidence in teaching visual art. Those seen as 'experts' had talked about developing confidence in teaching visual art through a variety of formal networks outside the school environment. Analysis of the document search and conversations with the principal had indicated a policy of using staff expertise in visual art and this 'strength teaching' policy could have created a group of teachers within the school who were perceived by others as visual art 'experts'. 
When first analysing the document search I felt this policy may contribute to teachers relying on the school 'experts' and therefore not develop their own confidence in teaching visual art. The evidence from my conversations with Mary and the volunteer participant teachers would point towards the perceived 'experts' supporting teaching staff and therefore helping to develop confidence in teaching visual art. The initial gaps in the emerging picture are starting to be filled. It seems that 'strength teaching' can develop teacher confidence in the teaching of visual art. Although it is still unclear if the 'strength teaching' policy is a common goal, it would seem the influence of this policy has created a group of teachers perceived as experts, and these teachers are able to support other teachers as they develop their confidence in teaching visual art.

\subsection{Developing confidence informally}

All the volunteer participant teachers talked about sharing ideas informally, through everyday conversations in each other's classrooms, corridors and the staffroom. Their replies point to the importance that the physical layout of the school had enabled the teachers to work collaboratively and to share ideas. Syndicate classes were grouped together, so when Jo talked about going into each other's classrooms for support, she was referring to the classrooms next door to her own classroom. The classes in Jo's syndicate are adjacent to one another, and from my observations the teachers would enter each other's classrooms to share ideas and seek support.

According to the volunteer participant teachers, the staffroom also provides an important environment for teachers to meet and talk informally. From my own observations the staffroom was well used at both morning interval and lunchtime. It seems, therefore, that the physical layout of the school and its facilities are a factor in the way the participants seek and gain support from one another.

When talking about how teachers share ideas in the school, both April and Catherine said the principal wanted teachers to share ideas in staff meetings. These comments, allied with my own observations of the staff meeting I attended, would indicate the principal has a role to play in the way the teachers work together and share ideas:

We don't have them [staff meetings] that often and they are sharing ones which is good. [The principal] has just brought that in, that's something new this year. (April) 
April talked about the format of the staff meetings being changed by the principal. This could mean teaching staff have not been used to the style of meeting he is introducing. By changing the format of staff meetings the principal was actively encouraging the teaching staff to use the forum of the meetings to share ideas. My observations of the first staff meeting I attended were that it was both informal and friendly and various staff members contributed to the meeting. The evidence from my observations and the volunteer participant teacher interviews points towards the principal attempting to create an environment in the staff meeting where ideas can be shared. When I asked the principal about wanting the teaching staff to share ideas in the staff meetings he said:

Talking with other people, going to - you know, all those sorts of things which were never done in the past, so there's a lot more transparent way of identifying the way that they were teaching or identifying things that they would like to do in their teaching. (Principal)

It seems from the principal's perspective staff had not been used to sharing ideas and that since his appointment he had wanted to create an environment where staff could reflect upon their own practice. April's and Catherine's comments on their perception of the principal's goals could indicate that the principal wanted to create an atmosphere of collegiality in the school and it could also indicate his intention for staff to develop common goals.

Using the montage metaphor to describe an environment where the volunteer participant teachers are able to develop their confidence in teaching visual art, the following elements are evident:

- a group of 'experts'

- school policy encouraging the use of experts

- principal encouraging the sharing of ideas

- an environment conducive to the informal sharing of ideas.

Just as in a well-balanced composition all the elements in this developing composition rely on each other and cannot stand alone.

\subsection{Sharing ideas with the support of the principal}

Not only did the principal actively encourage teachers to share ideas within the setting of the staffroom, he also supported Mary in her request for professional development in visual art. Having been encouraged by Catherine to attend a 
workshop outside school, Mary talked about asking the principal if she could attend the course:

....the principal supports anything like that for professional development which was great...he is very supportive of PD but I think it makes a difference when you know. (Mary)

As mentioned earlier, Mary's enthusiasm for the work she had done on the professional development course was immediate. This enthusiasm extended to the conversations she had in the staffroom following the course:

I'd been raving about how great the course was and I always give feedback so I'd feed back to the principal and said it was really worthwhile and I remember saying to him that it was the best PD l've ever done. Some of the staff, I think they'd seen what my kids were doing and l'd showed them samples and a few of the staff said 'wow, that's great, can you show me what you did?' And then when I had more than two or three I just said 'yes I'm happy to show you, I'm showing a few other people'. And I can't recall whose idea it was just to do it all at once. But I yeah I offered to show people what I was doing and so many people were interested that we just did it as a staff thing. (Mary)

I asked Mary if a staff meeting was arranged.

It wasn't compulsory. I just told everyone that on Friday afternoon l'd be I think I mentioned it at a staff meeting and said I will be showing people who are interested how to do this. [The principal] said we can have a couple of bottles of wine, it's Friday afternoon, we'll sit round in a classroom and have some wine and a few nibbles and so it was quite a nice relaxed thing. So originally I hadn't quite planned to take a whole staff development session but because there were so many people loved what I'd done and I was really happy to share the ideas. (Mary)

With the support of the principal Mary was able to pass on to other members of staff what she had learnt on her course. She describes the atmosphere as being relaxed and informal which I suspect was in part due to the refreshments provided by the principal. The supportive nature of the school had enabled Mary to seek advice from other members of staff knowing the principal would support her in her request to go on a professional development course to extend her expertise in visual art. The result had been that Mary had developed sufficient confidence in visual art to not only teach visual art to her class, but also to organise and lead a visual art professional development session with her teaching colleagues.

When focussing on one element in this developing montage composition, in this case the way Mary develops her confidence in teaching visual art, it seems the most important elements were the course she attended and the support given to her by the principal. Her developing confidence in teaching visual art is directly linked to the course she attended and the sharing of her developing confidence is directly linked 
to the principal. This would imply a way of developing teacher confidence in the teaching of visual art is the availability of visual art courses for teachers and the willingness of a school principal to support teachers in attending such courses.

\title{
5.6 Developing confidence in visual art formally in settings within the school
}

Although Mary described the nature of the session she took following her professional development course as informal, the session was supported by the principal and attended by the majority of teaching staff. Mary planned and structured the session and the principal sanctioned it, and in that sense it was formal. I asked Mary what had happened in the school since the after-school session.

\begin{abstract}
...that session was so successful and [the principal] was really impressed and he came along to that session, which was great and I think he really enjoyed it and he really liked what he produced. He contacted [visual art expert] or arranged for someone to do so and she came in and did a class, a course with the whole staff towards the end of last year and then at the beginning of this year the whole staff had another session with her. So, yeah, I think from that he realised how helpful it was and arranged two more. (Mary)
\end{abstract}

As a result of the course, the principal had used the enthusiasm and momentum generated within the school to develop more whole-school professional development in visual art. April, the newly appointed teacher in charge of visual art, also wanted to broaden the use of visual art professional development within the school:

I try and share some of my resources and l've got sketchbooks and things with ideas and give them some ideas ... really want to start up some more professional development with the staff... (April)

When I asked April about her perception of the staff's view of visual art within the school she also recognised the developing enthusiasm amongst teaching staff.

...quite positive this year, l've seen it moving on a lot, there's been a lot more enthusiasm from the staff, which I think is good. (April)

April had felt some staff were lacking in confidence in the teaching of visual art or were less than enthusiastic about the curriculum area, and now she noticed a developing enthusiasm for visual art. One of the reasons she gave was a turnover in staff, and that the new staff had brought with them a degree of enthusiasm. She also felt a course she had organised for the whole staff and the course Mary had attended plus its resulting whole staff session were additional reasons for the increased enthusiasm. The course April organised was requested by staff and was 
run at the school. April had used the visual art specialist Catherine recommended to Mary to run a session on the handling of some art materials for the whole teaching staff. The principal supported this initiative by funding the one day, whole schoolstaff development. As mentioned earlier the course was requested by the whole staff which would imply that it was a common goal. April felt this single course had the effect of fostering enthusiasm amongst the teaching staff and helped develop their confidence in using some art materials and processes in their classroom. The developing enthusiasm and confidence is directly linked to the common goal of the staff in wanting to continue to develop their confidence in the use of visual art materials.

It would seem the original conversation Catherine had with Mary had resulted in generating an opportunity for the teaching staff to develop their confidence in the teaching of visual art. The informal networks used by the teachers in the school, and the principal's encouragement of sharing ideas, had resulted in April being able to develop support in the teaching of visual art for all the teaching staff. When I asked April what the effect of the whole staff development had been she said:

\begin{abstract}
...it's almost like a snowball effect, once you get going on something people realise that it's not so difficult and there's ways of getting around it if you can make some of your own resources and have things to show, that you're better off in front of the kids and you can actually see it starting to feed through the school. (April)
\end{abstract}

April makes the connection between a lack of confidence in teaching visual art with a lack of experience in using visual art materials. Her view is supported by the view of Loewenberg Ball and Cohen (1999) and the findings of Andrews (2006) mentioned in 1.6. Like Rebecca and Catherine, April also links teacher confidence in teaching visual art to teachers' experiences in the use of visual art materials and processes. April saw the whole-school session on the handling of art materials as developing teachers' confidence and 'like a snowball effect' teachers then went on to feel more comfortable in front of their class when demonstrating the use of art materials. She also felt the effect of this developing confidence in the staff could be seen around the school in the work being done by the children.

April also talked about using the forum of staff meetings to share ideas about the teaching of visual art, mirroring the principal's strategy of using the meetings as sessions where teachers share ideas. This raises the question of whether April was influenced by the principal's strategy. If she had been influenced by the principal's strategy this would be further evidence the principal had been partly responsible for developing a school culture where staff can work together and develop their 
confidence in the teaching of visual art. It is also possible the principal's strategy influenced other teaching staff, thereby contributing to an atmosphere of collaboration where ideas could be shared.

It seems the teaching staff within the school developed their confidence in the teaching of visual art in a range of ways and in a range of formal and informal settings both inside and outside the school. Individual teachers within the school had a range of experiences in the use of visual art materials and processes outside the school environment and were then perceived by other staff members as 'experts'. These experts were then able to support those members of staff who lacked confidence in the teaching of visual art either with practical ideas or with advice on where to gain visual art experiences. The environment of the school where teachers could share ideas in an informal setting was encouraged by the principal and as a result in the words of April 'like a snowball effect' staff within the school developed their confidence in the teaching of visual art.

The developing montage composition at this stage was starting to become clearer. It was also becoming possible to focus on separate elements within the composition and find out how these elements were supported. Analysis of the element of Mary developing her confidence in teaching visual art clearly demonstrated she was able to do this with the support of the principal and use of an outside visual art expert (see 5.5). When focussing on the volunteer participant teachers it is now clear that they are able to share ideas in both formal and informal settings whereas earlier analysis of my observations only pointed towards formal settings (see 5.4 \& 5.6). The difference between the two settings is that the principal would have less influence over the informal settings. If viewed through the lenses provided by Talbert and McLaughlin (2002) and Crebbin (2004) (see $1.7 \& 1.8$ ), it is possible the school could support a non-hierarchical collaborative group of teachers that could work towards developing their confidence in the teaching of visual art. 


\section{CHAPTER SIX}

\section{School-wide plan to develop teacher confidence in teaching visual art (formal setting)}

The participants had talked about developing their confidence in teaching visual art by both sharing ideas in informal and formal environments (see sections 5.3, 5.4 \& 5.5). While analysing the data collected during the meetings organised and attended by the volunteer participant teachers I have used the term formal and informal to describe these meetings. The formal meetings were the ones chaired by a single staff member and with a set agenda or was any whole staff meeting or workshop instigated or supported by the principal. The informal meetings had no set agenda and no single person chairing them. Although whole staff meetings or workshops were often described by the participants as being informal in atmosphere, I made the assumption there was a perceived obligation to attend because they were either directly supported or instigated by the principal and therefore this hierarchical pressure created a formality to the sessions.

All the meetings I observed that were attended by the volunteer participant teachers took place in school at the end of the teaching day. With the exception of one meeting, none of the volunteer participant teachers directed the discussion or took the role of chair; the discussions developed as ideas were shared. In her role as teacher in charge of visual art April organised the majority of the meeting times, with all the meetings taking place in Carol's classroom.

For the volunteer participant teachers the action research cycle was structured around a series of informal meetings. During these meetings they discussed the analysis of theirs and the children's descriptions of the children's art-work and the development of a visual art self-assessment sheet. There was no set agenda, other than an agreed topic for discussion. I had often noted in my journal that I felt that April's enthusiasm was a factor in developing the discussions in the meetings.

During the study I attended one meeting that had a set agenda, was attended by all the volunteer participant teachers and was chaired by April. The discussion in this meeting was more structured than those observed in the informal settings. The main difference was that the areas of discussion were based on April's ideas whereas at the meetings in the informal setting the discussion was based around the ideas of all the volunteer participant teachers. 
As teacher-in-charge of visual art April had a series of ideas she wanted to implement within the school. Her overall aim was to develop staff enthusiasm and confidence in teaching visual art. The ways she thought she could implement this goal were to:

- encourage those teachers with a strength in teaching visual art to swap classes with other teachers and teach children a visual art process

- review and re-write whole school visual art plan

- create a central visual art materials area

- develop a range of teaching resources to support those teachers who lacked confidence in teaching visual art

- develop an in-school professional development programme in the use of visual art materials and processes.

April's goal of encouraging staff to swap classes is similar to the principal's strategic goal of encouraging teaching staff to 'swap' classrooms to allow 'strength teaching'. Although April was responsible for visual art it may be that the principal's strategic goal had influenced her. April's goal was therefore supported by the principal's strategic goal, as was her goal to re-write the whole school visual art plan. In my first meeting with the principal, he said:

This is at a time of a Visual Art review within the school. (Principal)

The instigation of visual art professional development within the school was also supported by the principal. Although the principal supported the development of her ideas, April also sought the support of the volunteer participant teachers and organised a meeting where she could discuss her goals for developing teacher confidence in the teaching of visual art.

\subsection{Volunteer participant teachers plan to develop and support teacher confidence in visual art}

April organised and chaired the meeting where she would present her ideas on developing a range of initiatives to develop teacher confidence in the teaching of visual art. At the start of the meeting she emphasised they should view this as 'developing a wish list' and as such they should try and be as comprehensive as possible in the range of things they discussed. By stating that the meeting was about 
developing a wish list, April was making the point that she wanted all those at the meeting to contribute to the ideas. Having asked if anyone would like to start the discussion and in the absence of any volunteers she started to outline her ideas about starting a central resource area that was for both materials and teaching resources.

The volunteer participant teachers accepted the idea immediately as one that could work well, and discussed the appropriate place to site such a centre. Carol identified an ad hoc storage space that could be used. They all agreed that both the space and its position would be an ideal central art storage area:

I think you should put it down, that's a really good idea Carol. (April)

All those at the meeting were involved, and all their ideas were noted by April in the meeting minutes. They expressed the view that the present system of organising materials was not working and the proposed new system would work well. Although instigating the discussion April quickly drew the other teachers into discussing the point she had raised. It was as if her first opening was a device to get the others in the meeting to develop and discuss her proposals. April's enthusiasm and her ability to include people in decision making are demonstrated by the way she opened the meeting. The participants were reluctant to initiate the discussion, yet when April congratulated Carol for her idea and contribution, and outlined her own ideas, the participants quickly became enthused about the topic. It was as if April's enthusiasm was contagious.

April mentioned the one-off professional development day in the use of visual art materials. She mentioned that the same outside provider had been booked to come into the school on four separate occasions. She suggested that it was important that professional development should be included in the long-term plan:

I think it's really important and especially with the enthusiasm amongst the staff, it's working well. (April)

The participants agreed and mentioned the session taken by Mary. The response from the participants confirmed to April that staff had enjoyed and appreciated the professional development she had organised and were looking forward to more. In my conversation with April she had talked about supporting the staff in the teaching of visual art and had mentioned generating enthusiasm amongst the staff. 
The participants talked enthusiastically about the professional development they had that year and this enthusiasm helped to move the meeting along as they talked about the future.

\subsection{April shares resources to develop and support teacher confidence in visual art}

April discussed her idea of developing a range of resources to support and develop teacher confidence in the teaching of visual art. She showed them some visual art resources she had developed. The resources consisted of a range of portraits by various artists representing a variety of styles and techniques.

I had seen April use these resources in her introduction to a topic on the "Whale Rider $^{4}$ which she had used with the children in her class who were developing an art-work in response to the novel (see example p. 76). The examples were placed around the room and were used as starting points for class discussions about the portraits and the techniques used by the artists. In this way April was able to use the resources as the children developed their own understanding about the portraits they were working on. The resources certainly enhanced the project and the children had responded to them well. In an earlier conversation with April it became evident that she had a range of similar resources for a variety of visual art topics.

At this part of the meeting she was showing the teachers some of the resources she had developed:

.... thought it would be easier for teachers, especially if they don't have any resources of their own or if they get stuck or find it a bit difficult, but if they've got something like this, it will really support them. (April)

April's idea was for the group to develop a range of resources to be used by the whole school. Her view was that if they knew what was being taught in visual art throughout the school then they could develop a range of resources for each topic being taught. She suggested that the resources could be stored in the central storage space they had just discussed setting up. Not only was April sharing her resources, she was also including the others at the meeting in her plan of developing a range of resources for the whole school. The implication was she felt confident in the other volunteer participant teachers' expertise in developing these resources. She wanted them to collaborate to develop the support material. This

\footnotetext{
${ }^{4}$ New Zealand novel 'Whale Rider' by Witi Ihimaera.
} 
message to the others at the meeting was inclusive and helped to engender enthusiasm for April's idea.

The participants talked about resources they had used and how helpful it would be to have such a system in the school. April had again shared her expertise and understanding of the teaching of visual art and by doing so had planted an idea with the participants that had become accepted and was now being seen as a positive change in the way they taught visual art within the school.

This meeting was structured around a series of ideas all instigated by April. Although the others responded to April's ideas, they were in fact a reflection of each idea as it was introduced by April. The ability for each of the volunteer participant teachers to develop their own ideas was curtailed by the ideas April had set in place. The 'informal' meetings differed from this 'formal' meeting in that the volunteer participants were not only informed by ideas generated by those at the meeting but also by the knowledge and understanding they had brought with them to the meeting. Significantly the discussions held in the 'informal' meeting focussed more on their own practice and as a consequence developed their confidence in the teaching of visual art:

I think it's a great idea and now that we've got this new resource room, it's a perfect place to keep it. (Carol)

Within the short space of one meeting the participants had accepted they would have a new resource centre dedicated to visual art, organise visual art professional development around topics being taught in the school and develop a range of resources that would support the teaching of visual art. April's goals to develop visual art within the school had become the common goals of all the volunteer teacher participants.

April saw that one of the keys to developing teacher confidence in the teaching of visual art was to provide teachers with experiences in the use of visual art materials. She also felt that teacher confidence could be supported with the development of a range of teaching resources. Her view reflects the views of Andrews (2006), Ball et al. (2005) and Loewenberg Ball and Cohen (1999) who all link confidence in teaching to the depth of content and curriculum knowledge.

April's ability to facilitate a meeting where all were involved had enabled the participants to set in place a range of new initiatives that would support the whole 
school in the teaching of visual art, both in terms of practical in-class support and professional development. April's skill in including the views and opinions of the others was one of the factors that enabled her to start the process of realising some of her ideas about changing the way visual art was taught in the school. Her skills at communication and working with people helped her to develop an enthusiastic response to her ideas to create a set of common goals. When I initially asked April if I might observe this meeting she said she thought I might be bored. On the contrary, I had just witnessed a dynamic teacher enthuse a group of teachers about her vision for the way visual art should be taught and at the same time include all of the teachers in the process of making changes.

April had used the metaphor of a snowball to describe the gathering enthusiasm for visual art within the school. The same metaphor could be used to describe the way visual art was being developed in the school. The principal had given April the responsibility to review and develop visual art and she had gathered around her others with a similar level of enthusiasm. This gathering momentum was helping to support staff develop their confidence in teaching visual art. The momentum of the 'snowball' had been started by April. At the start of the following year she was expecting a baby and would be on maternity leave, so it was not clear who would keep the momentum of the 'snowball' going.

Although the developing montage composition illustrates this group of volunteer participant teachers developing their understanding of visual art they are not developing their confidence in teaching visual art. They discussed a series of ideas that could in the future support teachers and enable them to develop their confidence in teaching visual art. The discussion was centred on one person's ideas. The composition is therefore dominated by one element which is April and her agenda; the other elements in the composition merely support this. 


\section{CHAPTER SEVEN \\ Children and volunteer participant teachers reflect upon children's visual art-work}

Ten children were randomly selected from each of the volunteer participant teachers' classes. Each child was interviewed by me and asked to describe an artwork they had produced in the class. I used a semi-structured interview with all the children that asked them to describe the art-work, the process and materials used and any changes they might make to the art-work if given the time. I then interviewed the volunteer participant teachers and asked them to describe the artworks described by the ten children from their class. I also used a semi-structured interview with the volunteer participant teachers with the questions focusing on the way the children had handled the materials, the finished art-work and improvements they thought the child could make to the art-work.

Of the 50 randomly selected children 48 were eventually interviewed. Each volunteer participant teacher analysed transcripts of their own description of 10 pieces of art-work produced by children in their class and compared this description to the children's description of the same art-work. Both the teachers and children described the art-work during individual interviews with me and neither was present at each other's interviews. During a series of meetings the volunteer participant teachers were able to discuss their analysis of the descriptions and as a consequence of this discussion develop their confidence in the teaching of visual art.

When I compared the children's descriptions of their own art-work with their teacher's descriptions of the art-work, many similarities emerged. One similarity was that both the children and the volunteer participant teachers identified the same successful elements in the art-work. The children and the volunteer participant teachers also identified the same areas of the art-work they thought could be improved upon. Examples of both the art-works and the corresponding comments are shown below. 


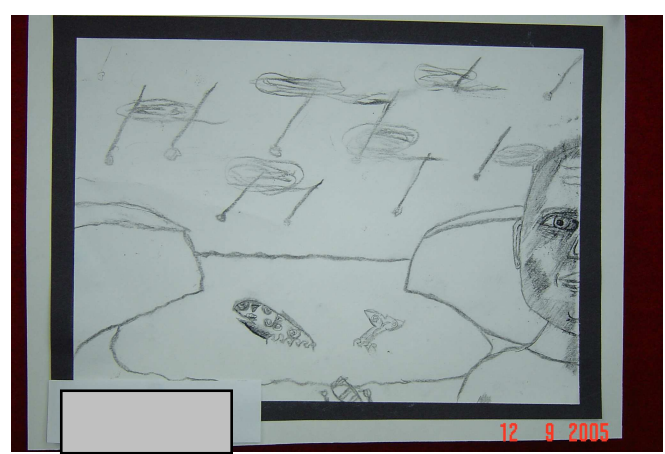

Figure 10: Example of work from April's class

When April described the art-works, she focused on how the portrait was drawn, the charcoal was handled and the composition developed. This pattern was repeated each time April described one of the children's art-works:

...he worked really hard on his drawing of his face and then he struggled with his background in getting it to what he thought was as good as his face. His most successful part is his face. Improvements - l'll be getting him to work on his background... (April)

The following is the child's description of the same art-work:

Making the face because it was quite interesting on what it turned out like. I liked the shading around the side of the face, which makes it look like, I don't really know how to explain it.

When asked directly what was the most successful part of the picture he replied:

Probably the face.

When I asked the child if he would change any part of the art-work in order to improve it he replied:

I'd probably do something different with the whale. I don't really like the whale being there.

Both April and the child identified the face as the most successful part of the drawing, April observed this was in part because the child had persevered when working on the face. Although the child identified the face as the most successful part of the drawing, he made no reference to the time spent drawing it.

The child said in order to improve the work he would focus on the background and change the whale. April said that in order to improve the work she would get the child to work on the background, although she did not identify the whale specifically. Therefore, both April and the child talked about the same aspects of the work when describing what they thought was successful and what they thought would improve 
the art-work. However, the child was more specific than April about what needed to be changed in the background in order for it to be improved.

The child made judgements about the art-work using a combination of their recollection of the art-making process and their recollection of April's feedback. The teacher used a combination of both the evidence of the work itself and her recollections of the effort the child put into the work.

All the transcripts of the descriptions from April's class followed a similar pattern, with both the teacher and the child identifying the same areas of success, and the same areas for improvement. When April and the child talked about the art-work, the comments about what had been successful and what could be improved were similar. The difference occurred when April used her recollection of the child's effort while completing the art-work.

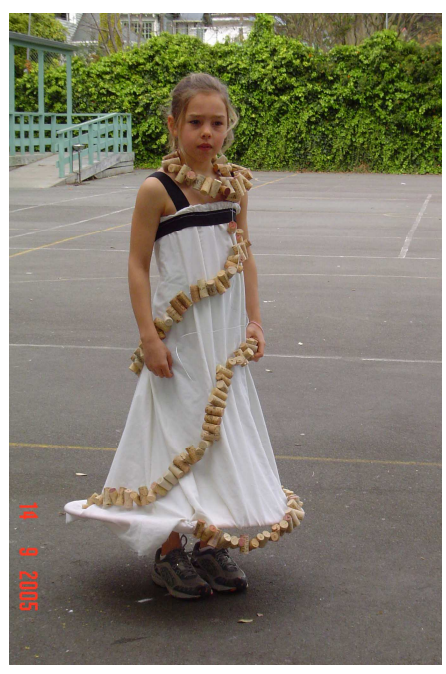

Figure 11: Example of work from Jo's class

All the transcripts from Jo's class also followed a similar pattern, with Jo and the child focussing on the same areas of success. Jo used a combination of the child's effort and work as evidence of success, but tended to focus more on the effort the child put into the work than April had.

Commenting on the example of work from her class, Jo said:

It all started off with a sheet and went from there. The hula hoop thing came on at the end as just another idea. She sat there and drilled every single one of those corks and threaded them through wire - and dedicated, unbelievably dedicated. Most successful - she found it really trying with the corks but she persevered and she did it, and that's her to a tee, she will persevere. (Jo)

When I asked the child what she liked about her design she said: 
I like the corks. I like it how it, like, goes down.

In reply to my question about how she might improve her design she said:

I'd, I might make the dress a little bit longer. It just feels a bit short and the straps are a wee bit too long. Next time I might, maybe do some more things because [indicating the costume].

Although the transcripts from Jo's class demonstrated a similarity between the teacher's and children's descriptions, the children tended to be more specific about the improvements that could be made to their designs. An example of this can be seen in the comments made by the child relating to the length of her costume. Observing the art-work, I would agree with her judgement, if the costume was longer it would appear to float.

Analysis of the transcripts from Catherine's class revealed a similarity between the areas she and the children talked about. Catherine and the children focussed on technique, colour and drawing ability when describing the work.

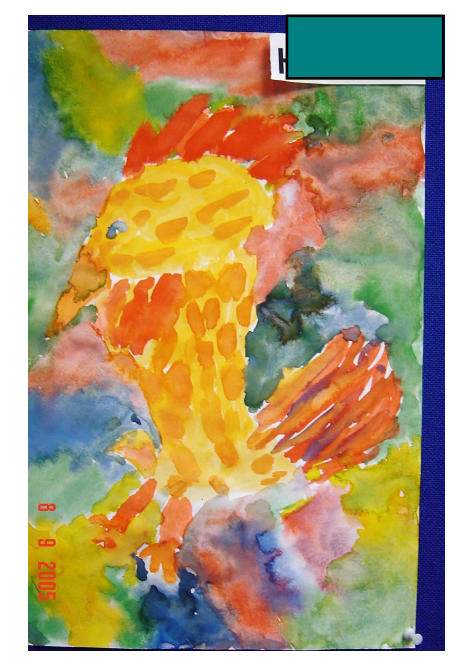

Figure 12: Example of work from Catherine's class

Catherine commented on the child's example:

I would look at her sketching and maybe adding some finer detail, how she would go about that because some of the colours actually on the body are a little bit similar and we could look at how she could lift that. (Catherine)

Catherine only uses the evidence of the art-work itself when talking about ways the child could improve it. She identified colour and the drawing as areas for improvement. 
The child had drawn a rooster and I asked if she would change anything about the way she had drawn it. She replied:

Yeah, cause I reckon it looks a bit funny, it's head looks a bit funny, so... I think it's the beak needs to be a different fit.

While describing the areas around the head and beak that she felt could be changed she pointed to the way she had drawn the head which lacked the detail which was also mentioned by Catherine as an area that could have been improved upon.

I asked the child if she would change the way she had painted the rooster and she replied:

Yeah. Oh, l'd probably do the shade different colours in the back - probably different design in the background and probably different coloured rooster.

All the transcripts from the descriptions from Catherine's class followed the same pattern with both the teacher and the child identifying the same areas of success and the same areas that could be improved upon.

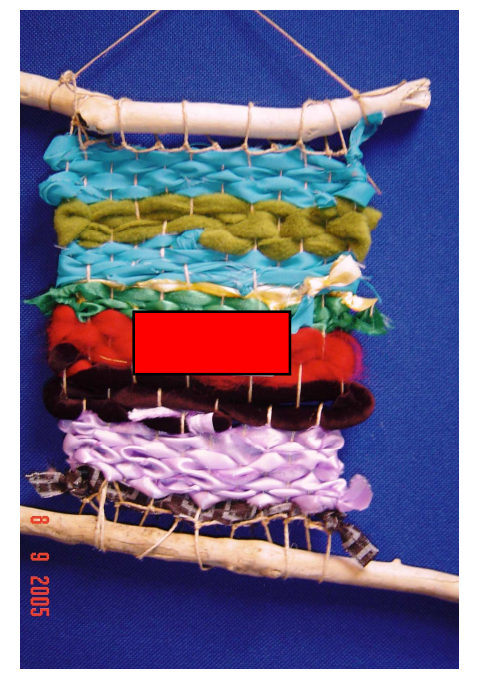

Figure 13: Example of work from Rebecca's class

The similarity between the teacher and child transcripts from Rebecca's class centred on Rebecca and the children focussing on the technique used to complete the weaving, and on the range of colours used:

My overall impression of this is that it's rather nice. Has got quite nice bands of colour. He has managed to weave in and out quite successfully and tied off all the knots. In terms of the actual technique, he's succeeded. His choice of colours is quite nice. I really like the combination of red and the dark purple and the light purple here at the bottom. I like the effect ... One of the things that could be done to improve it but he actually did not have any choice in this, is I don't really like this blue. It's too thin and it hasn't sort of filled up the strings and if I was doing it again, I would choose more carefully the colours I 
offered to the children to choose from. Overall he's achieved his aim - he's got sky, hills, sea, beach and bush. (Rebecca)

When I asked the child what he thought was the most successful part of his weaving he replied:

...the lines and then we had to turn around, I did the tight knots on the end of each fabric and the hills and then the sea and then the beach, all the grass behind it and here's some colours I liked. (Child)

When asked what he would do differently to improve the weaving he replied:

This colour, l'd put it into a different colour. [Pointing to the sky]. (Child)

When Rebecca describes the children's work she talks about three different areas. Firstly, she talks about the work in terms of the technique the child has used. Secondly, she talks about the colours chosen. Thirdly, she talks about possible improvements.

In the example, she makes the point the child has been successful in his use of the technique of weaving, which was a new experience for the class. She was impressed by his choice of colour and how that colour had enhanced the overall weaving. Finally, she points out that the material used for the sky was not suitable. Rebecca felt that in order to improve the woven landscape, a different material for the sky would need to be used. She does say the child did not have a choice in the material used for the sky and that she would, if teaching this again, be more careful in the materials she provides to the class. Not only is Rebecca describing the weaving, she is also using the weaving to reflect upon the lesson. Rebecca reaches the conclusion the weaving is successful as it achieved the goals she had set for the children.

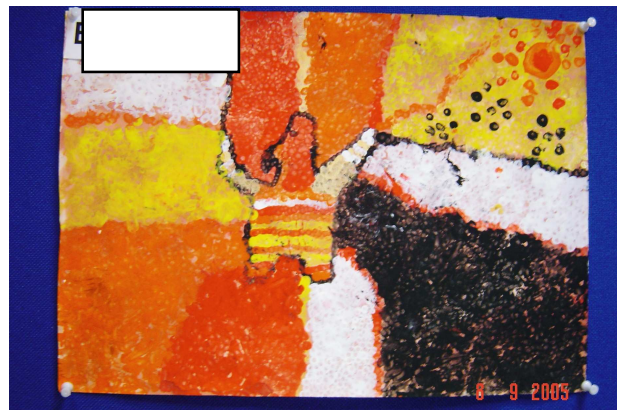

Figure 14: Example of work from Carol's class

Although the children in Carol's Year 2 class described similar parts of the painting to those that Carol described, only five of the 10 children interviewed identified the 
same areas for improvement that Carol identified. Carol describes one of the children's paintings:

I think her bird possibly could have been bigger, but I think this is a small picture, and the middle is very much what she does, she does a small one and then fills it out from there, perhaps next time, improvement could have been that his bird could have filled up more space. (Carol)

When I asked the child what her favourite part of the painting was she said:

Doing the bird.

When asked to describe the painting the child said:

Well first, I just did the bird, then I started doing the patterns. It's so I wasn't last finishing. I had to do some lines and the first colour I started with was orange, and then I went to white, then red, then yellow.

\subsection{Teacher feedback creates a common understanding between child and teacher}

Having observed the volunteer participant teachers teaching and analysed their comments, I felt the similarity between the teacher's and child's comments could be as a result of the feedback the teacher gives the class and the children individually during the lesson. Talking to the children during the art making process enables the teacher and child to develop a common understanding about the art-work. They are then able to talk about the art-work in a similar way, even when they are apart from each other.

If the similarity between the child's and teacher's comments is evidence of the teacher giving specific feedback to the child about their art-work during the lesson, it is also evidence of the child remembering that feedback.

In the field notes I made during April's lesson, I noted she gave feedback to the children in two ways. Firstly, she moved around the room working with individuals on the techniques involved in using the media and ways they could improve upon their composition. These individual conversations usually centred on asking the children about their work, encouraging them to make critical decisions about their own work. Secondly, April talked to the whole class about common themes she had observed. When doing this she used examples of the children's work and a range of visual resources she had placed around the room to illustrate a point. When I was talking to the children about their work, it is possible they remembered some of the comments made to them by April during the lesson. 
In the field notes I made during Catherine's lessons, I noted she always started the lesson with a series of statements written on the whiteboard. These were the learning intentions of the lesson. Catherine referred to these directly at the start and end of the lesson. During the lesson, when moving around the room talking to the children, she referred to these learning intentions. One of the reasons Catherine's descriptions are similar to the children's descriptions of the art-works could be her use of learning intentions and her reference to them throughout the lesson. The learning intentions she used often covered areas such as media techniques or the development of composition. Analysis of Catherine's descriptions and the corresponding children's descriptions show that these are the areas they both talked about.

\subsection{Summary}

There is a similarity between the way Rebecca and Catherine talk about their children's art-work. Both focus on the art-work and the learning intentions they gave to their class. Rebecca and Catherine linked their confidence in teaching visual art to their own experiences in using art media and processes. Analysis of Catherine's and Rebecca's descriptions of the children's art-work could be an indication that confidence in teaching visual art is also linked to confidence in assessing children's art-work. If there is a link between assessing children's art-work and a teacher's experience in using art materials, then this may also explain the difference between Jo's description of the children's art-work and the descriptions of the other volunteer participant teachers. Jo's descriptions focussed on the perseverance and attitude exhibited by the child rather than the art-work itself. The other volunteer participant teachers focussed more on the child's art-work. Jo had talked about her lack of confidence in teaching visual art, so possibly her lack of confidence extended to the way she viewed the children's art-work.

There was a difference between the way the Year 2 and the Year 3 children described their art-work, and the way the Year 5 and Year 7 children described their art-work. When asked to describe their work the Year 2 and Year 3 children tended to describe the process of completing the art-work. For example, when the children from Rebecca's class described their art-work, they tended to describe the process of weaving. The children from Carol's class also tended to describe the process of painting when I asked them to describe their art-work. 
There was a tendency for the children from Year 2 and Year 3 to describe their work in a narrative style. One reason for this could be that at this age visual art is used a great deal to support their developing literacy skills. The children could associate their art-work with story telling and writing. The children might have misinterpreted my question believing I wanted them to describe the process of making the work. All the interviews with the children followed the same semi-structured format. The opening question was, 'Can you describe to me your drawing/weaving/painting.' Maybe I should have re-worded the question for the younger children.

The difference could also reflect the children's developmental stages. Wolf (1989) makes the point that young children's drawings are often a result of a dialogue between production and perception. Meaning is applied to the art-work as the work is produced, and it is not until the age of seven that children start to develop an understanding of visual images.

Year 2 and Year 3 children talked about their art-work in a different way to Year 5 and Year 7 children. However, when comparing all the children's descriptions of the art-work with the teacher's descriptions of the art-work, there were many similarities. Of the 48 children interviewed successfully, 41 showed a strong similarity between their descriptions of their art-work and their teacher's descriptions of the same work, whatever their age. 


\section{CHAPTER EIGHT \\ Working collaboratively to develop confidence \\ (informal setting)}

Over a period of 11 months I observed five meetings where the volunteer participant teachers discussed:

- analysis of theirs and the children's descriptions of the children's art-work

- visual art teaching in the school

- developing, designing and trialing a visual art self-assessment sheet.

\subsection{Volunteer participant teachers reflect on teacher feedback to children}

The theme of this discussion was the volunteer participant teachers' analysis of theirs and the children's descriptions of the children's art-works. Having analysed both sets of descriptions all the volunteer participant teachers commented upon the similarities between their own descriptions and the children's descriptions of the artwork. The following quotes illustrate how the discussion about their initial reflection of their analysis started:

\footnotetext{
Most similarities I could find were things like, using a lot of colour and any patterns that they'd made. I might have mentioned that they were doing a spiral, and some of them have mentioned a spiral that they liked and that they enjoyed doing it. (Carol)

I do think many of mine have picked up on the same kinds of things that I had. Quite a few of them said that they would change colours and I had said that too, and that maybe because we'd actually talked about it together in class, so they may have been parroting what I had said. (Rebecca)
}

The volunteer participant teachers all followed a theme, started by Carol, with each of them building upon the previous comment and adding their own interpretation. Rebecca was the first teacher in this sequence to make the link between what was said in the classroom by the teacher and the voice of the child. As mentioned earlier, Rebecca was confident in teaching visual art and would talk to the children about the processes and materials they were using during the lesson. Carol had a similar style of teaching moving from child to child during the lesson, giving them specific feedback about their art-work by focussing on the techniques or processes they were using. Towards the end of the lesson she would talk to the class about their art-work to reinforce what they had focussed on during the lesson. 
Rebecca mentioned that the similarities between the child's and teacher's description could be accounted for by the children 'parroting' what she had talked about in class. 'Parroting' implies the children were repeating what they had heard without understanding it. In my view the children's descriptions showed they had used language obtained from the teacher to describe their work. They were repeating comments she had made indicating that they were informed by her. The data provide evidence that they had remembered what she had said. This evidence supports the comments Carol made about the children remembering what had been said during the lesson and then repeating this when asked to describe their work. This form of feedback enables the teacher to develop an understanding about what the children have remembered or how they have interpreted the content of the lesson. Rebecca's 'parroting' comment helped develop the next part of the discussion.

Catherine and April continued with Rebecca's comments; they also talked about the similarities between the children's and their teacher's descriptions. In fact, all the teachers seemed surprised at the similarities yet pleased that this analysis confirmed the children had remembered many of the points they had discussed in their class:

I did find quite a few similarities which I was pleased about, almost relieved in a way, and I was pleased that they picked up on ... a lot of the things when I was teaching them about what I wanted them to do and what we were aiming for and skills that we were teaching, they actually put that into their work and they picked up on things that I hadn't thought they had picked up on. (April)

Having analysed her transcripts April realised that the children in her class had developed their expertise in visual art and had achieved the goals she had set them. This process of analysis had enabled April to develop her understanding of the teaching of visual art. The discussion had enabled the volunteer participant teachers to share with each other what they found during their analysis. The informal nature of the group had allowed them to expand upon their original analysis. Each time one of the volunteer participant teachers talked about their analysis the others were able to build upon that analysis with their own findings. Sharing their information gave them a wider view of what was happening when the children were talking about their art-work; they were starting to realise that their own analysis was not isolated, but was being confirmed by the analysis presented by the others in the group.

It seems therefore that one of the ways teachers can develop their confidence in the teaching of visual art is working as a collaborative group to reflect upon the feedback given to them by children. According to McLaughlin and Talbert (2006), 
teachers are able to create knowledge of practice when they inquire into student work. By examining student work together as teachers they are able to consider how successful their practice has been. It would seem that this group of volunteer participant teachers supported this view by being able to consider their own practice while reflecting as a group upon the feedback given to them by the children.

\subsection{Volunteer participant teachers reflect on teacher language}

The next theme to be developed during the discussion was the use of teacher language. Rebecca was the first teacher to mention the language used by the children:

They used different words but they definitely described the same thing. (Rebecca)

Catherine realised that language used by the teacher had implications on the way she taught, and developed the discussion:

\footnotetext{
I was pretty pleased with mine actually. I thought that ... but now I'm thinking of what Carol said and the teacher language. The specific, precise language that I had used, and we had our learning intentions and our success criteria, and they are using the language that I had talked about, but that was something that we demonstrated and we'd gone through and I commented on and they talked a lot about when they did their work. (Catherine)
}

Catherine made the connection between the language used by the children in her class to describe their work and the language she introduced to them during the lessons. When teaching she listed the learning intentions on the whiteboard at the start of the lesson. Not only did the learning intentions indicate the lesson's focus, it also introduced them to art specific language.

I had observed one of the art specific terms she introduced to her students. She used the term 'wash' which is an application of a thin coat of colour, and the term of 'wet on wet' which is used to describe the application of a wash over a wet surface. She also talked to the children about using bright colours and blending the colours. Analysis of the children's descriptions from Catherine's class revealed that they all talked about either 'wet on wet', bright colours or blending colours. Catherine realised her use of specific learning intentions and success criteria, which used artspecific language, had informed the children and they had remembered that language when describing their work. At this point in the discussion the teachers were clearly working together to develop their understanding of how the children 
saw their art-work, sharing ideas about their own classroom practice and the impact that practice had on the children.

Carol and Rebecca made the observation that the children were probably repeating what they had heard from them, and Catherine made the link between this and the way she uses specific learning intentions at the start of every lesson. The teachers were developing a common understanding as they discussed the transcripts they had analysed, and this forum provided them with the opportunity to work collaboratively. The structure of the meeting was informal as they talked about the teaching of visual art. Hargreaves (1994) view of 'collaborative culture' is that it is informal and almost unnoticed. The informality of this discussion could be an example of Hargreaves' 'collaborative culture'. When discussing collaborative approaches to professional development Johnson (1999) makes the point that these approaches are often characterised by active teacher participation, systematic reflection on practice and group self-direction. This group of volunteer participant teachers were very much a reflection of Johnson's attributes of a collaborative group of teachers involved in professional development; they were actively involved in a process of systematic reflection that was directed by the group.

\subsection{Volunteer participant teachers reflect on their practice}

During the discussion the volunteer participant teachers talked about the feedback they had gained by analysing the children's descriptions.

They just know that they really enjoyed themselves and that they really liked using bright colours. (Carol)

They felt the data provided positive feedback about the visual art units they had been teaching. The feedback the children gave showed they found the unit being taught was enjoyable. Without this process of analysing the data the volunteer participant teachers may not have received any formal feedback from the children as to how they felt about the work they were doing. The process of discussing the analysis of the transcripts as a group allowed the volunteer participant teachers to use the children's voices to reflect upon their own practice. This is an important element of the action research process where the participants are able to develop an understanding of their own practice by reflecting upon all aspects of that practice. In this case the volunteer participant teachers were analysing the voices of the children in their class and then linking this analysis to the way they taught. 
All the teachers were in agreement that analysis of the data had revealed that the teacher's and children's descriptions were similar. The children's feedback had also informed them that the children enjoyed the unit of work. Their discussion focussed on the similarities of the descriptions, the difference in the language used by the child and the teacher, and the positive feedback they had received about the work the children were doing. While I observed the discussion I wondered how the teachers would use this analysis.

\subsection{Volunteer participant teachers' reflection leads to ideas on self-assessment}

Gipps, McCallum and Hargreaves (2000) argue that self-evaluation is a process of children evaluating how well a piece of work meets the learning requirements, with guidance from the teacher, or how they improve on a previous piece of work. The teacher guides the children in this process of evaluation, enabling them to reflect on their performance. According to Gipps et al., self-evaluation is part of the process of allowing children to take responsibility for their own learning. Children therefore become involved in evaluating their own work rather than relying on the teacher to tell them how successful a piece of work is. During this discussion the volunteer participant teachers assessed the ability of the children to reflect upon their performance. Their analysis of the transcripts enabled them to identify a clear relationship between the way the teachers give feedback to the children and the way the children use this feedback to reflect upon their art-work. Their discussion reflects Gipps et al.'s argument that the process of children evaluating their own work is allied to a teacher's guidance.

Carol pointed out that the transcripts from her Year 2 children's descriptions had shown that the children may have been repeating what she had told them during the lesson. If this was so then part of the process of helping children to reflect upon and evaluate their own work may involve the classroom teacher providing the children with specific feedback and asking questions about their work during the lesson. The children in Carol's class were six years old and starting to develop the skills to reflect upon their own work with the support of the classroom teacher.

Gipps (1994) argues that the age at which children can self-evaluate and selfmonitor is open to debate. Some teachers feel that it is an activity for older children and others that it is appropriate for younger children. Gipps makes the point that if children are to self-evaluate, considerable development will be required of teachers, 
as well as preparation of children in the art of self-evaluation. Carol, in her comments, was starting to make the connection between what she had told the children during the lesson and the ability of the children in her class to talk about their work. Her comments would therefore support the views expressed by Gipps. I asked the volunteer participant teachers if they felt there were more similarities than differences between the teacher descriptions of the art-work and the children's descriptions:

...it's obvious to me that there's probably more similarities. (Carol)

At this point the whole group agreed with the statement.

The volunteer participant teachers discussed the clear and definite ideas children have about their art-work and how the children seemed capable of analysing their work. The evidence of the analysed transcripts had shown how insightful the children could be about their art-work. They discussed how this may be related to the fact that they indicated the learning intentions of the session to the children at the start of each of the visual art sessions. When the children talked about their work their focus was the stated learning intention.

An example of this was demonstrated in the interviews with the Year 5 students who had focused on the techniques and colours used by Jane Evans ${ }^{5}$ in her paintings. The teacher's learning intentions for this session were about exploring these techniques. During the interviews, the children all talked about the colours and the water colour wash technique they had used. At this point in the discussion all the participant teachers at the meeting were analysing the importance of the use of learning intentions at the start of the lesson. They felt these learning intentions had probably contributed to the children and the teacher both describing the same things when they had talked about the art-work. By reflecting upon their analysis, the volunteer participant teachers were developing their understanding of the importance of using specific learning intentions when teaching visual art, and as a consequence were developing their confidence in the teaching of visual art.

I asked the volunteer participant teachers if they felt they could use the evidence of the children's insightfulness about their own art-work in any way. I wondered if they might consider using these findings to develop a way of assessing the visual artwork by using the voice of the children. However, the teachers said they talked to

\footnotetext{
${ }^{5}$ Jane Evans is a New Zealand painter who works mostly in gouache and watercolour.
} 
the children about their art-work all the time in an informal way, as a part of their teaching. I had observed this during their lessons, but the evidence they had just analysed and discussed had been a surprise to all of them. They were particularly surprised by the number of similarities between their descriptions and those of the children. If the child's view of their art-work had been actively sought during class discussions, then the analysis of the interviews should have confirmed what the teachers already knew. However, they were all surprised at the similarities in the descriptions.

And if they know what they are trying to achieve, and they know how they are going to go about getting there, then they can judge their work themselves. (Catherine)

The reference to knowing what they are going to achieve related to the learning intentions used in each lesson. Catherine was now making the link between the learning intentions and the fact that they could be used in conjunction with a form of self-assessment. At this point the group discussion focussed on the way selfassessment is already being used in some areas in the school, and how it might apply to visual art.

\subsection{Volunteer participant teachers develop confidence in assessing children's visual art}

Initial data from the study had indicated a lack of confidence among the volunteer participant teachers in assessing children's visual art. Analysis of official school documents and the staff questionnaire had revealed a discrepancy between school expectations of assessment in visual art and the assessment practices of the staff. Analysis of the questionnaire revealed $62.5 \%$ of staff at the school assessed children's visual art-works themselves against set criteria, although the school policy states, 'Pupils will, as far as is practical, be involved in the evaluation of their own learning'. All the volunteer participant teachers had earlier expressed a lack of confidence in the assessment of visual art. When I talked to them about assessing visual art four of them said that although they talked to the children about their artwork they did not feel comfortable in using self-assessment in visual art.

They haven't had the opportunity to assess each other's work. That would be something that I would like to do. I do that in other areas of the curriculum. (Carol) 
The evidence of the discussion on developing a visual art self-assessment system points to the volunteer participant teachers developing their confidence in the area of visual art teaching.

Earlier in the study all the teacher participants talked about wanting to use self and peer-assessment as an assessment tool in visual art and although they used this tool in other curriculum areas they felt that they lacked the confidence to use those tools in visual art. A common theme from my initial conversations with them was that they felt the process of self-assessment would take up time which was not available. When I first talked to them about asking the children questions about their work informally, they did not make the connection between that process of feedback through questioning and the process of self-assessment. From my point of view, asking the children to talk about their work in a class situation meant they were already helping the children develop self-assessment skills.

A project designed to look at art assessment in the United Kingdom recognised that as arts education encourages individual creative responses it needs an appropriate assessment methodology that genuinely reflects the expressive and creative dimensions of art (Ross, Radnor, Mitchell \& Brierton, 1993). Forming a part of this art assessment methodology includes interactive and collaborative modes of assessment. While describing an integrated arts project in Chicago, LeMoine (2001) makes the point that meaningful arts assessment should include self-evaluation, the design of rubrics, and the involvement of students in establishing standards of quality. In discussing a shift in the way that arts should be assessed in schools, Gardner (1996) talks about developing a child's ability to both contemplate and reflect upon the processes involved in making the art-work and critically evaluating the art-work. It seems from the literature that it is essential for children to be involved in the assessment of their own art-work.

The volunteer participant teachers were now discussing the development of a visual art self-assessment system and focussed on either using a system common across all age groups or changing the system according to different age groups. Earlier in the study I made the point that the volunteer participant teachers lacked confidence in using self-assessment in visual art; they were now developing both their understanding and confidence in the use of self-assessment by analysing the voice of the children in their class. From the evidence they had analysed and their discussion they concluded there was a difference between the way the Year 2 and Year 3 children described their work, and the way the Year 5 and Year 7 children 
described their work. This conclusion resulted in the discussion focussing on the development of a system that took into account the different needs of the various age groups. They also discussed the kind of information they would want from such a system and how teachers, children and parents would benefit from it. It was suggested such a system could complement a child's portfolio, a folder of examples of the child's work sent home to parents. The teachers felt they could develop a system where the child reflected upon the art-work that was in the portfolio.

Earlier I discussed the discrepancy in the school's stated assessment goals and the teachers' confidence in the assessment of visual art. The volunteer participant teachers were developing their understanding of the link between their analysis of the children's descriptions and visual art self assessment. This study had given them the opportunity to address their self reported lack of confidence in the assessment of visual art.

\subsection{Volunteer participant teachers reflect on the use of a common language in visual art}

The volunteer participant teachers discussed the language used by the teacher and the child and the point was made that the children could be repeating what they had heard the teacher say. As the discussion continued, each of the themes discussed was informed by the knowledge they had developed from previous themes in the discussion. The volunteer participant teachers discussed how they could ensure a common language was used by the teacher and the child when using a visual art self-assessment system. Catherine had made the point that the teacher and the child needed to have a common language in order for the self-assessment process to be helpful for both.

...quite a few of us from time to time actually have a self-assessment sheet where children look at their work, talk it through and they fill in on their sheet. (Rebecca)

I asked the group if this was a generic sheet used by all teachers and for all age ranges. They told me the kind of sheet varied according to the teacher, the work and the age of the child. They discussed the merits of using a generic self-assessment sheet for visual art, which could also be used with all age ranges throughout the school:

I don't know that it could not be completely generic because the range of different activities that you can do that come under visual arts, so that wonderful weaving for example would be very different from the one that you'd have for water colour. (April) 
But the principles and elements that we do in visual are the same. (Catherine)

The principles and elements Catherine is referring to are those found in the Arts curriculum. The Arts In The New Zealand Curriculum (Ministry of Education, 2000) states:

Students explore the relationship between elements and principles, and the use of art making conventions and techniques to organise and arrange their ideas. They develop skills in a range of techniques, investigate the properties of materials, and use appropriate tools and techniques. (p.72)

I was unsure if the volunteer participants had used the principles and elements when they planned visual art lessons. In each of the descriptions the children and the teachers identified the techniques, processes and tools that had been used. Neither the children nor the teachers had been specific about the elements and principles present in the art-works. If both the teacher and the child had used art specific language to describe the art-work in terms of elements and principles then they would have developed a common understanding about the art-work.

The art-specific language used to describe the elements and principles are as follows:

\section{Elements}

- Line

- Colour

- Value

- Texture

- Shape/form

- Space

\section{Principles}

Unity

Balance

Dominance

Repetition

Rhythm

Contrast

Theme/variation

Although we do sculpture and we do weaving, those principles and elements are the same ones across all of them... (Carol)

Carol and Catherine had answered April's point about the variety of work that is done, and the difficulties involved in creating a generic self-assessment sheet that would take this variety of work into account. Catherine immediately came up with a possible solution:

You could have a structured framework like a template and then you could just adapt it with a particular ... like going back to that learning intention, you know, you might have a structure there that you just put things into. (Catherine) 
The volunteer participant teachers discussed how they could use the transcripts they had analysed to develop a generic self-assessment sheet that could be used with all age ranges across the school. They had made the link between the use of learning intentions and the use of art-specific language which could then be used to create a generic self-assessment sheet for visual art. They were developing their understanding of visual art by discussing their analysis of the transcripts and working collaboratively. According to Day, Hall, Gammage and Coles (1993), meaningful collaboration between teachers occurs when they are engaged in open and honest examination of their practice. The volunteer participant teachers were able to look at their own practice as a group and as a result develop a visual art, school-wide self-assessment system.

Following this discussion on the development of a visual art self-assessment sheet April said:

I hadn't realised just how much they had got from me, or how much we had both agreed on. (April)

Although April was talking about the transcripts they had analysed, her comment, in my view, could also apply to the discussion the participants were having at that moment. They were working as one unit, discussing their findings and bouncing ideas off one another. The knowledge they were creating as a group had been developed by cooperating with one another and sharing ideas.

It seemed at this point that the discussion was coming to an end. As the teachers were getting ready to leave April asked if I could provide them with some examples of visual art self-assessment sheets they could look at.

\subsection{Participant observer dilemma}

For most of the meeting I had been an observer and had only participated by asking the whole group questions about how they would use the information they had gained through analysing the transcripts. If I chose not to provide the selfassessment examples, the process of the teachers developing a self-assessment sheet could come to an end. I therefore agreed to find a range of examples of selfassessment sheets and pass these on to the participants. This request from April is also an example of the reciprocal relationship that develops between the researcher and those involved in the research. 
By asking me about my knowledge of self-assessment sheets April was seeing me in another light. To her I was no longer the observer in a meeting, but an expert who could provide her with some information. Earlier April had talked about looking outside of school to develop her confidence in the teaching of visual art; here was an example of how she was prepared to use the expertise of others outside of school to help her in her role as teacher in charge of visual art.

\subsection{Summary of volunteer participant teachers' first discussion}

In 1.7, 1.8 and 1.10 I looked at the literature that both supported and cautioned against the view that collaborative groups of teachers could develop their own practice through a process of reflection into that practice (Crebbin, 2004; Huberman, 1993; Lieberman, 1996; Loewenberg Ball \& Cohen, 1999; Talbert \& McLaughlin, 2002). Johnson (1999) contends that teachers are more likely to change and improve the way they work if they are engaged in collaborative professional development activities. According to Johnson, these activities are often characterised by active teacher participation, focus on issues of concern, systematic reflection on practice and group self-direction. Talbert and McLaughlin (2002) make the point that teachers are able to consider the effectiveness of their practice when they collaborate and inquire into student work. The views of Johnson and Talbert and McLaughlin were exemplified by the volunteer participant teachers who had met in a school classroom and worked together in a non-hierarchical group. The informal nature of the discussion had allowed them to reflect upon their own practice as they discussed their analysis of the transcripts. They were able to analyse the voices of the children and through this analysis develop their confidence in the teaching of visual art.

When the volunteer participant teachers reported back their findings at a group meeting after analysing the transcripts, they observed many similarities between the teacher's descriptions and the child's description of the same work. Through discussion they had hypothesised that one of the reasons for this similarity was the way in which they used learning intentions at the beginning of a session to focus the children on specific teaching points. They came to the conclusion that their conversations with children individually while they were completing the art-work had influenced the way the children described their work. Having reached this conclusion they made the link between the importance of what is said to children during a lesson and the use of art-specific language, thus creating a common language to be used by the child and the teacher. This was a clear change in how the volunteer participant teachers had earlier viewed the informal discussions they had with the 
children in their class. Earlier in the study they had not made the connection between the conversations they had with children during the lesson and assessment. They had expressed a desire to develop their confidence in the use of self and peer-assessment tools in visual art. This informal group and open discussion had enabled them to develop their confidence in the use of the child's voice when assessing visual art. The culmination of this discussion was the possibility of developing a generic school-wide self-assessment template for visual art.

Although the meeting was informal and lacked a chair or agenda, the structure of the discussion did follow a logical sequence. Having analysed the child's and teacher's view of the child's art-work the volunteer teacher participants first analysed the voice of the child. This analysis triggered a range of ideas including the language teachers' use, the feedback they give to children and their own classroom practice in the use of learning intentions. The culmination of this discussion was not only that a child's self-assessment of their art-work would give teachers valuable feedback but also in order to support that self-assessment process the teacher and child would need to develop a common language. The volunteer teacher participants had clearly been able to develop their confidence in the teaching of visual art by working as a collaborative group. If the analysis of this meeting is viewed in conjunction with the analysis of the school document, my conversations with the volunteer teacher participants and the school principal, it would seem that in part the group was able to function because of the collegial atmosphere within the school and the common goal of the volunteer participant teachers.

At the start of the study the volunteer participant teachers had expressed a desire to develop their confidence in the use of self-assessment in visual art and this had become a common goal. The collegial atmosphere in the school was evident in the way volunteer participant teachers contributed to the discussion, taking it in turn to express their views and develop the ideas of others in the group. Although April was responsible for the development of visual art in the school, she did not guide the discussion; it developed as the participants used their analysis of the descriptions to further their understanding of visual art. Although April did not drive the discussion, I had made the observation in my field notes that I felt it was April's skill in allowing the discussion to develop that enabled this meeting to continue the way it did. She developed the momentum of the meeting but did not dominate it. 
The developing montage composition has changed. April is no longer a dominant element although she is a part of the discussion. The other volunteer participant teachers are also an integral part of the discussion. A new element in the composition is that they have been informed by the opinions of children from their classes. In the previous formal meeting the participants had not developed their confidence in teaching visual art; they had merely discussed a series of April's ideas. In this informal meeting their confidence in the teaching of visual art was improving. The changing elements between this meeting and the previous meeting is that the group is non-hierarchical and they are starting to listen to the voices of the children in their classes.

This was the first in a cycle of informal meetings which took place over a period of approximately 11 months covering two consecutive academic years. In the final meetings April was on maternity leave and at the time I wondered if the enthusiasm of the group would change in her absence. 


\section{CHAPTER NINE}

\section{Volunteer participant teachers developing confidence in assessing visual art (informal setting)}

When the volunteer participant teachers discussed their analysis of the children's and their descriptions of the children's art-work they concluded the children were able to assess their own art-work. The theme of this next discussion was the development of a visual art self-assessment system and again there was no agenda. This informal setting allowed the volunteer participant teachers to use the insights they had gained in their previous meeting to inform their own practice in the teaching of visual art.

\subsection{Volunteer participant teachers revisit their analysis and develop their expertise in teaching visual art}

Initially, the volunteer participant teachers discussed the kinds of questions they would need to ask children to enable them to reflect upon their work:

l'd been thinking about those questions that you asked the kids, just to get a bit more out of them. (Catherine)

Above Catherine makes a connection between the series of questions I used to allow the children to describe their work and how this could be used as a series of prompts on a self-assessment sheet (see below):

I mean it could be easily put onto a sheet. (Catherine)

The structure of this meeting was similar to the meeting analysed in Chapter Eight in that all the volunteer participant teachers continued to contribute to the discussion. The difference was that they were using the understanding they had gained in the previous meeting. This understanding had been gained collaboratively whereas the understanding they were using in the previous meeting was gained while analysing theirs and the children's descriptions and that process had been done individually. It was as if the knowledge they had gained in collaboration with each other had given them the confidence to develop a greater understanding of the relationship between their initial analysis and its implications in the development of a system of visual art self-assessment. 
Throughout the discussion a cycle of referring back to the original analysis was repeated by the volunteer participant teachers. They focussed on the type of information that would be needed on the self-assessment sheet they were designing and they decided on the following:

- image of the child's art-work

- child's motivation used to start the topic

- curriculum level the child was working at

- child's description of the work

- what the child liked about their work

- a statement about what the child learnt

- what the child would improve upon or change

- teacher comment

- techniques and materials used.

All the volunteer participant teachers contributed to the discussion and made references to the initial analysis of the descriptions of the art-work. While discussing the information needed on a self-assessment sheet they talked about the difficulties in designing a school-wide, generic sheet. They agreed the main difficulty was designing a sheet that catered for the range of ability from Year 1 - Year 8. They related this difficulty to the transcript analysis which showed there was a difference between the way the Year 1 and 2 students described their work and the way the Year 5 and 7 students described their work:

I'm thinking even the description of your work, like Year 1's, I mean for some of them you wouldn't, they'd spend half their time just trying to write "I did a painting", which tells you nothing really. (Catherine)

At this point in the discussion all participants were involved and April and Jo made notes about the ideas discussed. Although April was the curriculum leader she did not dominate the discussion and the focus remained on the difference between the way the younger and older children described their work. Carol and Rebecca felt there would have to be a different self-assessment sheet to cater for the needs of the children they taught. While discussing this point they decided the younger age range in the school would need to use symbols to gather information. They agreed there would have to be more than one standard sheet. The participants accommodated the views of the teachers of the younger children and quickly came to a decision:

Shall we split it up into year one and two, three and four, five and six, seven and eight? (April) 
April's suggestion of four variants of the self-assessment sheet would suit the particular needs of those age ranges and all those at the meeting agreed to April's suggestion. The volunteer participant teachers represented the spread of age ranges in the school and therefore they were all able to contribute to the discussion using their expert knowledge of the particular age range they taught.

\subsection{Volunteer participant teachers use children's work as evidence}

During the discussion the volunteer participant teachers talked about the various topics and art processes they had been using with their classes. Carol described a printmaking unit she had taught her class. In response to Carol's description, April said:

Didn't we have this discussion with our syndicate and we were saying how some things should not be done in the junior school? (April)

It seems that in a previous meeting it had been decided that certain visual art processes and procedures were not suitable for the junior classes and that April was under the impression that printmaking was one of those processes.

No, we were trying to work out how you could work out when to introduce things. But printmaking, I mean printmaking you can have a sponge with paint on and print in onto the paper. (Carol)

April and Carol clearly had a different opinion about when it was suitable to teach printmaking. April felt printmaking was unsuitable for Year 1 and 2 and that a decision had been made to exclude printmaking from the younger classes. April, who was responsible for visual art within the school and visual art whole-school planning, was questioning the visual art-work Carol was doing with her class. Although no-one was guiding the meeting, the dynamic of the discussion had clearly changed. April was talking in her role as teacher-in-charge of visual art.

Carol went on to make the point that printmaking was a broad field in visual art and a number of printmaking processes were ideally suited for Year 1 and Year 2 children. By coincidence, the meeting was taking place in Carol's teaching room and examples of children's art-work, including simple printmaking processes, were displayed on the walls. Carol used the children's art-work to demonstrate to the meeting how printmaking could be taught to Year 1 and Year 2 children. 
During this part of the meeting Carol was using the art-work produced by her class, to develop the volunteer participant teachers' understanding of some simple printing processes that could be used with younger children. She used her expertise and the children's work to help develop the other teachers' understanding of the teaching of visual art. April had the view that printmaking could not be taught to this age range, and that in her overall plan for visual art in the school printmaking processes would be taught to children who were older than Year 1 and 2. Carol questioned this view by demonstrating that certain printmaking techniques are ideally suited to Year 1 and 2 children and produced evidence to support her argument whereas April had no evidence to support her opinion. On the evidence provided by Carol, April conceded that printmaking could be taught to Year 1 and 2 children.

This exchange demonstrated that although April was responsible for the teaching of visual art in the school, she was open to the ideas and opinions of others. I felt the informal nature of the meeting had contributed to the fact that this discussion was able to take place. With the aid of the children's art-work as evidence, Carol felt safe in challenging the view of April and April was willing to listen to Carol's opinion and change her own view.

In section 1.10 I looked at the view of Talbert and McLaughlin (2002) who felt that teachers can support their own professionalism in collaborative teacher communities as they work together on common goals. The volunteer participant teachers were working on a common goal and were able to develop their confidence in the teaching of visual art within this environment. The meeting had provided the forum for this to happen. The open discussion about a self-assessment system for visual art had given Carol the opportunity to share information about a printmaking unit she had completed with her class.

\subsection{Volunteer participant teachers use analysis of the children's descriptions to develop their confidence}

The volunteer participant teachers considered the language children use to describe their art-work and the appropriate time to introduce children to art-specific language. They referred back to the analysis they had done of the transcripts. They made the point that one of the differences between the two descriptions was the language used by the teacher and the child. They emphasised that the younger children tended not to use art-specific terms. Carol also used the printmaking unit she had 
discussed earlier to make the point that there would be a variation in levels of ability, thus making it difficult to design a generic self assessment sheet.

...different levels, I mean printmaking with Year 1 and 2 is going to be completely different to printmaking in year seven and eight. (Carol)

Referring back to the evidence that Carol had presented, the volunteer participant teachers reached the conclusion that age would not exclude children from working in any visual art field. Having reached this conclusion they decided that a common element in the self-assessment sheets they were designing would be the various visual art fields. Having reached this decision the group disagreed about the appropriate time to introduce art-specific terms. When discussing this point April said:

...you could say it but I wouldn't expect them to use it, you know, like to be able to introduce it to them. (April)

Others in the meeting disagreed and felt that they should be introducing art-specific language at an early age:

...the sooner you start talking about it the better. And it's going to help them with their comments. (Carol)

Carol made the point that by introducing art-specific language at an early age the comments they wrote on their self-assessment sheets would have a commonality with the comments made by the classroom teacher. They concluded that it was important to introduce art-specific language to the children as early as possible, thus creating a common language between the teachers and children. They felt this common language would help the children to assess their art-work.

Again I felt the informal nature of the meeting had enabled this discussion to take place. The volunteer participant teachers who worked with the Year 1-3 children were able to share their expertise and understanding of this particular age range with the others at the meeting. Carol and Rebecca felt safe in sharing their views. They were able to develop this visual art self-assessment sheet using each other's expertise.

The format of the self-assessment sheets started to take shape as they decided on the common elements for each sheet and how each sheet would vary according to the ages of children who were going to use them. The main focus of the conversation on developing the self-assessment sheet was the use of art specific language and the difference in the age of the children and how that would effect the 
design on the self-assessment sheet. They did not consider the four strands used in the Arts curriculum to describe how children might work within the $\operatorname{arts}^{6}$. The structure of the Arts curriculum could have informed the development of a selfassessment sheet and it was unclear why they did not consider this aspect of the curriculum. One reason could be that all their discussions had focussed on art specific language and the age of the children and the role of the Arts curriculum in planning and assessment had not been fully considered.

Jo volunteered to develop some draft sheets from ideas they had discussed and bring them back to another meeting. Five weeks remained before the end of the academic year and in that time there were reports to write and other commitments associated with the end of a school year. They thought they could get a draft selfassessment sheet ready and trial it amongst themselves before the end of the year. Unfortunately the pressure of end-of-school-year commitments prevented this taking place, and the group decided to pick up the idea in the following year. Comparing this meeting with the previous meeting (see Chapter Eight), I felt the confidence of the volunteer participant teachers had developed enabling them to be more assured in the way they discussed their ideas. They were able to use more of their own expertise, and knowledge gained from the previous meeting.

\subsection{April's role enables volunteer participant teachers to develop their confidence in visual art teaching}

This meeting had enabled the participants to use the analysis of the teacher's and children's descriptions of the child's art-work to develop a school-wide selfassessment system for visual art. The atmosphere of the meeting had allowed a free exchange of ideas with no one individual dominating the discussion. Analysis of the children's descriptions had enabled them to realise the importance of the language used in the classroom by both the children and the teacher. In my observation of the meeting I concluded that April's ability to facilitate this meeting was a factor in allowing the participants to develop their confidence in the teaching of visual art. Her enthusiasm and skill was a factor in allowing the discussions to take place by encouraging effective collaboration. As mentioned in Chapter Seven I was concerned that with the absence of April the momentum and enthusiasm of the group of volunteer participant teachers would diminish.

6 The four strands are Developing Practical Knowledge, Developing Ideas, Communicating and Interpreting and Understanding in Context. 
The montage composition is now starting to develop a familiar range of elements. The group is non-hierarchical with all the volunteer participant teachers expressing their ideas. They are informed by both the knowledge they gained from their previous meeting and their analysis of the children's voices. It would now seem that the developing montage is indicating that teachers can develop their confidence in the teaching of visual art if they work in a non-hierarchical collaborative group on a common goal and analyse the voice and visual art work of children in their class. 


\section{CHAPTER TEN}

\section{Developing and sharing resources (informal setting)}

The meetings described in this chapter took place in the first term of the following academic year. April was now on maternity leave and the remainder of the meetings continued to take place in Carol's classroom being organised by either Catherine or Rebecca. In previous meetings organised by April the volunteer participant teachers had discussed the following:

- $\quad$ setting up a visual art resource room

- organising whole school professional development in visual art

- organising a school-wide art competition.

My concern had been that the momentum started by the enthusiasm of April would come to end as she was on maternity leave. I asked the volunteer participant teachers if they had been able to develop any of the ideas they had discussed in the previous year.

The central resource room had been set up and they were gradually filling it with a full range of art materials. They had started to gather and develop visual art teaching resources and said that was an ongoing project. The first professional development session had taken place and three more were planned and the exhibition/competition was still being looked at.

The majority of the ideas they had discussed in the previous year had been followed through, and in April's absence the teachers were still developing the area of visual art within the school. From their replies to my initial questions, they were all working towards a common goal and the absence of April had not stopped the momentum. Perhaps the momentum had reached a critical mass as the group carried on developing their ideas. The cycle of meetings had continued into the next academic year and the volunteer participant teachers were still working towards developing their confidence in the teaching of visual art. When I first met the volunteer participant teachers they had expressed a concern about the impact of this study on their workload. I felt at the time that perhaps teachers were reluctant to work on projects outside of their normal teaching duties if they had no input into the project or if they saw no immediate relevance to their own practice. The entire cycle of meetings had been controlled by the volunteer participant teachers where they had been able to develop their own confidence in a collaborative setting. None of the 
volunteer participant teachers had mentioned that time was an issue; perhaps time is less of an issue when teachers are able to implement their own ideas rather than the ideas of others to improve their classroom practice.

\subsection{Sharing resources}

This meeting followed the same format as the previous informal meetings; there was no set agenda and no one took the role of chair. The main theme of the discussion was the development of a visual art self-assessment system. Rebecca started the discussion as she shared a system she had been trialling with her class:

We are doing drawing this term so this is our unit that I...basically it's sort of ideas that they can all use in my team. This is just for my team. This is a weekly plan for them to fill in what they're going to do, I've given them some guidance here about how to progress through, I don't expect them to stick to it because everyone is a bit individual with art. They can fill in their own one and l've given them a troubleshooting sheet so things that are not working out ...why and what they can do about it. (Rebecca)

Rebecca had developed an assessment sheet that could be used to guide the children through a drawing unit. She had designed this student self-assessment sheet for all the classes in her syndicate. It seemed from the reaction of the teachers at this meeting that they had not seen this before. The following is a conversation between Catherine and Rebecca after Rebecca had shown the others at the meeting her assessment sheet.

Did you make that up? (Catherine)

No, I found it in a book. It's a useful thing though. (Rebecca)

I wouldn't mind a copy of that. (Catherine)

And there is also a sheet for following when you are looking at an artist's work. A guided way of critiquing somebody else's work. (Rebecca)

Catherine was obviously impressed by the sheet that Rebecca had developed and saw that she could use it in her teaching. Rebecca mentioned another sheet she had found which could help guide a child when critiquing an art-work. I asked her if she intended to use both of these tools in her classroom:

... they all get that package kind of thing. At the end of the session, at the end of the term they will all get their children to do a drawing of something and they will assess according to this. So this is our five point system, this being amazingly outstanding and this being not very good at all. So what l've done is taken each idea and progressed it so my drawing is a simple outline shape my drawing is the right shape, I have filled it in but not used many different kinds of lines right up to you know. (Rebecca)

Rebecca intended the self-assessment system to be used at the end of a unit with the children making judgements about certain aspects of their work. When the 
participants analysed the two transcripts, one of the similarities they found was the teacher and child identified the same areas in the art-work that could be improved upon. The children could therefore reflect upon their own work and use this reflection to make decisions about what to work on next. This would inform the teacher about areas to be included in future units of work. Rebecca's system required the children to rate aspects of their work, but not to offer any insight into what they would need to do to improve the work.

And you'll give them the learning intentions and like basically, most of these are success criteria? (Catherine)

Catherine made the connection between the use of the learning intentions for each lesson and how this could be linked to the success criteria of a self-assessment sheet. Catherine then went on to say that her syndicate were also going to focus on drawing that term.

When I'm taking art I tell them what it is we're looking for and the success criteria, this is what your picture could have and that is how they match them to that but I haven't got them to match the 1 to 5 . I mean, that would be the next step that I should actually be doing. (Catherine)

Catherine had picked up on the theme started by Rebecca but not questioned it; she was developing her own ideas but kept closely to Rebecca's original idea. Having seen that Rebecca is using a system of $1-5$ to assess various aspects of the child's work Catherine makes the assumption that this is the system she should be using. Perhaps Catherine lacked the confidence to develop the idea any further at this point because this was the first time she had seen the self-assessment sheet.

To be honest, this was really more with the teachers in mind than the children. (Rebecca)

Rebecca admits that when designing this system of assessment she was thinking about how the teacher would use it and not how the child would use it or what useful information both the child and the teacher would need from such a system. The understanding they had gained from analysing the transcripts had not influenced the way Rebecca viewed assessment; she came to it from the viewpoint of how the teacher would use the system. I had assumed that at the end of the meeting when the transcripts were analysed, the understanding they had developed would influence the way they viewed assessment, but the evidence did not support this.

Yes you could easily use it for a teacher as that was supposed to be but you'd have to do it more basic smiley face kind of, possibly one on one with the child. (Carol) 
Carol recognises that if this system were to be used across the whole school by all children, variations would have to be designed to cater for all ages. This topic had been discussed at the previous meeting and they had decided that they would need four assessment sheets for the whole school. No-one made any reference to the previous meeting and I wondered if April had been at this meeting whether she would have remembered their previous discussion.

\begin{abstract}
I think it's necessary to come up with some kind of assessment for art because of writing and report writing...eventually somewhere in the year you are going to have to come down yourself so you need something to follow, particularly if this is not your subject, you know, it's good to have a way of assessing the children. In the reports you see you have to use this 1 to 5 system in the report. (Catherine)
\end{abstract}

Catherine links assessment to the school report system; their report documents use a system of $1-5$ to denote attainment and they assume therefore that visual art should be assessed in this way. No-one at the meeting questioned this statement. They all agreed they would need some form of data that rated the art-work on a scale of 1 - 5 so they could complete the school report.

The discussion had taken an unexpected turn. I assumed they would discuss how they could use the voice of the child when assessing the child's art-work; instead they discussed how they could develop an assessment system that aligned itself with a report that was sent home to parents. The report system was not questioned and no-one referred to the analysis they had done of the two descriptions of the artwork. Perhaps it was the word assessment that got in the way? It seemed for these teachers assessment meant demonstrating where a child's work stood on a predetermined continuum. It did not include the child reflecting on their work.

I assumed, at the end of the previous year when the participants started to develop their self-assessment sheets, they would use the analysis of the two descriptions of the children's art-work to inform their self-assessment sheet design. It had been three months since the previous meeting and perhaps momentum from the previous year had been lost. Another reason for not referring back to the discussions they had in the previous meeting could be the absence of April. Perhaps she had been an important element in the way the participants worked together. During this meeting Catherine and Rebecca dominated the discussion. Perhaps Rebecca was taking on April's role? It was Rebecca who presented examples of self-assessment sheets and the other participants had accepted these examples. It was only Catherine who seemed to develop the ideas presented by Rebecca. Rebecca and Catherine were more experienced teachers in terms of the number of years they had been teaching. It could be that they were 
perceived by others at the meeting as experienced and therefore their ideas were not questioned. Whatever the reason, the dynamic of the group had changed and at that time more concern was being shown for the school report system than the understanding they had developed about the way the children viewed their art-work.

\subsection{Teachers develop shared resources}

The volunteer participant teachers trialled variations of the assessment sheets Rebecca had shown the meeting. Once trialled they met again and shared the various self-assessment sheets they had developed. This was the final volunteer participant teacher meeting I attended.

Catherine started the discussion by describing a new system she had introduced to her visual art lessons. Catherine provided the children in her class with a sketch book in which they could reflect upon the learning intentions of each visual art unit they had worked on. Each workbook contained a series of both visual and written responses (see Figure 15).

Each child has got a book and I get them to write the learning intention in, which was to achieve, to identify and use a variety of lines in a design, and then I just get them to do, yes, I can do that or, no, I can't do that and you can see, you can just visually see..... Oh here, this was the second part of it - my assessment is, yes I can do that now, six designs, two lines, so they had to do six designs using only two lines, he said he could do that and he hasn't assessed these but you can just see, I find the learning intention on the page and I like them to stick the motivation in ... (Catherine)

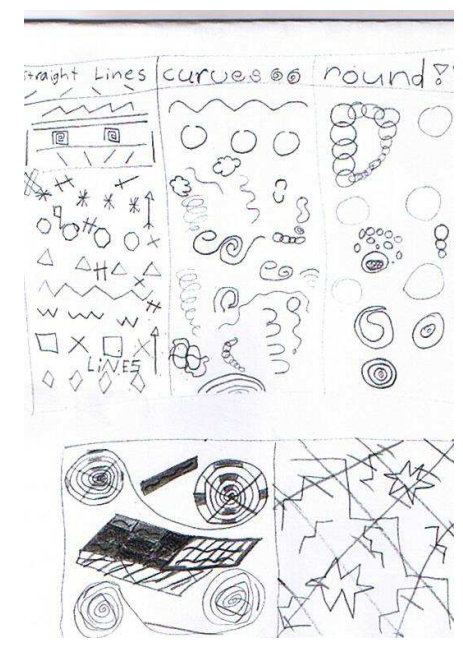

Figure 15: Example from a page Taken from one of Catherine's class workbooks

Catherine went on to describe a self-assessment system she had introduced to her class (see Figure 16). She had talked to the teachers in her syndicate and indicated that they would all being using this method of self-assessment with their classes. 
Student Rubric for Painting Unit

Year 5 and 6 Term 22006

\begin{tabular}{|c|c|c|c|c|c|}
\hline $\begin{array}{l}\text { Learning intentions } \\
\text { Students will: }\end{array}$ & $\begin{array}{l}1 . \\
\text { Not achieved }\end{array}$ & $\begin{array}{l}2 . \\
\text { Beginning }\end{array}$ & $\begin{array}{l}3 . \\
\text { Achieved }\end{array}$ & $\begin{array}{l}4 . \\
\text { Advanced }\end{array}$ & $\begin{array}{l}5 . \\
\text { Mastery }\end{array}$ \\
\hline $\begin{array}{l}\text { Experiment with } \\
\text { colour mixing and } \\
\text { using a variety of } \\
\text { techniques, tools } \\
\text { materials, } \\
\text { processes and } \\
\text { procedures to } \\
\text { create a painting }\end{array}$ & $\begin{array}{l}\text { I was not able to } \\
\text { talk about my work } \\
\text { I have not } \\
\text { completed any } \\
\text { paintings }\end{array}$ & $\begin{array}{l}\text { I understand some } \\
\text { of the techniques } \\
\text { and can use them } \\
\text { at times } \\
\text { I can talk about my } \\
\text { paintings a bit } \\
\text { I completed one } \\
\text { painting }\end{array}$ & $\begin{array}{l}\text { I am getting skilled } \\
\text { at using paints and } \\
\text { different brush } \\
\text { strokes } \\
\text { I can talk with } \\
\text { confidence about } \\
\text { my work, Is able to } \\
\text { speak with } \\
\text { increasing } \\
\text { confidence } \\
\text { Both paintings are } \\
\text { completed }\end{array}$ & $\begin{array}{l}\text { I can mix colours } \\
\text { well and use a lot } \\
\text { of different } \\
\text { brushstrokes with } \\
\text { confidence and } \\
\text { flair } \\
\text { I can discuss own } \\
\text { work with } \\
\text { confidence } \\
\text { My skills are } \\
\text { getting very good } \\
\text { Both paintings } \\
\text { were completed }\end{array}$ & $\begin{array}{l}\text { I can mix colours } \\
\text { well and use a lot } \\
\text { of different } \\
\text { brushstrokes with } \\
\text { confidence and } \\
\text { flair } \\
\text { I can discuss my } \\
\text { own work with } \\
\text { confidence. My } \\
\text { work shows skill, } \\
\text { creativity and the } \\
\text { Wow factor } \\
\text { Both paintings } \\
\text { were completed } \\
\text { and mounted } \\
\text { More attempted or } \\
\text { finished }\end{array}$ \\
\hline $\begin{array}{l}\text { Identify features } \\
\text { and techniques } \\
\text { from a range of } \\
\text { New Zealand } \\
\text { artists and use } \\
\text { these techniques } \\
\text { to produce our own } \\
\text { work }\end{array}$ & $\begin{array}{l}\text { I was not able to } \\
\text { identify any } \\
\text { features or } \\
\text { techniques of any } \\
\text { artist or use them }\end{array}$ & $\begin{array}{l}\text { I was able to } \\
\text { identify } 2 \text { features } \\
\text { of one artist and } \\
\text { used } 1 \text { in own work }\end{array}$ & $\begin{array}{l}\text { I was able to } \\
\text { identify } 2 \text { features } \\
\text { and techniques of } 2 \\
\mathrm{NZ} \text { artists and } \\
\text { used } 1 \text { in my own } \\
\text { work }\end{array}$ & $\begin{array}{l}\text { I was able to } \\
\text { identify more than } \\
2 \text { features and } \\
\text { techniques of } 2 \mathrm{NZ} \\
\text { artists and use } \\
\text { them in my own } \\
\text { work }\end{array}$ & $\begin{array}{l}\text { I was able to } \\
\text { identify } 3 \text { or } 4 \\
\text { features and } \\
\text { techniques of } 2 \mathrm{NZ} \\
\text { artists and use } \\
\text { them in my own } \\
\text { work with } \\
\text { confidence and } \\
\text { flair }\end{array}$ \\
\hline
\end{tabular}

Figure 16: Example of Self Assessment from Catherine's classes

\begin{tabular}{|c|c|c|c|c|c|}
\hline $\begin{array}{l}\text { Learning intentions } \\
\text { Students will: }\end{array}$ & $\begin{array}{l}1 . \\
\text { Not achieved }\end{array}$ & $\begin{array}{l}2 . \\
\text { Beginning }\end{array}$ & $\begin{array}{l}3 . \\
\text { Achieved }\end{array}$ & $\begin{array}{l}4 . \\
\text { Advanced }\end{array}$ & $\begin{array}{l}5 . \\
\text { Mastery }\end{array}$ \\
\hline $\begin{array}{l}\text { Experiment with } \\
\text { colour mixing and } \\
\text { use a variety of } \\
\text { techniques, tools, } \\
\text { materials, } \\
\text { processes and } \\
\text { procedures to } \\
\text { create a painting }\end{array}$ & $\begin{array}{l}\text { Work shows little } \\
\text { understanding of } \\
\text { taught elements } \\
\text { Is not able to } \\
\text { explain work } \\
\text { Work not } \\
\text { completed }\end{array}$ & $\begin{array}{l}\text { Work shows some } \\
\text { understanding of } \\
\text { taught elements } \\
\text { Is able to explain } \\
\text { some of own work } \\
\text { One painting } \\
\text { completed }\end{array}$ & $\begin{array}{l}\text { Shows an } \\
\text { understanding of } \\
\text { techniques and } \\
\text { some degree of } \\
\text { skill } \\
\text { Is able to speak } \\
\text { with increasing } \\
\text { confidence } \\
\text { Both paintings } \\
\text { completed }\end{array}$ & $\begin{array}{l}\text { Colours mixed and } \\
\text { used expressively } \\
\text { A wide variety of } \\
\text { techniques used } \\
\text { with confidence } \\
\text { and flair } \\
\text { Is able to discuss } \\
\text { own work with } \\
\text { confidence } \\
\text { Is gaining } \\
\text { proficiency of skill } \\
\text { Both paintings } \\
\text { completed }\end{array}$ & $\begin{array}{l}\text { Colours mixed and } \\
\text { used expressively } \\
\text { A wide variety of } \\
\text { techniques used } \\
\text { with confidence } \\
\text { and flair } \\
\text { Is able to discuss } \\
\text { own work with } \\
\text { confidence } \\
\text { Work shows skill, } \\
\text { creativity and } \\
\text { mastery } \\
\text { Both paintings } \\
\text { completed } \\
\text { More attempted or } \\
\text { finished }\end{array}$ \\
\hline $\begin{array}{l}\text { Identify features } \\
\text { and techniques } \\
\text { from a range of } \\
\text { New Zealand } \\
\text { artists and use } \\
\text { these techniques } \\
\text { to produce our own } \\
\text { work }\end{array}$ & $\begin{array}{l}\text { Was not able to } \\
\text { identify any } \\
\text { features or } \\
\text { techniques of any } \\
\text { artist or use them }\end{array}$ & $\begin{array}{l}\text { Was able to } \\
\text { identify } 2 \text { features } \\
\text { of one artist and } \\
\text { used } 1 \text { in own work }\end{array}$ & $\begin{array}{l}\text { Was able to } \\
\text { identify } 2 \text { features } \\
\text { and techniques of } 2 \\
\mathrm{NZ} \text { artists and } \\
\text { used } 1 \text { in own work }\end{array}$ & $\begin{array}{l}\text { Was able to } \\
\text { identify more than } \\
2 \text { features and } \\
\text { techniques of } 2 \mathrm{NZ} \\
\text { artists and use } \\
\text { them in own work }\end{array}$ & $\begin{array}{l}\text { Was able to } \\
\text { identify } 3 \text { or } 4 \\
\text { features and } \\
\text { techniques of } 2 \mathrm{NZ} \\
\text { artists and use } \\
\text { them in own work } \\
\text { with confidence } \\
\text { and flair }\end{array}$ \\
\hline
\end{tabular}

Figure 17: Example of teacher assessment from Catherine's classes 
Catherine had used a combination of the information she had gained from analysing the two descriptions of the children's art-work and the trial assessment sheet Rebecca had shown them during the previous meeting. This information helped her to develop a system of assessment that allowed the child to reflect on their own work. Having developed the self-assessment system she had passed this on to other members of her syndicate. Catherine was responsible for planning visual art units in her syndicate. She was now extending that role by developing a visual art self-assessment system and then passing this on to other members of the syndicate. Catherine went on to talk about the way the children used the system she had developed:

Kids don't actually mind doing these things. They actually think, oh yeah, well that's something, and then you'd probably look at, you'd probably say to them, what do you think your next step is, and they're quite honest....... and narrowing it down so that they can look at their work critically and say what is it about your work, and because they're older, as we knew, we found out last year, we know that the older children are more articulate and they can say what it is that they're working on or perhaps their next step. (Catherine)

Catherine referred back to the analysis of the children's descriptions of their artwork, using the knowledge she gained to design the self-assessment system, and then passed this on to other members of her syndicate. The confidence she gained within the confines of the group of volunteer participant teachers is now spreading through the school.

Carol had also developed a visual art self-assessment sheet (see Figure 18).

Art Painting Success Criteria

YEAR TWO WILF: What I am looking for

\begin{tabular}{l}
\hline I can add black and white to a colour to \\
make it darker or lighter. \\
I am able to point out tone (light and \\
dark) in art pieces. \\
$\begin{array}{l}\text { I have recreated art by an artist that I } \\
\text { can name. }\end{array}$ \\
\hline
\end{tabular}

Figure 18: Example of self-assessment from Carol

This is an art painting success criteria and it's just the year two WILF 'what l'm looking for' and so the children will read this, the child-friendly language of this - I can add black and white to a colour and make it darker or lighter, and if they agreed with that and they think that they've achieved that then they just colour in the smiley face. (Carol) 
Carol made the point that this sheet had been developed in collaboration with another teacher from her syndicate. She said she had been influenced by the analysis she had done of the descriptions of the art-work. Like Catherine, Carol was also using her developing confidence in the teaching of visual art to design a selfassessment sheet. Unlike Catherine she was working in collaboration with another member of her syndicate.

In my original semi-structured interview with Carol and Catherine they talked about the way their syndicates planned visual art units. Catherine talked about planning units on her own and Carol talked about planning together as a syndicate. It seems that Catherine and Carol work differently within the structure of their syndicate in areas other than unit planning. Carol developed her self-assessment ideas with her syndicate while Catherine developed her self-assessment ideas on her own.

Throughout the cycle of meetings the volunteer participant teachers have both developed their confidence in the teaching of visual art and influenced the way visual art was taught in the whole school. I had been concerned that April was the key factor in the way the group developed their ideas but in her absence the group was still able to use the confidence and knowledge they had developed in previous meetings. They were able to build upon this to inform their own practice and support other members of staff to develop their confidence.

It would seem that the emerging montage composition of this collaborative group of volunteer participant teachers is more reliant on the way they worked together rather than the individual members of the group. They were all able to share their ideas and question and reflect upon those ideas. The informality and freedom they had to work on their own ideas was powerful enough to keep the momentum of the group moving forward. They were implementing their own ideas and as a result their confidence in teaching visual art was improving. If it is the structure of the group which allows them to develop their confidence in the teaching of visual art then the elements within the school that support this structure are as important as the group.

Earlier in the study analysis of the school documents revealed that one of the arts strategic goals was for staff to be able to use a range of assessment tools. I felt that one of the reasons the principal had allowed me into the school was that he had recognised a shortfall in the ability of staff to assess visual art. He had also made it clear to staff that he wanted them to share their ideas in a more informally structured staff meeting. He had given April the responsibility of developing visual art within the 
school and April was able to develop her ideas with the support of the volunteer participant teachers. The volunteer participant teachers had started to develop their confidence in the teaching of visual art and now that confidence was being shared among other members of staff. Although the developing montage that describes the way the volunteer participant teachers were able to become confident in the teaching of visual art is becoming clear, the influence of the principal is re-emerging. 


\section{CHAPTER ELEVEN}

\section{Conclusion}

My original concern was the erosion of traditional support for primary school teachers in the teaching of visual art. This traditional support from School Support Services and the time allocated to the visual arts in pre-service teacher education are being reduced consequently the confidence of teachers in their ability to teach visual art is being threatened. Using the methodology of participatory action research the study focussed on a group of generalist primary teachers in a single primary school as they taught visual art. Participatory action research was used to enable those volunteer teacher participants to reflect upon their own practice and use that reflection to improve that practice. The five volunteer participant teachers worked as a non-hierarchical collaborative group to analyse the voices of the children in their school and reflect upon their own practice. Having analysed these voices they were able to make the connection between the importance of what is said to children during a lesson and the use of art-specific language. Reflecting on the common language used by the child and the teacher, led the teachers to design a visual art self-assessment system.

During the study the principal, the volunteer participant teachers and Mary, the provisionally registered teacher made reference to the importance of teaching visual art as a way of learning. In Chapter Two I looked at the development of visual art in New Zealand and its many changes since the late 19th century. The view that visual art is a way of learning and that the critical skills developed in visual art are transferable reflects the work of Gardner (1983) and Eisner (1972). The principal, volunteer participants and Mary could have been exposed to the theories of Gardner and Eisner during their own pre-service training or during subsequent professional development, and this would explain their view that of visual art as a way of learning.

The volunteer participant teachers linked practical expertise in visual art to confidence in teaching visual art, a view that reflects of the work of Tovey. As National Supervisor of Art and Craft Tovey, strove for twenty years from 1946 onwards to make visual art an integral part of the development of every child. To support his work he developed a comprehensive network of support for primary school teachers throughout New Zealand (see 2.4). Four of the volunteer teacher participants, the principal and Mary were products of the New Zealand education system. They would have experienced primary school classrooms where visual art 
teaching was rich and varied. As primary school teachers their view of visual art will in part be a reflection of their own experience as students in primary schools. The work of Tovey lives on through the views held by those involved in this study. The difference is that the level of traditional support is no longer in place.

Analysis of the data collected during this study revealed a complex system within the school that supported the teachers as they sought to develop their confidence in the teaching of visual art. The system can be divided into two distinct components: firstly, the school environment as described by the views of the principal, the volunteer participants and the goals set out in official school documents (see Chapter Four) that supported the volunteer participant teachers as they developed their confidence in the teaching of visual art; secondly the collaborative group of teachers as they developed their understanding of teaching visual art and as a result, their confidence in its teaching. Both components relied on each other to function efficiently. The collaborative group were able to work together partly because of the school environment, and the school environment was able to support other members of staff because of the confidence developed by the collaborative group.

\subsection{Sharing a common goal in a non-hierarchical group}

In Chapter One I looked at the work of Loewenberg Ball and Cohen (1999) who felt teachers could work in collaborative groups in order to develop an understanding of their practice. Although this view of collaborative groups has been challenged (see 1.7), the literature (Crebbin, 2004; Talbert \& McLaughlin, 2002) suggests the key to successful collaborative groups is that they work towards a common goal and are non-hierarchical. At the start of the project the volunteer participant teachers expressed a desire to develop their confidence in the teaching of visual art and this became their common goal. Throughout the project the focus of the volunteer participant teachers' discussions was centred on this goal.

The non-hierarchical nature of the group is not as clear-cut. April, the teacher-incharge of visual art, was given the responsibility of developing visual art within the school. This implies that her role created a hierarchical structure. A hierarchy within the group of participants could also be described by the varying expertise of the participants. April was seen as an 'expert' by Jo, and Carol had sought advice from Rebecca. The group of volunteer participant teachers had a range of expertise that could be shared and developed. It seems, therefore, from the evidence of this study 
that although there was a hierarchy of expertise, this was not translated into a hierarchical management structure. Shared responsibility was demonstrated by the fact that all the participants were able to share ideas and express their opinions. The group only became hierarchical when the volunteer participant teachers met in a formal setting, with April chairing the meeting and working from an agenda.

\subsection{Supporting collaborative groups}

I believe the volunteer participant teachers were an effective 'collaborative community' as described by Talbert and McLaughlin (2002). I also believe the school environment was an essential element in supporting this community. I have suggested the principal was in part responsible for developing an environment that enabled this kind of community to survive. In 1.10 I explained that Lieberman (1996) felt that in order to encourage collaborative communities, the following would need to be put in place:

- putting new and experienced teachers together to learn from each other

- creating common planning sessions to make connections across subject areas

- using staff expertise to provide leadership for in-house workshops.

The data from this project would certainly support Lieberman's view. April and the principal had encouraged those with expertise within visual art to share ideas. April had actively sought, and succeeded in developing, in-house workshops where staff shared their expertise. The participants met as a group to plan for the whole school. Both the principal and April were responsible for the planning sessions. The principal was indirectly responsible as he helped create an environment where these meetings could take place, and April was responsible for developing the meetings and for engendering enthusiasm among the other staff. I also suggested the principal was responsible for recognising April's enthusiastic personality and giving her a degree of responsibility, possibly knowing that her enthusiasm would help develop visual art within the school.

It is unclear from the evidence of the data whether the school environment described in Chapter Four had always supported a culture where ideas were shared openly between staff, thus encouraging a collaborative community. However, the participants did make the point that the principal wanted staff to share their expertise at staff meetings. If the principal was responsible for the development of this culture within the school, then the hierarchical structure of the principal making a decision and setting in place a train of events has resulted in an effective collaborative community. 
This interrelated system of support mechanisms only functioned when all elements were working. When a component was altered or disrupted its structure collapsed. This was clearly illustrated when the school was disrupted by building works. The environment established by the principal was changed physically causing the participants to become stressed and frustrated. They then viewed the principal differently, attributing his high expectations as the reasons for their stress.

In 3.3 I made a reference to the view of Hart (2000) who felt the potential for teachers to learn from each other's experiences would be lost if there were no formal structured opportunities to share these experiences. I believe a formal structure within the school enabled the volunteer participant teachers to work collaboratively. This structure gave them the opportunity to reflect upon their own analysis of the children's art work and analyse the children's view of their own work. This analysis then enabled them to develop their confidence in teaching visual art. The evidence of this study would therefore suggest the participants were able to develop their confidence in the teaching of visual art within a structured environment. It was the dynamic within the group that enabled them to share their individual experiences and expertise, and develop their own classroom practice, rather than any individual. I also believe that this confidence was starting to trickle down to other parts of the school beyond the original volunteer participant teachers. When Carol had developed her self-assessment sheet (see Figure 18) she had worked with another teacher from her syndicate. She had used her developing confidence to help another teacher in the school to develop their confidence. The dynamic of the collaborative groups was now influencing others within the school. This may also be an indication that the process of working collaboratively to develop confidence in the teaching of visual art is ongoing.

\subsection{Informal collaborative groups}

Hargreaves (1994) described a school's 'collaborative culture' as one that is informal, with teachers working together spontaneously to develop their own initiatives. It seems from the evidence of this study that the informality described by Hargreaves may only emerge if there is a degree of formality in the way the school is structured. However, within that structure the teachers are then able to develop their own initiatives. The evidence would also suggest that the spontaneity described by Hargreaves relies on the group being able to share and develop each other's ideas. The spontaneity of the discussions relies on the formality or structure of focussing on a collective goal. 
Timperley (2001) talks about the learning conversations that occur between teachers as they share responsibility and analyse problems in their school environments. It is these conversations, which are based on analysing evidence, that enable these groups to think about ways to improve their own practice. The volunteer teacher participants analysed the evidence of the children's descriptions of their art-work along with their own views of the same work. It was the conversations about their analysis that enabled the volunteer participant teachers to develop their confidence in the teaching of visual art.

At the beginning of this study the volunteer participant teachers wanted to develop their confidence in the way they assessed children's art-work. At the last informal meeting I attended they presented a range of visual art self-assessment tools to each other that they had trialled with the children. Meeting and working collaboratively had enabled them to gain a level of confidence in the teaching of visual art that in turn helped them to produce a range of assessment tools. Catherine's increased confidence, for example, enabled her to design a visual art self-assessment system, and then share her work with others in the group.

The task of developing their confidence in the teaching of visual art became a motivator for the volunteer participant teachers. They wanted to develop a selfassessment system for visual art and this motivation helped them develop their relationships with each other, and work as a collaborative group. Initially they reported back their findings from their analysis of theirs and the children's descriptions of the children's art-work, then reflected upon their own practice and developed their own confidence in the teaching of visual art. Timperley and Robinson (2002) talk about the relationship of the participants developing along with the task. This dynamic was demonstrated by the volunteer participant teachers as they were able to develop their own professional relationship. Once the volunteer participant teachers had developed their relationship they were not only able to analyse their own practice but also question the views and assumptions of others in the group.

Analysing the volunteer participant teacher meetings also highlighted a difference between the formal meeting (Chapter Six) and the informal meetings (Chapters Eight, Nine and Ten). During the formal meeting the discussion was controlled by April, who chaired the meeting and set the agenda. Although the volunteer participant teachers were able to express their ideas, the discussion was narrower than the discussion that occurred during the informal meetings. During the informal 
meetings the ideas expressed by the volunteer participant teachers were often informed by the ideas of others at the meeting making the discussion wide-ranging. The discussion at the formal meeting was solely centred on April's agenda. A further important difference between the two meetings was that the volunteer participant teachers were able to analyse and discuss the views of the children at the informal meeting and not at the formal meeting.

\subsection{Children's voices trigger development of teacher confidence}

The evidence of this study would suggest the catalyst that started the volunteer participant teachers' task of analysis, reflection and problem solving in order to develop their confidence in the teaching of visual art was their analysis of the children's descriptions of their art-work. The volunteer participant teachers' realisation that the children's insight into their own art-work was not only close to their own insights but at times more insightful, triggered a chain of events that led to the development of their own confidence in the teaching of visual-art. If the teachers had not analysed the voices of the children in their classes they may not have been able to develop their confidence in teaching visual art. The school supported the group and the task motivated the group but without listening to the voice of the children none of this process would have occurred.

\subsection{Action research process enables development of teacher confidence}

The action research process was another factor that enabled this collaborative group of volunteer participant teachers to develop their confidence in the teaching of visual art. They analysed the voices of the children, reflected upon that analysis, developed ideas from their reflections, trialled ideas, and then analysed the outcome of those ideas. As a participant observer I was able to observe this cycle. In Chapter Three I referred to the view of Herr and Anderson (2005) who made the point that action research is able to produce knowledge that is grounded in local realities and is useful to local participants. The reality of this study was that the volunteer participant teachers had expressed a desire to develop their confidence in the teaching of visual art and the action research process had provided them with a tool to address this desire. 
It seems therefore that the factors that enabled this group of volunteer participant teachers to develop their confidence in the teaching of visual art were:

- working in a non-hierarchical group

- analysing the voices of the children

- using the action research process.

I set out to discover how a group of primary school teachers worked to develop their confidence in the teaching of visual art. The evidence of the analysed data has shown that they were able to do this in a non-hierarchical collaborative group. This group was in turn supported by the structure of the school. The data also indicated a number of pre-requisites needed for this structure to work:

- a school-wide expectation that ideas can be shared openly

- a principal who supported the arts

- a common goal for the collaborative group

- a level of expertise among the staff that could be shared

- outside support for staff (in visual art)

- a teacher responsible for the development of visual art.

\subsection{An expectation that ideas could be shared openly}

The principal's expectation that staff openly share ideas was met as participants described how they shared ideas and expertise around the school. All the participants talked about the informal way they shared ideas and looked for support. Mary talked about going to members of staff for support and being supported by the principal in her request for professional development in the teaching of visual art.

It seems, therefore, that for a primary school to support the development of visual art teaching, the management of the school must first set in place an environment where ideas are shared openly. It also seems that within the school there must also be a degree of expertise in the teaching of visual art, for without that expertise, support within the school would not be available.

Having an environment where the participants shared their ideas openly also enabled the volunteer participant teachers to analyse the views of children in their classroom. It was April who realised that the children in her class had developed their expertise in visual art and had achieved the goals she had set them. The process of analysis enabled April to develop her understanding of the teaching of 
visual art through the reflections of children in her own class. Once she had developed this understanding she was able to pass this knowledge on to other teachers in an environment of collaboration. This environment also gave the teachers the opportunity to reflect upon the feedback given to them by children in their class. Without reflecting upon the views of the children in the school the volunteer participant teachers could not have developed the self-assessment system, and therefore their confidence in the teaching of visual art.

\subsection{Principal who supported visual art}

Evidence from the document search, semi-structured interviews with the participants and with the principal, all formed a picture of a principal who supported visual art within the school. When I asked April if she felt supported by the principal in her role as teacher in charge of visual art, she said:

I'm one hundred percent certain that l'll get support from ... because he's fantastic with the arts.

When I asked Mary about his support for her as she developed her confidence in the teaching of visual art, she said:

...the principal supports anything like that for professional development.

His support also allowed me to enter the school and allowed April to develop her ideas about the teaching of visual art. The support had allowed Mary to attend a course in visual art and develop her confidence in the teaching of visual art. Having developed this confidence the principal encouraged and supported her as she shared the knowledge she had gained with her colleagues. The principal's support of April had given her the confidence to fulfil her desire to develop visual art teaching within the school. It would seem, therefore, that the role of the principal was essential in enabling teachers within the school to develop their confidence in the teaching of visual art.

\subsection{Support for teachers outside the school}

Some of the volunteer participant teachers had developed their confidence in the teaching of visual art outside the school. This confidence had either come from the Ministry of Education or from private providers. They were able to use this expertise to support their colleagues. The participants talked about having gained experience in the use of visual art materials and processes and linked this to their confidence in teaching visual art. I believe the evidence of the teachers' descriptions of the 
children's art-works also indicated that the teachers who were confident in teaching visual art were also confident in the way they assessed the children's art-works. It would seem there is a role for professional development provided by outside 'experts'. This does not have to be for all members of staff as evidence from this study has shown that confidence in the teaching of visual art can develop using the support of staff 'experts' within the school.

\subsection{Pivotal role of teacher responsible for visual art}

April was the teacher responsible for the development of visual art within the school and having a teacher assigned to this role enabled the participants to focus on a range of ideas developed by her. She was pivotal in enabling the participants to develop their understanding of the teaching of visual art. She used her enthusiasm and expertise to include all the participants in the process of developing visual art within the school.

\subsection{Compensating for diminishing support in visual art}

Before starting this study my concern was that diminishing support for primary school teachers in the teaching of visual art would result in an increased lack of confidence in their ability to teach it. I had not been able to find any New Zealand literature that either offered any solutions to this problem or studies that looked at ways in which teachers could develop their confidence in the teaching of visual art without the traditional forms of support. The evidence of this study has shown that it is possible for a group of primary school teachers to develop their confidence in the teaching of visual art by working together in an informal collaborative group.

Once the volunteer participant teachers had developed their confidence they were able to develop the confidence of other teachers within the school in the teaching of visual art. In 1.1 I referred to the findings of the Ministry of Education's curriculum stock-take (McGee et al., 2003) that found $72.2 \%$ of teachers questioned felt the most important source of curriculum support came from their own colleagues. If this is the case, then confidence in the teaching of visual art can be developed in schools using key members of staff.

When the principal described the school appraisal system, he likened this to a system of mentoring from outside the school and of expertise leadership from within the school. This study has shown that under the right conditions, experts within a 
school can develop both their own confidence in the teaching of visual art and that of other members of staff.

Mentoring from outside the school could be performed by School Support Services. Professional development could be targeted and support offered to the key members of staff. Key members of staff from a number of primary schools could form their own support network in clusters of schools and School Support Services could offer professional development to the cluster. The role of the school experts would then be to develop their colleagues' confidence in the teaching of visual art within their own schools. For this model to work, the school experts would need the skills to develop workshops within their own schools, knowing they had the full support of their principal.

I am sure this school is not unique in the way its culture has enabled the participants to work together. If this is the case, the question arises about how rare or common this culture is. If this culture is common then the model I have suggested could be developed on a large scale. If the culture is rare, then support would need to be given to schools to help them develop such a culture.

During my first meeting with the volunteer participant teachers they expressed concern about increasing their workload by taking part in this study. The principal had also talked about the reluctance of teachers to take on extra responsibility because of the increase in their workload. At the time I felt the workload issue was perhaps related to the direct input teachers could have on the project they worked on and its benefits to their teaching. Over a period of 11 months, covering two academic years, the volunteer participant teachers met and worked as a collaborative group. All the meetings, and the work on developing a visual art selfassessment system took place in the teachers' own time, and none of them mentioned workload as an issue. I would suggest that the control they had over the project and the direct benefit the project had on their own classroom practice eliminated the workload issue.

\subsection{Gaps in the composition}

The narrow focus of this study has resulted in some gaps in the developing montage. The motivation of the volunteer participants to develop their knowledge of visual art processes and materials was not fully explored in this study. Although the participants talked about having always being interested in visual art, the data do not 
indicate why they had always been interested in visual art. Was it the influence of family, education, culture or a pre-disposition?

Another area not explored in depth in this study concerned the pressures and tensions the principal and teachers touched upon in Chapter Four. Was the tension between the principal, the Ministry of Education, the Board of Trustees and parents the key element in creating tension between the staff and the principal or was it merely the disruption caused by the building works?

Although the volunteer participant teachers developed their confidence in the teaching of visual art they did change the focus of their discussions over the series of meetings I observed. Initially the focus of the discussions was their analysis of the children's voices and the implications of that analysis on a potential self-assessment system. When they started to develop the self-assessment system they focussed on the school report system rather than the voice of the child. They all talked about the similarities of their's and the child's descriptions of the child's art-work, as shown below:

I do think many of mine have picked up on the same kinds of things that I had. (Carol)

I did find quite a few similarities which I was pleased about, almost relieved in a way, and I was pleased that they picked up on... (April)

And if they know what they are trying to achieve, and they know how they are going to go about getting there, then they can judge their work themselves. (Catherine)

Catherine makes the point that the children '..can judge their work themselves' and yet ironically in later meetings designs a system that focuses on a rubric that is related to the school reporting system. Perhaps for these volunteer participant teachers the pressure to conform to a school report system was stronger than the knowledge they had gained in their earlier meetings. They had talked about the pressure of management expectations.

And we are reminded of expectations of the community a lot. (Volunteer teacher participant)

It filters down. (Volunteer teacher participant)

In my view the use of the child's voice as an assessment tool would certainly enhance a school reporting system. The volunteer participant teachers did not follow through with their initial findings and develop them and it is unclear why they did not. Although they did develop their confidence in the teaching of visual art, they moved in a direction that I had not foreseen. It may have been the absence of April or the 
pressure they felt from the school management or it may have been the lack of an external voice to add another dimension to their discussion. An external voice could have refocused the group and enabled them to use the voice of the child in their self-assessment system.

The narrow focus of this study made it difficult to answer these questions. The limited timeframe of the study also meant it was impossible to know if the volunteer participant teachers were able to sustain their collaborative working relationship. And the question also remains of what would happen if members of the group changed? Using the metaphor of a developing montage the emphasis is clearly on the word developing. The montage is only as good as the data available and as such still needs data to fill in the gaps.

\subsection{Need for further research}

These gaps in the montage and unanswered questions highlight the need for further research. There is a need to research the influences on primary teachers' attitudes to visual art. Why are some teachers pre-disposed to developing their understanding of visual art processes and materials while others find it difficult? Answering these questions would provide vital data that would support teachers and enable them to develop their confidence in the teaching of visual art.

There is also a need to find out if collaborative groups of teachers are sustainable over a longer period of time, especially when group members change. If these groups are sustainable, no matter whom the members are, then evidence from research may offer answers to enable schools to develop such groups. In New Zealand, Robinson et al. (1995) investigated the dynamic of the principal, the Ministry of Education and community in their study of schools in Mangere and Otara as they worked to improve the schools and schooling. From their evidence it seems tensions occurred between various groups when a common understanding of the task either did not exist or was unclear. The evidence from this study would suggest that the volunteer participant teachers had a common goal, but it was unclear if there was a common understanding of expectations between the principal, community, Board of Trustees and the teachers. Further research would need to be done to establish whether a common understanding of expectations between the various groups involved in managing a school can lead to an environment where expectations of teachers do not create tension. 


\section{13 Recommendation}

Based on the evidence of this study I would recommend that a small group of schools with a similar culture to the school in this study be identified, and a programme of developing the expertise of key members of staff in the use of visual art materials and processes undertaken. The volunteer participant teachers had identified their own experiences in the use of visual art materials as contributing to their confidence in teaching visual art. Developing their experiences in the use of visual art materials could be undertaken by either School Support Services or another provider.

Having analysed the children's voices the volunteer participant teachers were able to develop generic self-assessment system for visual art. In the early stages of the study they had expressed a desire to specifically develop their expertise in the assessment of visual art. Through a series of reflection and action within the action research cycle they were able to reach their goal. I would recommend therefore that the focus of each group of experts would be to work collaboratively within their school to reflect upon their own practice through the analysis of the voices of the children they teach. The evidence of the study showed that it was when the volunteer participant teachers analysed the voices of students that they began to further develop their confidence in the teaching of visual art.

This group, supported by School Support Services, could then develop the confidence of colleagues within their own school in the teaching of visual art through a series of inhouse workshops. Once the confidence of staff within each school had been developed, each school could act as a centre of excellence within the area of visual art and work to develop the confidence of other schools within its geographical area. Incentives could be given to schools to develop such a professional development model. The range of incentives could include enhanced visual art facilities and time to enable staff to develop their confidence in the teaching of visual art.

This recommendation pre-supposes that visual art is a sufficiently important subject to support in New Zealand primary schools. The literature (Atkinson \& Dash, 2005; Collinge, 1978; Eisner, 1972; Grierson, 2003; Hickman, 2000; Mansfield, 2003; Taylor, 1992; Thistlewood, 1990) points to visual art being an important element in helping children to develop. In New Zealand, in 2004, the Ministry of Education commissioned Chris Holland and Dr Peter O'Connor to research effective teaching in the arts. Their final report (Holland \& O'Connor, 2004) made the point that children learn through the arts in an environment in which critical thinking and deeper understanding about their 
lives occurs. The evidence would suggest that visual art is a vital element in the development of children and a key curriculum area in primary schools.

It seems the importance of visual art in New Zealand classrooms is well documented. Perhaps it is now time to support that importance in an organised and sustainable way by providing primary schools with a structure where they can develop their confidence in the teaching of visual art. 


\section{References}

Andrews, B. (2006). Re-play: Re-assessing the effectiveness of an arts partnership. Canadian Teacher Education: Review of Education, 52, 443-459.

Apple, M. W. (1986). Teachers and texts. London: Routledge.

Atkinson, D., \& Dash, P. (2005). Introduction to art in education: Critical and social practice. In D. Atkinson \& P. Dash (Eds.), Social and critical practices in art education (pp. xi-xviii). Stoke on Trent, U.K: Trentham Books.

Ball, T., Russell, B., \& Smales, J. (2005). Facing the realities of being a beginning teacher. In P. Adams, K. Vossler \& C. Scrivens (Eds.), Teachers' work in Aotearoa New Zealand (pp. 279-295). Southbank, Victoria: Dunmore Press.

Barth, R. (1990). Improving schools from within. San Francisco: Jossey-Bass Publishers.

Birch, M., \& Miller, T. (2002). Encouraging participation: Ethics and responsibilities. In M. Mauthner, M. Birch, J. Jessop \& T. Miller (Eds.), Ethics in qualitative research (91-106). Thousand Oaks: Sage Publications.

Bishop, R., \& Glynn, T. (1999). Culture counts: Changing power relations in education. Palmerston North: Dunmore Press.

Blase, J., \& Anderson, G. (1995). The micropolitics of educational leadership: From control to empowerment. London \& New York: Cassell.

Bloomfield, A. (2000). Teaching integrated arts in the primary school: Dance, drama, music and the visual arts. London: David Fulton.

Bogdan, R., \& Biklen, S. (2007). Qualitative research for education: An introduction to theories and method ( $5^{\text {th }}$ ed.). Boston: Pearson.

Bracey, T. (2003). Art education in New Zealand: Questions of theory and criticality. In E. Grierson \& J. Mansfield (Eds.), The arts in education: Critical perspectives from Aotearoa New Zealand (181-198). Palmerston North: Dunmore Press.

Bresler, L. (1994). Zooming in on the qualitative paradigm in art education: Educational criticism, ethnography, and action research. Visual Arts Research, 20(1), 1-19.

Bresler, M. (1996). Traditions and change across the arts: Case studies of arts curriculum. International Journal of Music Education, 27(1), 24-35.

Bryant, A. \& Charmaz, K. (2007). Introduction Grounded Theory Research: Methods and Practices. In A. Bryant \& K. Charmaz (Eds.), The Sage handbook of Grounded Theory (pp. 1-28)). Los Angeles, London, New Delhi, Singapore: Sage publications.

Callaway, G., \& Kear, M. (2000). Improving teaching and learning in the arts. London: Falmer Press.

Cardno, C. (2003). Action research: A developmental approach (pp. 56-57). Wellington: NZCER. 
Chalmers, F. G. (1990). South Kensington in the Farthest Colony. In D. Soucy and M. Stankiewcz. (Eds). Framing the Past: Essays on Art Education (71-85). Reston V.A. : National Art Education Association.

Chalmers,F. G. (1999). Cultural Colonialism and Art Education. Eurocentric and Racist Roots of Art Education. In D. Boughton and R. Mason. (Eds). Beyond Multicultural Art Education: International Perspectives (173-183). New York; Waxmann Publishing.

Cherryholmes, C. (1988). Power and criticisms: Poststructural investigations in education. New York: Teachers College, Columbia University.

Cohen, L., Manion, L., \& Morrison, K. (2001). Research methods in education ( $5^{\text {th }}$ ed., pp. 53-56). London \& New York: Routledge / Falmer.

Collinge, J. (1978). A background. In Art in schools: The New Zealand experience. Wellington, New Zealand: Department of Education.

Collins English Dictionary: Desktop edition. (2004). London: Collins.

Crebbin, W. (2004). Quality teaching and learning: Challenging orthodoxies. New York: Peter Lang Publishers.

Davis, H.J. (2005). Framing education as art: The octopus has a good day. New York: Teachers' College Press.

Day, C., Hall, C., Gammage, P., \& Coles, M. (1993). Leadership and curriculum in the primary school. London: Paul Chapman.

Deleuze, G. (1983). (H. Tomlinson trans.). Nietzche and philosophy. New York: Columbia University Press.

Department of Education. (1945). An Art Scheme for Primary School. Wellington: Schools Publications Branch.

Denscombe, M. (2005). The good research guide for small scale research $\left(2^{\text {nd }}\right.$ ed., pp. 89-92). Maidenhead \& Philadelphia: Open University Press.

Denzin, N.K., \& Lincoln, Y.S. (2005). Introduction: The discipline and practice of qualitative research. In N.K. Denzin \& Y.S. Lincoln (Eds.), Handbook of qualitative research (pp. 1-18). London: Sage Publications.

Dewey, J. (1934). Art as experience. New York: Minton, Balch.

Donaghy, A. (2003, August). Curriculum stocktake: National school sampling study. Teachers' experiences in curriculum implementation: The arts and health and physical education. New Zealand: Ministry of Education.

Dorn, C. M. (1999). Mind in art cognitive foundations in art education (pp. 254-255). New Jersey \& London: LEA Publishers.

Durrheim, K. (2006). Research Design. In M. Blanche, K. Durrheim \& D. Painter (Eds.). Research in Practice. Applied Methods for the Social; Sciences (3 ${ }^{\text {rd }}$ ed.). Cape Town: University of Cape Town Press. 
Eby, J., Herrell, A.L., \& Hicks, J. (2001). Reflective planning, teaching, and evaluation; K-12 ( $2^{\text {nd }}$ ed. $)$. Englewood Cliffs, NJ: Prentice Hall.

Efland, A. (2002). Art and cognition: Integrating the visual arts in the curriculum. New York, London: Teachers' College Press.

Eisner, E. (1982). Cognition and curriculum: A basis for deciding what to teach. New York: Longman.

Eisner, E. (1988). Discipline-based art education: Its criticisms and its critics. Art Education, 41(6), 7-13.

Eisner, E. (1998). Does experience in the arts boost academic achievement? Art Education, 51(1), 7-15.

Eisner, E. (2002). The arts and the creation of mind. Yale: Yale University Press.

Eisner, E.W. (1972). Educating artistic vision. New York: Longman.

Elliott, J. (1991). Action research for educational change. Buckinghamshire: Open University Press.

Feldman, E. (1996). Philosophy of art education. New Jersey: Prentice Hall.

Fiske, E. (Ed.). (1999). Champions of change: The impact of the arts on learning. Washington, DC: Arts Education Partnership.

Flood, A. (2004). Communicating in the 21st century. Australian Art Education, 27.

Gall, M., Borg, W., \& Gall, J. (1996). Educational research: An introduction (6 ${ }^{\text {th }}$ ed., pp.574-575). New York: Longman Publishers.

Gardner, H. (1983). Frames of mind: The theory of multiple intelligences. New York: Basic Books.

Gardner, H. (1996). The assessment of student learning in the arts. In D. Boughton, E. Eisner \& J. Ligtvoet (Eds.), Evaluating and assessing the visual arts in education (pp.131-155). New York \& London: Teachers College Press.

Ghaye, A., \& Ghaye, K. (1998). Teaching and learning through critical reflective practice. Philadelphia: Taylor \& Francis.

Gipps, C. (1994). Beyond testing: Towards a theory of educational assessment (p. 128). London, Washington: The Falmer Press.

Gipps, C., McCallum, B., \& Hargreaves, E. (2000). What makes a good primary school teacher? Expert classroom strategies. London, New York: Routledge Falmer.

Goethals, M.S., Howard, R.A., \& Sanders, M.M. (2003). Student teaching: A process approach to reflective practice $\left(2^{\text {nd }}\right.$ ed.). Englewood Cliffs, NJ: Prentice Hall.

Goldberg, M. (2006). Integrating the arts: An approach to teaching and learning in multicultural and multilingual settings. Boston: Pearson Education.

Grierson, E. (2003). Framing the arts in education: What is really at stake? In E. Grierson, \& J. Mansfield (Eds.), The arts in education: Critical perspectives from Aotearoa New Zealand (93-117). Palmerston North: Dunmore Press. 
Griffin, G. (1991). Interactive staff development: Using what we know. In A. Lieberman \& L. Miller (Ed.), Staff development for education in the '90s: New demands, new realities, new perspectives ( $2^{\text {nd }}$ ed., pp. 250-251). New York: Teachers' College Press.

Guskey, T.R. (2000). Evaluating professional development. Thousand Oaks, CA: Corwin Press.

Hammersley, M., \& Atkinson, P. (1995). Ethnography: Principles in practice $\left(2^{\text {nd }}\right.$ ed.). London: Routledge.

Hargreaves, A. (1994). Changing teachers, changing times: Teachers' work and culture in the postmodern age. London: Cassell.

Hart, S. (2000). Thinking through teaching: A framework for enhancing participation and learning. London: David Fulton Publishers.

Herr, K., \& Anderson, G. (2005). The action research dissertation: A guide for students and faculty. Thousand Oaks: Sage Publications.

Hickman, R. (2000). Art education 11 - 19: Meaning, purpose and direction. New York: Continuum.

Hickman, R. (2005). A short history of 'critical studies' in art and design education. In R. Hickman (Ed.), Critical studies in art and design education (19-29). Bristol, UK: Intellect Books.

Holland, C., \& O'Connor, P. (2004). Like writing off the paper: Report on student learning in the arts. (Report to the Ministry of Education). Wellington: Ministry of Education Research Division.

Holton, J. (2007). The Coding Process and Its Challenges. In A. Bryant \& K. Charmaz (Eds.), The Sage handbook of Grounded Theory (pp. 265-289). Los Angeles, London, New Delhi, Singapore: Sage publications.

Huberman, M. (1993). The model of the independent artisan teachers' professional relations. In J.W. Little \& M.W. McLaughlin (Eds.), Teacher's work: Individuals, colleagues and, contexts (pp.11-50). New York: Teachers' College Press.

Hudson, S. (2005). Exploring first-year pre service teachers' confidence to teach art education. Paper presented at AARE Conference. Paramatta.

Johnson, N. (1999). Meeting the Challenge: Becoming learning communities. In J. Retallick, B. Cocklin \& K. Coombe (Eds.), Learning communities in education (pp. 26-43). New York, London: Routledge.

Kauchak, D., \& Eggen, P. (2005). Introduction to teaching: Becoming a professional $\left(2^{\text {nd }}\right.$ ed.). Upper Saddle River, NJ: Pearson Education.

Kelly, K. (2006). From encounter to text: collecting data in qualitative research. In M. Blanche, K. Durrheim \& D. Painter (Eds.). Research in Practice. Applied Methods for the Social; Sciences $\left(3^{r d}\right.$ ed.). Cape Town: University of Cape Town Press.

Kemmis, S., \& McTaggart, R. (2000). Participatory action research. In N. Denzin \& Y. Lincoln (Eds.), Handbook of qualitative research ( $2^{\text {nd }}$ ed. Pp.567-605). Thousand Oaks: Sage Publications. 
Kemmis, S., \& McTaggart, R. (2005). Participatory action research. In N. Denzin \& Y. Lincoln (Eds.), Handbook of qualitative research ( $3^{\text {rd }}$ ed. Pp. 559-603). Thousand Oaks: Sage Publications.

Kemmis, S., \& McTaggart, R. (Eds). (1988). The action research planner ( ${ }^{\text {rd }}$ ed.). Victoria: Deakin University Press.

Kottler, J., Zehm, S., \& Kottler, E. (2005). On being a teacher: The human dimension $\left(3^{\text {rd }}\right.$ ed.). Thousand Oaks, California: Corwin Press.

Lally, V. and Scaife, J. (1995). Towards a Collaborative Approach to Teacher Empowerment. British Educational Research Journal, Vol. 21, No. 3, 323-338.

LeMoine, A. (2001). Beyond the unit: Assessment and the learning cycle. In G. Burnaford, A. Aprill \& C. Weiss (Eds.), Renaissance in the classroom: Arts integration and meaningful learning (pp.85-114). Mahwah, New Jersey, London: Lawrence Erlbaum Associates.

Leonard, P. E. and Leonard, L. J. (2001). The collaborative prescription: remedy or reverie? International Journal of Leadership in Education; (4), p383-399.

Lieberman, A. (1996). Practices that support teacher development: Transforming conceptions of professional learning. In M. McLaughlin \& I. Oberman (Eds.), Teacher learning: New policies, new practices (pp.185-201) New York: Teachers College Press.

Loewenberg Ball, D., \& Cohen, D. (1999). Developing practice, developing practitioners: Towards a practice-based theory of professional education. In L. Darling-Hammond \& G. Sykes (Eds.), Teaching as the learning profession: Handbook of policy and practice (pp3-32). San Francisco: Jossey-Bass Publishers.

Lowenfeld, V. (1947). Creative and mental growth. New York: Macmillan.

Lundeberg, M., Bergland, M., Klyczek, K. and Hoffman, D. (2003) Using Action Research to Develop Preservice Teachers' Confidence, Knowledge and Beliefs about Technology. The Journalof Interactive Online Learning. 1, (4), pp 1-16.

Madoff, S. (2007). School is out: Rethinking art education today. In R. Tatley (Ed.), Modern painters (September 2007) (74-79). New York: LTB.

Mansfield, J. (2003). Beyond the 'beauty full' classroom: The arts curriculum and teacher education in the postmodern context. In E. Grierson \& J. Mansfield (Eds), The arts in education: Critical perspectives from Aotearoa New Zealand (63-79). Palmerston North: Dunmore Press.

Mason, J. (1996). Qualitative researching. London: SAGE Publications.

McGee, C. Harlow, A., Miller, T., Cowie, B., Hill, M., Jones, A., \& Donaghy, A. (2003). Curriculum stocktake: National School Sampling Study. Teachers' experiences in curriculum implementation: General curriculum, the art, and health and physical education. The University of Waikato.

McGee, C., Harlow, A., Miller, T., Cowie, B., Hill, M., Jones, A. \& Griffin, G. (1991). Interactive staff development: Using what we know In A. Lieberman \& L. Miller (Ed.), Staff development for education in the '90s: New demands, new 
realities, new perspectives (2 ${ }^{\text {nd }}$ ed. pp. 250-251).. New York: Teachers' College Press.

McKernan, T. (1991). Curriculum action research. London: Kogan Page.

McLaughlin, M., \& Talbert, J. (2006). Building school-based teacher learning communities: Professional strategies to improve student achievement. New York: Teacher College Press.

Ministry of Education. (1989). Art education: Junior classes to form 7, syllabus for schools (p.5). Wellington: Learning Media.

Ministry of Education. (1993). The New Zealand curriculum framework (pp. 7 \& 19). Wellington: Learning Media.

Ministry of Education. (2000). The arts in the New Zealand curriculum (pp. 7, 71-72, 74-75 \& 89). Wellington: Learning Media.

Morse, J. And Richards, L. (2002). Readme First for a User's Guide to Qualitative Methods. Thousand Oaks, London: Sage publications.

Murphy, C., Peter, N. and Beggs, J. (2007). Primary science teacher confidence revisited: ten years on. Educational Research, 49 (4), 415-430.

Naughton, C. (2007). Creative arts as a service industry. Paper presented at the 2007 Philosophy of Education Society of Australasia, Wellington, New Zealand.

O'Neill, J. (2005). Reshaping teachers' work to serve the global economy. In P. Adams, K. Vossler \& C. Scrivvens (Eds.), Teachers work in Aotearoa New Zealand (pp.51-59). Victoria: Dunmore Press.

Oja, S., \& Smulyan, L. (1989). Collaborative action research: A developmental approach (pp. 177-179). London: The Falmer Press.

Piaget, J. (1970). Piaget's theory. In P.H. Mussen (Ed.), Carmichael's manual of child psychology (Vol. 1). New York: Wiley.

Read, H. (1943). Education through art. New York: Pantheon Books.

Retalick, J., \& Butt, R. (2004). Professional well-being and learning: A study of teacherpeer workplace relationships. Journal of Educational Inquiry, 5(1), 85-99.

Robinson, V.M.J., Halliday, J., \& Timperley, H. (1995). How schools solve complex problems. Report of Phase 2: Organisational learning for self managing schools. (Report to the Ministry of Education). Wellington: Research and Statistics Division, Ministry of Education.

Ross, M., Radnor, H., Mitchell, S., \& Brierton. C. (1993). Assessing achievement in the arts. Buckingham, Philadelphia: Open University Press.

Ryan, G. And Bernard, R. ( 2003). Data Management and Analysis Mehtods. In N. Denzin \& Y. Lincoln (Eds.) Collecting and Interpreting Qualitative Materials (pp. 259-309). Thousand Oaks, London: Sage publications.

Sanchez-Janowski, M. (2002). Representation, responsibility and reliability in participant-observation. In T. May (Ed.), Qualitative research in action (pp.144145). Thousand Oaks: Sage. 
Shifrin, S. (2007). Visual literacy in North American secondary schools: Arts-centred learning, the classroom, and visual literacy. In J. Elkins (Ed.), Visual literacy. New York, London: Routledge.

Silverman, D. (2005). Doing qualitative research $\left(2^{\text {nd }}\right.$ ed.). London: SAGE Publications.

Speck, M., \& Knipe, C. (2005). Why can't we get it right? Designing high-quality professional development for standards-based schools ( $2^{\text {nd }}$ ed., pp. 68-69). Thousand Oaks California: Corwin Press.

Talbert, J., \& McLaughlin, M. (2002). Professional communities and the artisan model of teaching. Teachers and Teaching: Theory and Practice, 8(3/4).

Taylor, R. (1992). Visual art in education. London: Falmer Press.

Thistlewood, D. (1990). Issues in design education. London: Longman.

Thorpe, K. (2007). Essential creativity in the classroom: Inspiring kids (p. 75). London \& New York: Routledge.

Thurber, F. (2004). Teacher Education as a Field of Study in Art Education: A Comprehensive Overview of Methodology and Methods Used in Research About Art Teacher Education. In E. Eisner and M. Day (Eds). Handbook of Research and Policy in Art Education.(pp. 487-522). New Jersey, London: Lawrence Erlbaum Associates.

Timperley, H. (2001). Mentoring conversations designed to promote student teacher learning. Asia-Pacific Journal of Teacher Education, 29(2).

Timperley, H., \& Robinson, V. (2002). Partnership: Focusing the relationship on the task of school improvement. Wellington: NZCER.

Winter, R. (1989). Action research and the nature of social inquiry: Professional innovation and educational work. Aldershot: Gower.

Wolf, D. (1989). Artistic learning as conversation. In D. Hargreaves (Ed.), Children and the arts. Milton Keynes, Philadelphia: Open University Press.

Zuber-Skerritt, O. (1992). New directions in action research. London, Washington: The Falmer Press. 


\section{Appendix A}

VICTORIA UNIVERSITY OF WELLINGTON

Te Whare Wananga o te Upoko o te Ika a Maui

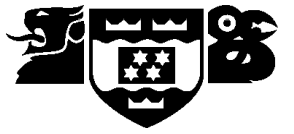

School of Education Studies

Te Kura Akoranga Matauranga

\section{Developing primary school teachers' confidence in the teaching of visual art}

To

Principal of

School.

Kia ora

My name is lan Bowell. I am a Masters student at Victoria University of Wellington. For the thesis component of my degree I would like to research the way that primary school teachers can develop their confidence in the teaching of visual art.

I have had a long involvement in the visual art education both at primary and secondary level. My recent work within the area of in-service training in the primary sector for the arts curriculum has led me to believe that far more in-service work can be achieved by the staff within schools rather than using outside expertise. As part of the curriculum stock-take report to the Minister of Education in 2002, $90.5 \%$ of the respondents in a national sampling study felt that they needed more professional development in the arts. There is little research in New Zealand relating to alternative ways of developing confidence in the teaching of visual art.

My intention is to analyse, with four teacher co-researchers, the way teachers and children view the child's art-work. The research will focus on how the four participating teachers work collaboratively to develop their confidence in the teaching of visual art, using the child's view of their own work as a framework.

Your school has been recommended to me by the primary arts advisors as one that has strength in the teaching of the arts curriculum area.

If you agree to participate this will mean that:

- I will both observe visual art lessons and work with the volunteer coresearchers;

- I will interview selected children about their artwork;

- I will interview the four participating teachers about the same artwork;

- I will conduct a document search of all official school documents

- Teacher co-researchers will analyse data in the form of transcripts and check accuracy of their own transcribed interviews;

- Teacher co-researchers will attend meetings to discuss data;

- You are welcome to have a summary of the final report at the end of the study.

- Please be assured that the identity of your school will remain confidential. 
I am mindful that my presence in both your school and the co-researchers classrooms will be a change in the daily routine of the classroom. I will be as flexible and unobtrusive as possible. I would like to visit your school on several occasions prior to the data collection process so that both the staff and children can get to know me.

If you agree to me entering your school to undertake this proposed research I would outline the proposal to the teaching staff at a staff meeting before asking for volunteers to be the co-researchers.

Victoria University of Wellington's Human Ethics Committee has approved this research project and the project is to be supervised by Dr Barbara Craig (04 463 5404) and Anne Hynds (04 463 9543).

If you have any questions related to this request please don't hesitate to contact me on 04463 9617, or email ianbowell@vuw.au.nz.

Many thanks for considering this request,

Ian Bowell 


\section{Appendix B}

\section{VICTORIA UNIVERSITY OF WELLINGTON \\ Te Whare Wananga o te Upoko o te Ika a Maui}

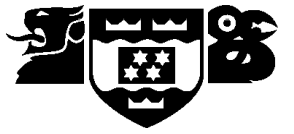

School of Education Studies

Te Kura Akoranga Matauranga

Developing primary school teachers' confidence in the teaching of visual art

\section{Consent Form}

(School)

I give consent for lan Bowell carry out this research project within this school.

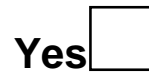

No

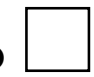

I give consent for data collection using

Audio tape recording

Notebooks
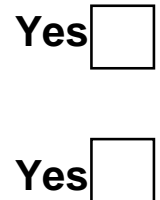

No

No
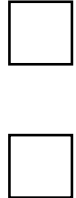

I give permission for the dissemination or presentation of the findings of this research to appropriate conferences and publications.

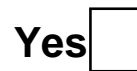

No

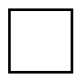

I understand that all the data will be destroyed on completion of the study.

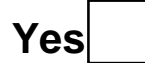

No

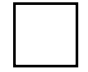

I understand that I have the right to withdraw from the research at any stage prior to the completion of the data collection and that I can withdraw approval for the use of any particular data at any time.

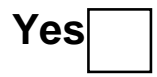

No

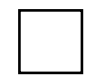

I would like a summary of the final report.

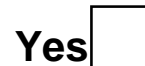

No

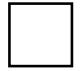


I choose the following pseudonym for this school to maintain confidentiality

I have read the information relating to this research and I understand that by signing this form I give my consent to take part in the research.

Signed

Name

Title

Date 


\section{Appendix C}

VICTORIA UNIVERSITY OF WELLINGTON

Te Whare Wananga o te Upoko o te Ika a Maui

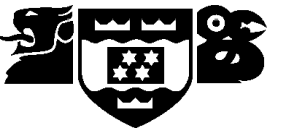

School of Education Studies

Te Kura Akoranga Matauranga

\section{Developing primary school teachers' confidence in the teaching of visual art}

Kia ora

My name is lan Bowell. I am a Masters student at Victoria University of Wellington. For the thesis component of my degree I would like to research the way that primary school teachers can develop their confidence in the teaching of visual art.

I have had a long involvement in the visual art education both at primary and secondary level. My recent work within the area of in-service training in the primary sector for the arts curriculum has led me to believe that far more in-service work can be achieved by the staff within schools rather than using outside expertise. As part of the curriculum stock-take report to the Minister of Education in 2002, $90.5 \%$ of the respondents in a national sampling study felt that they needed more professional development in the arts. There is little research in New Zealand relating to alternative ways of developing confidence in the teaching of visual art.

My intention is to analyse, with four teacher co-researchers, the way teachers and children view the child's art-work. The research will focus on how the four participating teachers are able to work collaboratively to develop their expertise in the teaching of visual art, using the child's view of their own work as a framework. Further to this it will also provide an opportunity for the participating teachers to develop their confidence in the teaching of visual art and share this confidence with the remainder of the teaching staff.

In order to gain a clear picture of your school I need to gain the teaching staff's view of the visual art strand of the curriculum, the way visual art is assessed and the amount of professional development received in the assessment of visual art.

To gain this view I would be grateful if you could complete the attached questionnaire. The data collected from this questionnaire will only be used for the purpose of this study and you will not be able to be identified from the completed questionnaire. All data collected for this research project will be stored in a locked file and destroyed five years after the conclusion of this research.

Victoria University of Wellington's Human Ethics Committee has approved this research project and the project is to be supervised by Dr Barbara Craig (04 463 5404) and Anne Hynds (04 463 9543). A copy of the completed thesis will be made available to the school.

Thank you for your time

Ian Bowell 


\title{
Appendix D
}

\author{
Staff Questionnaire \\ VICTORIA UNIVERSITY OF WELLINGTON \\ Te Whare Wananga o te Upoko o te Ika a Maui

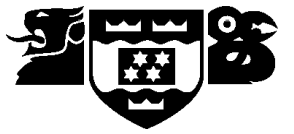 \\ School of Education Studies \\ Te Kura Akoranga Matauranga
}

1. Which year group do you teach?

(PLEASE CIRCLE GROUP OR GROUPS YOU TEACH)

YEAR 1

YEAR 2

YEAR 3

YEAR 4

2. How many years have you been teaching?

(PLEASE CIRCLE ONE)
0-6
6-11
11-16
16-20
OVER 20

3. Have you attended any in-service training for the visual art strand of the Arts Curriculum?

(PLEASE CIRCLE)

YES NO

4. If you answered yes to question 3, approximately how many hours of inservice training in the visual arts did you receive?

\section{NUMBER OF HOURS}

5. Have you had any in-service training in the area of visual art assessment?

(PLEASE CIRCLE)

YES

NO

6. If you answered yes to question 5, approximately how many hours of inservice training in the assessment of visual art did you receive?

NUMBER OF HOURS 
7. Which method or methods do you use to assess the visual arts in your classroom?

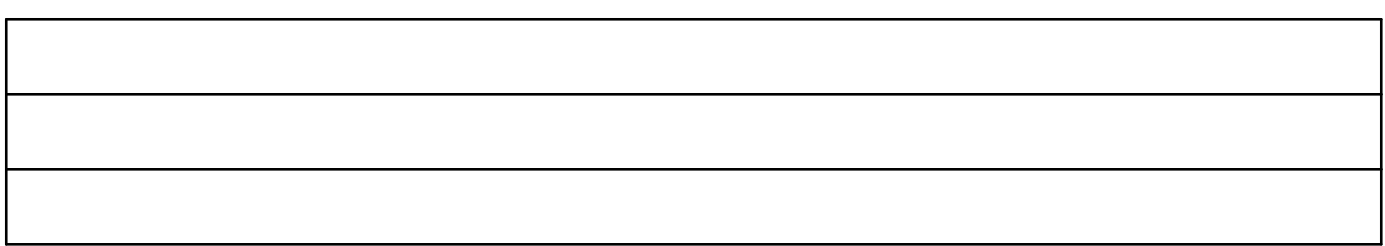

8. How confident do you feel in assessing visual art?

(PLACE A CROSS ON THE LINE THAT REPRESENTS YOUR LEVEL OF CONFIDENCE)

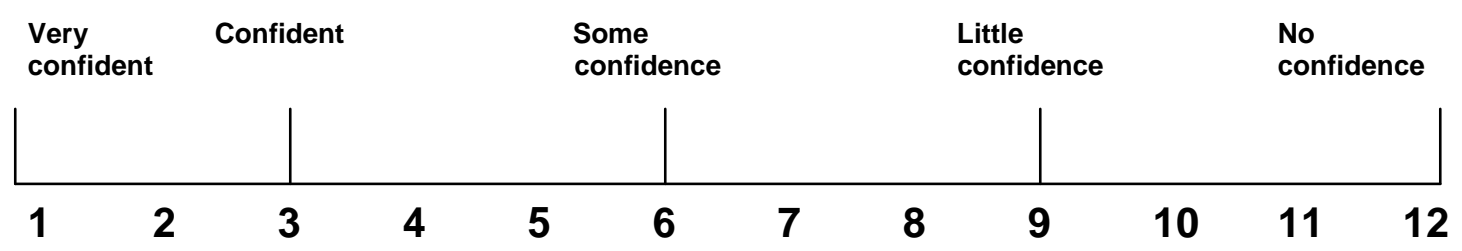

Thank you for the time you have spent in answering the questionnaire.

lan Bowell 


\title{
Appendix E
}

\author{
VICTORIA UNIVERSITY OF WELLINGTON \\ Te Whare Wananga o te Upoko o te Ika a Maui
}

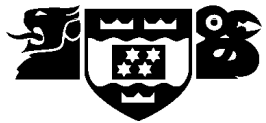

School of Education Studies

Te Kura Akoranga Matauranga

\section{Developing primary school teachers' confidence in the teaching of visual art}

Teacher Information sheet

Kia ora

My name is lan Bowell. I am a Masters student at Victoria University of Wellington. For the thesis component of my degree I would like to research the way that primary school teachers can develop their confidence in the teaching of visual art.

My intention is to analyse, with four teacher co-researchers, the way teachers and children view the child's artwork. The research will focus on how the four participating teachers work collaboratively to develop their expertise in the teaching of visual art, using the child's view of their own work as a framework.

My study could help provide an insight into the similarities and differences between the teachers and the child's view of the child's artwork. Further to this it will also provide an opportunity for the participating teachers to develop their confidence in the teaching of visual art and share this confidence with the remainder of the teaching staff.

I you agree to participate this will mean that:

- I will observe visual art lessons in your classrooms

- Interview you about the children's visual artwork

- You will be given the opportunity to comment upon the information that you provide and change any of it if you so wish

- You will, together with myself and other co-researchers, analyse data

- You will work with co-researchers to develop your expertise in the teaching of visual art

Please be assured that your identity along with that of the school will remain confidential. All written material will be kept in a locked file, all electronic information will be in a password-protected file and all material will be destroyed 5 years after the conclusion of the research.

The research data will be seen by myself and my university supervisors, Dr Barbara Craig 044635404 and Anne Hynds 044639543.

If you are willing to participate please complete the attached form and return it to me in the stamped addressed envelope enclosed.

Please contact me by phone; 04463 9617, or email ianbowell@vuw.au.nz if you have any questions or want any further information.

Many thanks for considering this invitation,

Ian Bowell 


\section{Appendix F}

VICTORIA UNIVERSITY OF WELLINGTON

Te Whare Wananga o te Upoko o te Ika a Maui

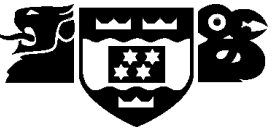

School of Education Studies

Te Kura Akoranga Matauranga

\section{Developing primary school teachers' confidence in the teaching of visual art

\author{
Expression of interest to be a participating teacher/co-researcher
}

Kia ora

My name is lan Bowell. I am a Masters student at Victoria University of Wellington. For the thesis component of my degree I would like to research the way that primary school teachers can develop their confidence in the teaching of visual art.

My intention is to analyse the way the four participating teachers are able to work collaboratively to develop their expertise in the teaching of visual art, using the child's view of their own work as a framework.

My study could help provide an insight into the similarities and differences between the teachers and the child's view of the child's artwork. Further to this it will also provide an opportunity for the participating teachers to develop their confidence in the teaching of visual art and share this confidence with the remainder of the teaching staff.

I you agree to participate this will mean that :

- I will observe visual art lessons in your classrooms

- Interview you about the children's visual artwork

- You will be asked to attend meetings which will be audio taped and then transcribed

- You will be given the opportunity to comment upon the information that you provide and change any of it if you so wish

- You will asked to analyse data in the form of transcripts

- You will work with co-researchers to develop your expertise in the teaching of visual art

Please be assured that your identity along with that of the school will remain confidential. All written material will be kept in a locked file, all electronic information will be in a password-protected file and all material will be destroyed at the end of the research.

Victoria University of Wellington's Human Ethics Committee has approved this research project and the research data will be seen by myself and my university supervisors, Dr Barbara Craig 044635404 and Anne Hynds 044639543.

If you are willing to participate please complete the attached form and return it to the school office in the envelope enclosed. I will contact you by phone when I receive your expression of interest. 
Please contact me by phone; 04463 9617, or email ianbowell@vuw.au.nz if you have any questions or want any further information.

Many thanks for considering this invitation,

lan Bowell

\title{
Developing primary school teachers' confidence in the teaching of visual art
}

\author{
Expression of interest to be a participating teacher/co-researcher
}

Name.

Contact details.

Year level of class..

Signed 


\title{
Appendix G
}

\author{
VICTORIA UNIVERSITY OF WELLINGTON \\ Te Whare Wananga o te Upoko o te Ika a Maui

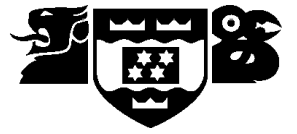 \\ School of Education Studies \\ Te Kura Akoranga Matauranga
}

\section{Consent Form \\ (Participating Teacher Co-researchers)}

I consent to be a participant in the research undertaken by lan Bowell

$$
\text { Yes } \square \quad \text { No }
$$

I consent for lan Bowell visit my classroom and observe the teaching of visual art.

$$
\text { Yes } \square \quad \text { No }
$$

I give consent for data collection using:

Audio tape recording

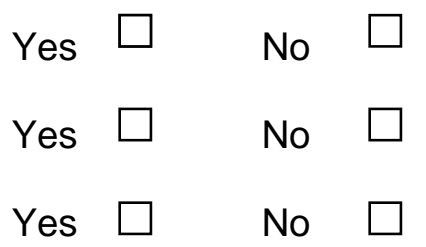

Field notes

Semi-structured interviews

I understand that l'll be asked to attend meetings and that these meetings will be audio taped Yes No

I understand that I will be analyzing data in the form of transcripts of interviews and discussions Yes $\square \quad$ No

I give consent for the dissemination or presentation of the findings of this research to appropriate conferences and publications Yes $\square \quad$ No

I understand that I have the right to withdraw from the research at any stage prior to the completion of the data collection and that I can withdraw approval for the use of any particular data at any time.

Yes

No

I would like a summary of the final report.

Yes

No

I have read the information relating to this research and I understand that by signing this form I give my consent to take part in the research.

Signed

Date 


\title{
Appendix H
}

\author{
VICTORIA UNIVERSITY OF WELLINGTON \\ Te Whare Wananga o te Upoko o te Ika a Maui

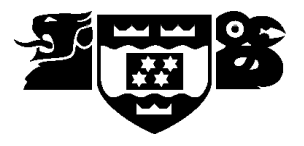 \\ School of Education Studies \\ Te Kura Akoranga Matauranga
}

\section{Developing primary school teachers' confidence in the teaching of visual art \\ Parent/Caregiver Information sheet}

Kia ora

My name is lan Bowell. I am a Masters student at Victoria University of Wellington. For the thesis component of my degree I would like to research the way that primary school teachers can develop their confidence in the teaching of visual art.

My intention is to analyse, with four teacher co-researchers, the way teachers and children view the child's artwork. The research will focus on how the four participating teachers work collaboratively to develop their confidence in the teaching of visual art, using the child's view of their own work as a framework.

has been selected to take part in this study. The study will involve a selected group of children describing their artwork in an informal interview. This interview will be audio taped and then transcribed and the artwork they describe will be photographed.

Please be assured that the identity of your child along with that of the school will remain confidential. All written material will be kept in a locked file, all electronic information will be in a password-protected file and all material will be destroyed at the end of the research.

Victoria University of Wellington's Human Ethics Committee has approved this research project with he research data will be seen by myself and my university supervisors, Dr Barbara Craig 044635404 and Anne Hynds 044639543.

A copy of the completed thesis will be made available to the school.

If you are willing for your child to participate please complete the attached form and return it to me in the stamped addressed envelope enclosed.

Please contact me by phone; 04463 9617, or email ianbowell@vuw.au.nz if you have any questions or want any further information.

Many thanks for considering this invitation, 


\section{Appendix I}

\section{VICTORIA UNIVERSITY OF WELLINGTON}

Te Whare Wananga o te Upoko o te Ika a Maui

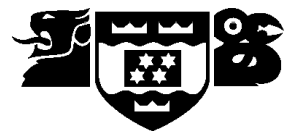

School of Education Studies

Te Kura Akoranga Matauranga

\section{Consent Form: Collaborative Inquiry}

(Parent/Caregiver)

I give consent for by lan Bowell. to be a participant in the research undertaken Yes $\square$ No

I consent for lan Bowell to interview about their visual artwork.

$$
\text { Yes } \square \quad \text { No }
$$

I give consent for data collection using:

Audio tape recording

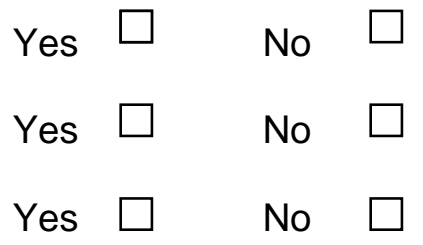

Field notes

Semi-structured interviews

$$
\text { Yes } \square \quad \text { No }
$$

I give consent for my child's artwork to be photographed and for the photograph to be used as data in this research.

Yes $\square \quad$ No

I understand that my child's original artwork will be returned and that any photographic image of the artwork can only be used in publications or presentations related to this research project.

$$
\text { Yes } \square \quad \text { No }
$$

I give consent for the dissemination or presentation of the findings of this research to appropriate conferences and publications Yes $\square \quad$ No

I understand that I have the right to withdraw my child from the research at any stage prior to the completion of the data collection and that I can withdraw approval for the use of any particular data at any time.

$\square$ es

$\square$ No

I would like a summary of the final report.

Yes

No 
Please supply your address if you require a summary of the final report

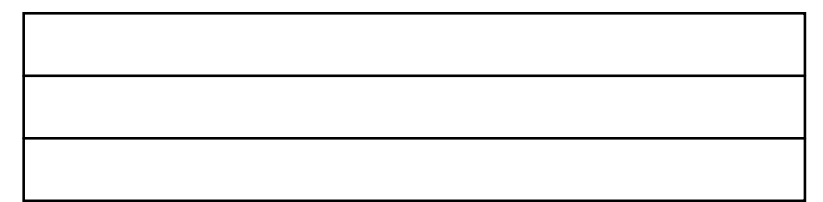

I have read the information relating to this research and understand that by signing this form I give my consent for to take part in this research.

Signed Date 